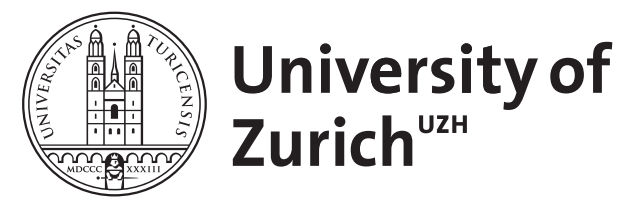

Zurich Open Repository and Archive

University of Zurich

University Library

Strickhofstrasse 39

CH-8057 Zurich

www.zora.uzh.ch

Year: 1977

\title{
Jeremia und die falschen Propheten
}

Meyer, Ivo

Posted at the Zurich Open Repository and Archive, University of Zurich

ZORA URL: https://doi.org/10.5167/uzh-150079

Monograph

Published Version

Originally published at:

Meyer, Ivo (1977). Jeremia und die falschen Propheten. Freiburg, Switzerland / Göttingen, Germany:

Universitätsverlag / Vandenhoeck Ruprecht. 
MEYER - JEREMIA UND DIE FALSCHEN PROPHETEN 
Im Auftrag des Biblischen Institutes der Universität

Freiburg Schweiz

herausgegeben von

Othmar Keel und Bernard Trémel

\section{Zum Autor}

Ivo Meyer (1938) studierte Theologie in Luzern und Freiburg/ Schweiz und Bibelwissenschaft in Rom und Jerusalem. Er wurde 1965 ordiniert und arbeitete dann als Vikar vier Jahre in der Seelsorge. 1969-1974 war er Assistent bei Prof. H. Gross in Regensburg, wo er 1973 aufgrund der vorliegenden Arbeit promoviert wurde. Ivo Meyer ist Professor für Altes Testament an der Kath. Fachhochschule Nordrhein-Westfalen, Abteilung Paderborn. Von ihm erschien 1973 zusammen mit F. L. Hossfeld «Prophet gegen Prophet. Eine Analyse der alttestamentlichen Texte zum Thema: Wahre und falsche Propheten» (Biblische Beiträge 9, Freiburg/ Schweiz). Demnächst erscheint von ihm «Gedeutete Vergangenheit. Könige und Chronik» (Stuttgarter Kleiner Kommentar 7, Stuttgart). 


\section{ORBIS BIBLICUS ET ORIENTALIS 13}

IVO MEYER

\section{JEREMIA UND DIE \\ FALSCHEN PROPHETEN}

UNIVERSITÄTSVERLAG FREIBURG SCHWEIZ VANDENHOECK \& RUPRECHT GÖTTINGEN 
(C) 1977 by Universitätsverlag Freiburg Schweiz

Paulusdruckerei Freiburg Schweiz

UV IS BN 3-7278-0166-2 V\& R IS BN 3-525-53316-0

Digitalisat erstellt durch Florian Lippke, Departement für Biblische Studien, Universität Freiburg Schweiz 
Meinen Eltern 

Se ite

VORWORT

I "Dieser Mann ist nicht des Todes schuldig; denn im Namen Jahwes, unseres Gottes, hat er zu uns geredet." Jer 26

II "Ich habe sie nicht gesandt, ich habe sie nicht aufgeboten und habe nicht zu ihnen gesprochen." Jer 14,10-16

II "Sie heilen den Schaden meines Volkes leichthin indem sie sagen: Heil, Heil, wo es doch kein Heil gibt."

Jer $2,8.26 .30$

IV "Hört nicht auf die Propheten!" Jer 23,9-32 

"Jeremia und die falschen Propheten" war das Thema meiner Dissertation, die 1972 fertiggestellt und 1973 von der Katholisch-Theologischen Fakultät der Universität Regensburg als Promotionsarbeit angenommen wurde.

Angesichts angekündigter einschlägiger Publikationen (vor allem THIEL W., Die deuteronomistische Redaktion von Jeremia 1-25 und WEIPPERT H., Die Prosareden des Jeremiabuches) wurde die Veröffentlichung seinerzeit zurückgestellt.

Anderweitige berufliche Beanspruchungen haben mich dann gehindert, die neuere Literatur in voller Breite für die Bearbeitung zu sichten.

Die vorliegende Arbeit will die exegetischen Begründungen nachliefern für jene Sicht des Jeremiabuches und des Prophetenkonfliktes, wie sie in HOSSFELD F.L. / MEYER I., Prophet gegen Prophet, zusammenfassend dargestellt wurde.

Professor Dr. H. Groß habe ich herzlich zu danken für die Betreuung meiner Promotion, Professor Dr. 0 . Keel für die Aufnahme der Arbeit in die Reihe $0 B 0$.

Paderborn, September 1976 

E INFOHRUNG

Die vorliegende Arbeit entstand im Zusammenhang einer Studie über wahre und falsche Propheten ${ }^{1}$. Exegetisch verantwortbare Aussagen zu diesem theologischen Thema sollten mit historisch-kritischen Methoden erarbeitet werden.

Worte von Propheten und Berichte über Taten und Geschick von Propheten haben durch Aufnahme in den Kanon heiliger Schriften ihr offizielles Güte- und Echtheitssiegel aufgeprägt bekommen. Aber der Segen von Tradition und Lehramt allein garantieren diesen Texten kaum mehr eine große Leserschaft. Erinnerung an die Anfangsetappen auf dem Weg zur kanonischen Urkunde vermag vielleicht neues Interesse zu wecken und gleichzeitig die Ambivalenz der offiziellen Kirche diesen Schriften gegenüber zu erhellen ${ }^{2}$.

Man darf erwarten, daß, wo äußere Protektion fehlte, die innere kraft einer Botschaft am deutlichsten sichtbar wird. In klarster Ausprägung wird dieser Tatbestand faßbar, wo auch noch ein wie immer geartetes Prestige eines allgemein akzeptierten Prophetentums wegfällt, weil Spruch gegen Spruch, Prophet gegen Prophet steht. Spuren solcher Konflikte haben sich nur spärlich erhalten. Nachträglicher Triumph der einen Seite hat sie verwischt.

Die Jeremiaüberlieferung scheint am ergiebigsten, wohl weil Person und Botschaft sich in besonderem Maße

1 HOSSFELD/MEYER, Prophet gegen Prophet.

2 Feierliche Beteuerung ihrer Wirde - praktische Vernachlässigung in lehramtlichen Verlautbarungen - selektiver Gebrauch in den liturgischen Leseordnungen.

Vgl. LIMBECK, Bedarf der Christ des Alten Testaments? 77-84. 
verschränken und das Leiden des Propheten wie die Ablehnung seines Wortes schon in ältesten Tradentenkreisen zum Thema werden.

Besondere Schwierigkeiten für unsere Auslegung der einschlägigen Texte ergeben sich aus dem für moderne Lesegewohnheiten verwirrenden Bild, das uns das Jeremiabuch bietet.

DUHM, der bahnbrechende und bis heute anregendste Ausleger, gesteht im Vorwort zu seinem Kommentar, er habe sich "vor diesem Buch immer mehr gefürchtet als vor irgendeiner anderen alttestamentlichen Schrift"1, und sein Zeitgenosse CORNILL meint, die hebräische Gestalt des Buches Jeremia habe "noch kein Mensch rationell zu erklären vermocht" 2 .

Der unbefangene Leser wird wenig System finden im bunten Nebeneinander von prophetischen Sprüchen mit Klagen, Anklagen und Strafansagen in poetischer Form, prosaischen Redeeinheiten sowie erzählendem Material, bestehend aus Selbst- und Fremdberichten unterschiedlichsten Umfangs.

In der Auslegungsgeschichte sind eine ganze Reihe von Hypothesen durchgespielt worden, die den Mangel an formaler und sachlicher ordnung erklären sollen; ein allgemeiner Konsens wurde bisher nicht erreicht ${ }^{3}$.

Der historische Aspekt des hier interessierenden theologischen Problems zwingt nun dazu, den offensicht-

1 DUHM, Das Buch Jeremia VII.

2 CORNILL, Das Buch Jeremia, zitiert nach MOWINCKEL, Zur Komposition des Buches Jeremia 4.

3 Auf den Abdruck des forschungsgeschichtlichen Teils meiner Dissertation kann verzichtet werden, da neben den Einleitungen in den Kommentaren nun Oberblicke zugänglich sind bei THIEL, Deuteronomistische Redaktion 3-31 und WEIPPERT, Die Prosareden des Jeremiabuches 1-21; e in knappes Resumé in HOSSFELD/MEYER, Prophet gegen Prophet 58-60. 
lich komplizierten literarischen Befund mit Hilfe literaturwissenschaftlicher Methoden zu deuten ${ }^{1}$.

Die Auswahl der Texte ergab sich durch den gewählten inhaltlichen Gesichtspunkt, die Reihenfolge aus dem Bestreben, den thematisch-theologischen und den literarischen Befund exemplarisch zu erarbeiten und konzentriert darzustellen.

1 Text-, literar-, form-, gattungs-, traditions- und redaktionskritische Arbeitsgänge sollen praktiziert werden und jeweils in dem Umfang Raum bekommen, wie sich für unser Thema signifikante Resultate abzeichnen. Methodentheoretische Oberlegungen sind gelegentlich in Auseinandersetzungen mit der Literatur anzustellen. 
. 
"Dieser Mann ist nicht des Todes schuldig; denn im Namen Jahwes, unseres Gottes, hat er zu uns geredet." Jer 26 
Eine ausfühlichere Auseinandersetzung mit der umfangreichen Sekundärliteratur $z u$ diesem Kapitel haben wir in einem Aufsatz "Der Prophet vor dem Tribunal" veröffentlicht ${ }^{1}$, was eine Entlastung der Darstellung hier erlaubt.

Anstoß zu einer genaueren Analyse des Textes gibt zunächst das erstaunliche Nebeneinander verschiedener prophetischer Gestalten.

Da begegnet einmal Jeremia, der zwar nicht Prophet genannt, dessen Tätigkeit aber unter anderem als "prophezeien" (VV 9, 11, 12) bezeichnet wird. Namentlich ist weiterhin von Micha, dem Moraschtiter, die Rede, der als Prophet aufgetreten sei ( $V$ 18), sowie von einem Urija, der ebenfalls als Prophet gewirkt habe ( $V 20$ ).

Daneben berichtet die Erzählung, d i e (namenlosen) Propheten hätten Jeremias Rede im Tempel gehört ( $V 7$ ), ihn ergriffen $\left(\begin{array}{l}V \\ 8\end{array}\right)$, eines todeswurdigen Verbrechens bezichtigt ( VV 8.9) und ihn vor einem Gericht verklagt ( $V$ $11)$, ohne allerdings eine Verurteilung durchsetzen zu können ( $v 16)$.

Die zitierte Botenrede Jeremias hingegen spricht von d e $n$ Propheten allgemein und ohne nähere Kennzeichnung, die Jahwe als seine Knechte unermuidich und erfolglos gesandt habe ( $V 5$ ).

Stutzig wird der Leser auch angesichts der Tatsache, daß einerseits die Oberen und das Volk Jeremia nach V 16 freisprechen wollen, nach $V 24$ hingegen nur der Einsatz eines gewissen Achikam Jeremia aus der tödlichen Bedrohung durch das Volk zu retten vermag.

Bei genauerem Hinsehen sind weitere formale und inhaltliche Unebenheiten und Spannungen zu entdecken.

In einem ersten Arbeitsgang, der sein Schwergewicht in der literarkritischen Frage nach Einheitlichkeit oder

1 HOSSFELD/MEYER, Der Prophet vor dem Tribunal. Zur Auslegungsgeschichte des Kapitels bis $1968 \mathrm{vgl}$. WANKE, Baruchschrift 82-87. 
Zusammengesetztheit des Textes hat, soll darauf eingegangen werden. Wir gliedern zu diesem Zweck das Kapitel und benennen die Teile. Die gewählten Bezeichnungen nehmen dabei manchmal - wo dies unbedenklich schien - in vorläufiger Weise Beobachtungen zu Form und Gattung vorweg.

\section{Abschnitt I}

$\checkmark 1$ Formelhafte, berichtende Einleitung ${ }^{1}$ vom Ergehen eines Jahwewortes mit Datumsangabe und Ankündgung einer Botschaft.

VV 2-6 Zitat einer Gottesrede:

$\checkmark 2$ Eröffnung mit "Botenformel",

Auftritts- und Redebefehl mit Orts-, Adressaten- und Inhaltsangabe, Warnung vor verkürzung.

V 3 Reflexion über mögliche Folgen der Verkündigung.

V 4-6 Neuer Redebefehl, Beginn der bis V 6 reichenden wörtlich zu zitierenden Botschaft; Einleitung mit Botenformel; Botschaft in Form eines Konditionalgefüges: Protasis in V 4 - Apodosis in V 6.

1 Eine Diskussion der Einleitungsformeln ist nicht beabsichtigt.

Sie hätte vor allem Beobachtungen aufzunehmen, wie sie NEUMANN, Das Wort, das geschehen ist ... 171-217 für Jer 1-25 angestellt hat. Für unseren Zweck genügt die Feststellung, daß 26,1 unzweifelhaft den Beginn einer neuen Einheit markiert, die in 27,1 - analog eingeleitet - von einer anderen Einheit abgelöst wird. Ob hier gleichzeitig "der Bericht über den Kampf und das Leiden des Propheten Jeremia" beginnt (LAMPARTER $z$. St.), Kap 26 "das älteste Stück der Baruch-Erzählung von Jeremias Leiden in seinem prophetischen Beruf" darstel1t (RUDOLPH z.St.), ist dem Text selbst nicht zu entnehmen. 
$\checkmark 5$ Geprägte Wendung, die unermüdliche Sendung von Propheten und die Taubheit des Volkes betreffend.

In diesem ersten Abschnitt fordern drei Elemente eine eingehendere Diskussion:

1) Die "Botenformel" in V 2;

2) der doppelte Redebefehl V 2 und V 4;

3 ) die Wendung von der Prophetensendung $\vee 5$.

ad 1)

Auch wenn die gängige Ansicht recht haben wird, die aus der profanen Botenpraxis stammende כה - und NNFormel habe in prophetischer Anwendung ihren ursprünglichen Ort am Obergang zwischen Anklage (oder Scheltwort) und Gerichtsansage (oder Drohwort) ${ }^{1}$ gehabt, so ist doch auch allgemein anerkannt, daß sie diese prägnante Position spätestens auf redaktioneller Ebene verloren hat.

Das Jeremiabuch bietet Beispiele, wo Jahwe selbst mitten in eigener Rede diese Formel braucht (vgl. etwa $7,20.21 ; 29$ passim). Es müßte systematisch geklärt werden, ob in solchen Fällen die Formel bloß ein Indiz redaktioneller Nachlässigkeit oder ein Mittel der Gliederung oder der Hervorhebung darstell $t^{2}$.

Eigentümlich bleibt auf jeden Fall in unserem Text, daß Jahwe selbst die Formel in den Mund nimmt zur Einleitung einer Mitteilung, die gar nicht als Botschaft durch einen Boten an einen Dritten weitervermittelt werden sol $1^{3}$. Hier ist nun noch die Beobachtung hinzu-

1 So WESTERMANN, Grundformen prophetischer Rede 107; dagegen RENDTORFF, Botenformel und Botenspruch 165-177, vor allem Anm.3o S.175.

2 Zu ungewohntem Gebrauch vgl. unten zu 14,15.

$3 \mathrm{Vgl}$. WILDBERGER, Jahwewort $46 \mathrm{f}$. 
zunehmen, daß das Jeremiabuch zahlreiche erzählende $A b-$ schnitte kennt, die mit "So sprach Jahwe zu mir" (bzw. zu Jeremia) $(13,1 ; 17,19 ; 25,15)$ oder auch kurz "So sprach Jahwe" $(19,1 ; 22,1)$ eingeleitet und mit einem Befehl zu prophetischem Auftritt fortgefüht werden.

כה ist also eine durchaus mögliche selbständige Erzählungseinleitung geworden und muß in diesem Zusammenhang sicher mit einem Erzähltempus wiedergegeben werden ${ }^{1}$.

Andererseits ergeben auch die Elemente von $V 1$ ( $v g 1$. 27,1 ; 36,1 oder die Variante "Das Wort, welches ... erging von Jahwe"; 7,$1 ; 11,1 ; 18,1 ; 21,1 ; 25,1 ; 32,1 ; 34$, 8 und 37,1$)$ ihrerseits eine vollständige Erzähleinleitung.

Der paradoxe Eindruck, Jahwe selbst würde ein privates Gespräch mit dem Propheten mit der Botenformel einleiten ( $v g 1.15,9 ; 16,5)$, wird noch in den Einleitungsformulierungen $27,1 \mathrm{ff}$ und $34,1 \mathrm{ff}$ ( $v g 1$. auch 30,1 ) erweckt. Es besteht aber starker Verdacht, daß diese Einleitungen alle nachträglich aufgefiullt wurden, und zwar in 26 ; 27 und 34 jeweils durch Datumsangaben ${ }^{2}$.

ad 2)

Der doppelte Redebefeh1 $V 2$ und $V 4$.

Das Objekt zum ersten Befehl suggeriert einen Auftrag zur Wiederholung der Gesamtbotschaft (die Forderung nach Vollständigkeit wird noch eingeschärft durch die

1 Zur Wiedergabe als Botenformel vgl. RENDTORFF ebd. 167, anders ZIMMERLI, Ezechiel, BK XIII, S. 73; WOLFF, Amos, BK XIV/2, S. 166. WILDBERGER, Jahwewort 47 nimmt an, Baruch habe beim Vorsetzen von $V 1$ eine andere Einleitungsformel ersetzt.

2 Es ergeben sich also erhebliche Bedenken gegen den Versuch HYATTS, The Beginning of Jeremiah's Prophecy 204-214, mit Hilfe von 26,1 den Erstauftritt Jeremias zeitlich zu fixieren. Zur Diskussion des Berufungstermins vgl. VOGT, Jeremias-Literatur 357-365, ferner HOLLADAY, A Fresh Look at "Source B" and "Source $C^{\prime \prime}$ in Jeremiah 394-412. 
"halbe Kanonformel": Nichts wegnehmen; vgl. Dtn 4,2; 13,1; Koh 3,14) analog zu Kap $36^{1}$; VV 4-6 hingegen bieten ein ganz konkretes Einzelwort als Redeinhalt.

ad 3)

Die geprägte Wendung von Jahwes nimmermider Prophetensendung findet sich mit geringfügigen Abweichungen im Wortlaut noch an fün weiteren Stellen $(7,25 ; 25,4 ; 29$, $19 ; 35,15 ; 44,4)$. Sie sitzt uberall locker im Kontext und stört den Ablauf. HORST nennt die Konstruktion in Kap 26 VV 4-6 "entsetzlich verschroben", "nahezu türkisch"2. V 5 stört den Obergang von der Protasis zur Apodosis, verdoppelt in unschöner Weise - wie immer man die Infinitiv-Konstruktion auf $V 4$ bezieht - das Element des Hörens und nimmt der in $V 3$ geweckten Spannung ihre kraft.

Abschnitt II

$\checkmark 7$ und $V$ 8a zwei temporale Vordersätze zu $8 b$.

$\checkmark 8 \mathrm{~b} \quad$ Nachsatz; Bericht von Gefangennahme und Androhung der Todesstrafe.

$\checkmark$ 9a Beschuldigungsfrage.

V 9b.10 Bericht vom Zusammentreten des Gerichts ${ }^{3}$.

1 Genau genommen handelt es sich an beiden Stellen um Wiederholung der Botschaft für bestimmte Adressaten.

2 Die Anfänge des Propheten Jeremia 150; 145. WEIPPERT, Prosareden 31 ergänzt in ihrer Obersetzung "zu hören a $u c h$ die Worte meiner Knechte ...", wozu der Text kaum berechtigt. Die Einfügung widerspricht der von ihr behaupteten Kürzung der Rede von Kap 7 "um die Dynamik der Handlung nicht durch eine längere Rede gleich zu Beginn zu blockieren" 33 .

3 Die Entscheidung, welche der beiden von den Lexika für das nif.

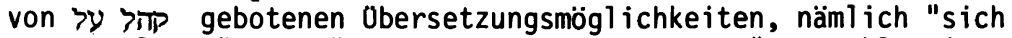
versamme In um" oder "sich zusammenrotten gegen", zu wählen ist, kann nur vom Kontext her getroffen werden. Unsere Wahl findet ihre Begriundung in der Auslegung. 


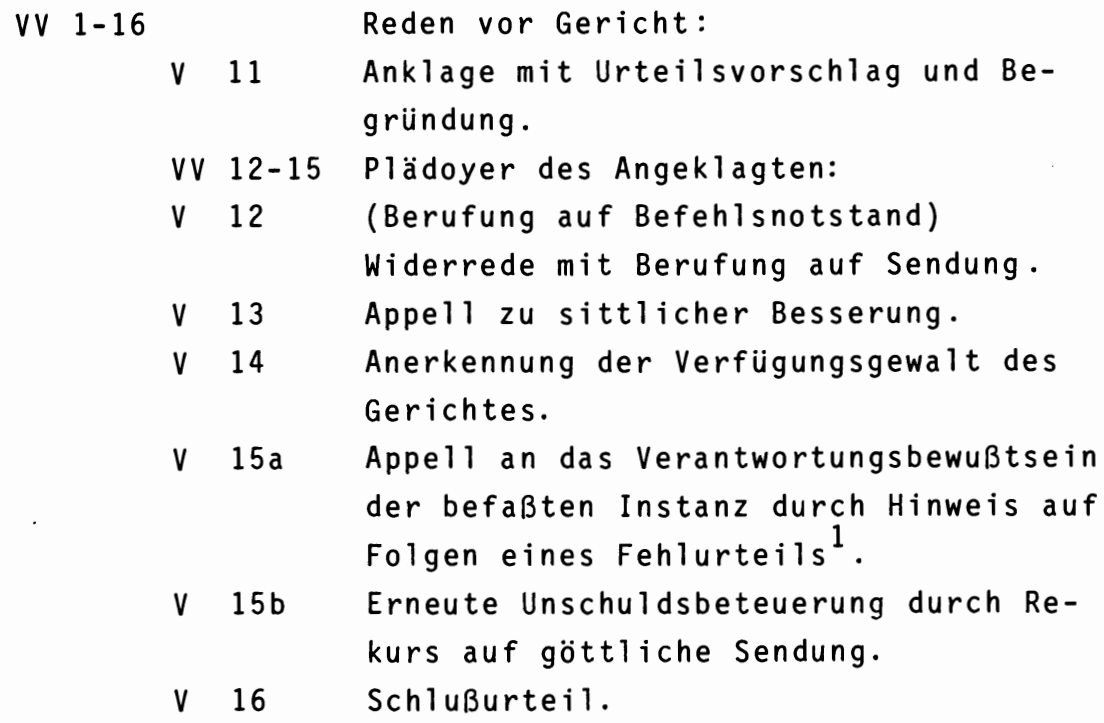

Dieser Abschnitt fordert die Diskussion folgender Punkte:

1) Der doppelte Vordersatz $z u V 8 b$ in $V 7$ und V $8 a$;

2) die Erwähnung des Volkes in $V 8 a$ und $V 8 b$;

3) die Beschuldigungsfrage in $V$ 9a;

4 ) die Differenz zwischen Beschuldigungsfrage und Anklage;

5) die Widerrede VV 12 und 15b;

6) der unpräzise Rekurs auf Augenzeugenschaft;

7) der Appel1 V 13;

8) der Adressatenwechsel in der Verteidigungsrede;

9) das Schlußurteil.

ad 1)

Wie WANKE wahrscheinlich gemacht hat ${ }^{2}$, ist $v 7$ aufgrund eines Vergleiches mit $20,1 \mathrm{ff} ; 26,10 ; 36,11 \mathrm{ff}$ nicht

1 Zur Vorstellung "Blut auf sich laden" vgl. KOCH, Der Spruch "Sein Blut bleibe auf seinem Haupt" und die israelitische Auffassung vom vergossenen Blut 396-416.

2 ebd. 88. 
als Hauptsatz, sondern als temporaler Vordersatz zu $V 8 b$ $z u$ übersetzen. Dasselbe gilt aber auch von $V 8 a^{1}$. Inhaltlich bezieht sich $V 7$ auf das konkrete Gotteswort, VV (4), 6, 8a hingegen auf die in $V 2$ geforderte Gesamtverkündigung.

ad 2)

Die Erwähnung des "ganzen Volkes" in V 8 a wirkt überflüssig; in $V 8 b$ ist sie störend, weil Gefangennahme zwecks Vorführung vor ein Gericht (darum handelt es sich zunächst - und nicht um Ausbruch des Volkszorns mit Versuch zu Lynchjustiz!) nicht Angelegenheit des Volkes ist und vor allem nicht zu seiner Rolle in $v 16$ paßt. Wir haben es offenbar mit Glossen zu tun, deren Tendenz wir bei der Auslegung der Bearbeitungsstufen im Auge behalten müsen ${ }^{2}$.

ad 3)

BOECKER ${ }^{3}$ hat den Halbvers $9 a$ als Beispiel für eine der zwei Arten von Formeln identifiziert, mit denen in der vorgerichtlichen Auseinandersetzung in Frageform einem Beschuldigten ein Vergehen vorgeworfen wird.

1 DUHM 2.St. wollte für diese Verdoppelung Baruchs Stil verantwortlich machen: "Baruch erzählt öfter mit einer gewissen anschaul ichen Breite."

2 GRAF z.St. empfiehlt כל העם "nicht im strengen Sinn zu nehmen". GIESEBRECHT z.St. fragt sich, ob jeweils ein Teil des Volkes gemeint sei. KEIL z.St. ist da von seiner Lösung überzeugter: V כל העם V 89 zu unterscheiden, und das Wort כל, alle, nicht zu premiren, beide Male nur eine große Menge bezeichnend." Meist wird aber empfohlen, in $V 8 b$ כל כל העם zu streichen (DUHM, ERBT, CORNILL, CONDAMIN, KOEBERLE, DENNEFELD, GELIN, NOETSCHER, PATERSON z.St.).

3 Redeformen 26-31. Der Vergleich der formal naheliegendsten Parallelen zeigt Folgendes: Nach Auswe is von 1 Kön 1,6 kann dieselbe Frageform auch in der Situation des familieninternen Tadels gebraucht werden. In Ex 1,18f ergeht der Vorwurf an die Hebammen in Form einer Beschuldigungsfrage; dabei hat die Frageform zwar nicht den Sinn, den Tatbestand zur Debatte zu stellen, sie will 
Auffällig sind die Entsprechungen und Differenzen zu VV 4-6. Das Wort, welches das Schicksal des Jerusalemer Tempels mit Schilo vergleicht, kann offensichtlich variiert werden (vgl. auch $7,12 !)^{1}$.

Auffälliger noch ist, daß die Beschuldigungsfrage unterschlägt, daß die Unheilsansage in VV 4-6 an eine Bedingung geknüpft war. Zwei Erklärungsmöglichkeiten sind zu erwähnen: Entweder böswillige Kürzung durch die Kläger (so RUDOLPH z.St.) oder nachträgliches Zuwachsen von $V 4$ und damit der Bedingung ${ }^{2}$.

ad 4)

Sowohl in der Beschuldigungsfrage wie im Anklagevotum geht es um korrekte Festlegung des Tatbestandes. Er$z a ̈ h l e r i s c h$ verständlich ist die Formalisierung des in $V$ 9a zitierten Prophetenspruches zur Aussage: "gegen die Stadt prophezeien". Erklärungsbedürftig aber ist, daß n $u r$ die Stadt, nicht auch der Tempel als Adressat des inkriminierten Wortes genannt wird. Möglich scheint folgende Erklärung: Ein kultisches Gericht würde dem Wort gegen den Tempel das Hauptgewicht beimessen; das befaßte Gericht besteht aber aus Fürsten und Volksversammlung, ist also eine politische Instanz ${ }^{3}$.

aber doch ein konkretes Gegenüber zu einer Stellungnahme veranlassen (was in Jer 26 offenbar wegfäl1t).

2 Sam 16,10 zeigt dann aber deutlich:

- eine solche Frage kann mehr sein als beliebiges Element in irgendeinem Dialog;

- sie braucht nicht auf eine Antwort zu zielen;

- sie ist eine mögliche Form, wie ein Vorwurf mit eventuellen erheblichen juristischen Konsequenzen erhoben wird.

Aufschlußreich ist auch ein Vergleich von 26,9a mit Jer 36,29 und 32,3 ; hier werden in fragender Anredeform Vorwürfe als Begründung für Sanktionen erhoben, obwohl der Beschuldigte gar nicht gegenwärtig ist.

1 Zum Grundbestand der Tempel rede vgl. ROSE, Ausschließlichkeitsanspruch, vor a1lem $224 \mathrm{f}$.

2 Schon WELCH, Jeremiah, his Time and his Work 137-140 hat hier 
ad 5)

Die Widerrede VV 12 und 15b mit dem Rekurs auf Jahwes Sendung könnte man zunächst als Berufung auf Befehlsnotstand bezeichnen. Die Auslegung wird die notwendigen Modifikationen anzubringen haben.

ad 6)

Die Kläger erinnern in ihrem Votum $V 11$ die Richter an das, was sie mit eigenen Ohren gehört haben. Daß die oberen nur Information aus zweiter Hand besaßen, wird auch in Jeremias Verteidigung und im Urteil nicht mehr. berücksichtigt. Der Erzähler hielt offenbar solche Präzision für überflüssig.

ad 7)

Auffällig ist die Allgemeinheit des Inhalts dieses Appells und seine inhaltliche und terminologische Verwandtschaft mit $V 3$. BOECKER" sieht hier einen "Schlichtungsvorschlag", kann dafür aber nur imperativische Form als Indiz anführen. Weshalb ein Schlichtungsvorschlag sich an die Richter (so die ausdrückliche Adressangabe in $V 12$ !) und nicht an die Kläger richten sollte, ist nicht einsichtig.

ad 8)

Jeremias Apologie subsumiert nicht nur stillschweigend die Oberen unter die Ohrenzeugen, sie unterscheidet auch nicht zwischen Adressaten der prophetischen

ein Argument gefunden, einen Redaktor zu postulieren, der aus einer absoluten Unheilsansage Jeremias eine bedingte Drohung gemacht hat.

3 Das ist eines der Indizien, die gegen die Deutung von SCHULZ, Todesrecht 118-123, sprechen; vg1. die folgenden Anmerkungen.

1 ebd. 117-121. 
Botschaft ("Jahwe hat mich zu euch gesandt" $V$ 15b) und richterlicher Instanz ("Ich bin in eurer Hand" V 14). Zu literarkritischen Operationen berechtigt diese Beobachtung kaum.

ad 9)

Das Verständnis von $V 16$ als Schlußurteil ist umstritten. SCHULZ ${ }^{1}$ und RIETZSCHEL ${ }^{2}$ z.B. sehen in ihm ein Votum einer Gerichtspartei. Für unsere Sicht spricht:

- In V 16 reden die ausdrücklich genannten Adressaten der Anklage- und Verteidigungsrede, also doch wohl die Richter.

- V 16 ist der letzte von drei Redegängen mit gleicher Einleitung "Und es sprachen" (bzw. "Es sprach"). Der nächste Vers hebt sich deutlich ab durch ein Verb der Bewegung, durch eine völlig neue Sprechergruppe und einen neuen Adressaten, sowie inhaltliche Nuancen, die noch zu erörtern sind.

- Inhaltlich bringt $V 16$ keine neuen Elemente (im Gegensatz zu Anklage, Verteidigung und dem $A$ ltestenvotum VV 17-19), sondern gibt eine Stellungnahme zu den ersten beiden Redegängen: der Urteilsvorschlag der Anklage wird abgelehnt, die Argumentation der Verteidigung wird übernommen.

All diese Beobachtungen legen nahe, in $V 16$ das Schlußurteil zu sehen.

1 ebd. 118-123. V 16 ist für SCHULZ "Plädoyer der königlichen Beamten, gerichtet an die priesterlich-prophetische Anklagevertretung" und V 17 das "Plädoyer der Altesten an die ganze kultische Gerichtsgemeinde (Qahal)". Ein Urteilsspruch sei nirgends genannt. SCHULZ muß selbst gemerkt haben, daß der Text seiner Interpretation Widerstand leistet. Es ist ja wohl nicht zufällig, $\mathrm{da} B$ er in der Beschreibung der verschiedenen Redegänge ausgerechnet bei der Verteidigungsrede des Angeklagten den Adressaten nicht nennt, weil ja nicht einzusehen wäre, weshalb ein Beschuldigter sich nur an eine bestimmte Gerichtspartei, und zwar nicht an die klagende, wenden sollte. Konsequent wird denn auch der nächste Redegang nur den königlichen Beamten zugeschrieben und 
VV 17-19 Angehängtes Plädoyer der Ältesten:

V 17 Von VV 11.12 und 16 abweichende Einleitung.

$\checkmark 18$ Berufung auf historischen Präzedenzfall mit wörtlichem Zitat.

V 19 Vergleich des Verhaltens von Hiskija und Juda und dessen Folgen mit der gegenwärtig anstehenden Entscheidung.

VV 20-23 Erzähleinheit ohne Redegänge, mehrfach mit $\checkmark 18 f$ verknüpft.

V 24 Abschließende Notiz über Jeremia.

Einer Diskussion bedurfen:

1) Der Neueinsatz von V 17 ;

2) die Verknüpfung der Erzähleinheit mit dem Prozeßbericht;

3) die inhaltlichen Spannungen zwischen V 24 und V 16 sowie $V 17$.

ad 1)

Die wichtigsten Beobachtungen für die Annahme eines Neuansatzes sind oben unter ad 9) zusammengefaßt ${ }^{1}$. Könnte man im Ausdruck "die ganze Volksversammlung" in V 16 zunächst noch einen neuen Namen zur Bezeichnung derselben Adressatengruppe - nämlich der Gerichtsversammlung sehen, so zeigt $V 18$, daß jetzt ganz deutlich das Volk als Prophetenpublikum angesprochen wird. Anders wäre nicht verständlich, wieso die präzise Adressangabe des

die Beteiligung des Volkes unterschlagen.

2 RIETZSCHEL, Urrolle 97-99.

1 RUDOLPH'S Vorschlag z.St., V $17 \mathrm{ff}$ plusquamperfektisch zu übersetzen und sachlich und zeitlich vor V 16 einzuordnen, erkennt zwar die Bedeutung von $V 16$ als SchluBurteil, kann aber nicht erklären, weshalb hier die Stilform des Nachtrags gewählt wurde und übersieht die Eigentümlichkeiten des Abschnitts. 
im übrigen wörtlich zitierten Michawortes Mich $3,12^{1}$ geändert wurde. Die oben beobachtete Tendenz, die Reaktion des Volkes ins Zentrum zu rücken, taucht hier erneut auf. Wichtig ist, daß durch VV $17 \mathrm{ff} V 16$ seine abschließende Stellung und damit seine Funktion als Urteil mit Freispruch verliert, das Verfahren also wieder in Schwebe gebracht wird.

ad 2)

Der nun wieder offene Prozeß hält aber auch das Interesse am Schicksal des Angeklagten wach. Dieses Interesse wird nun noch gesteigert durch die Erzähleinheit VV 20-23. Die mehrfache Verknüpfung zeigt ein ausgeprägtes Bemühen, den Bericht über Urija mit dem Geschick Jeremias zu parallelisieren.

ad 3)

Deutungen, die Kap 26 als Einheit auslegen, müssen zu fragwürdigen massenpsychologischen Erwägungen ${ }^{2}$ über den Wankelmut des Volkes greifen, um verständlich zu machen, weshalb eben dieses Volk, das in V 16 für Freispruch plädierte, nun nur noch durch einen mächtigen Fürsprecher Jeremias von Lynchjustiz abgehalten werden kann ${ }^{3}$.

1 Das einzige ausdrückliche, wörtliche Zitat eines Kollegen in der prophetischen Literatur!

2 DUHM z.St.: "das Volk läßt sich von religiösen Autoritäten leicht bearbeiten". ERBT z.St.: "Die ganze Geschichte zeigt aber, wie leicht dieses Volk in religiösen Dingen zu lenken war." Ahnlich CORNILL z.St. u.a.

3 Für HITZIG war dieser Widerspruch kein Problem. Er kann zu VV 16ff schreiben: "Diese Allegierung Micha's kam ... nicht erst hinterdrein; sondern während das Volk im Allgemeinen schon durch die Rede Jer's ihn loszusprechen vermocht wurde, wußten Einzelne noch einen besonderen Grund für ihn beizubringen." V 24 kommentiert er: "Das Volk hätte ihn gesteinigt." Am geschicktesten argumentiert GIESEBRECHT z.St.: In V 24 gehe es nicht um die Gefährdung von VV 1-19, sondern um das Risiko Jeremias, wie Urija behandelt zu werden, dessen Verfolgung ja wohl nicht in Jojakims Akzessions- 
Das Resultat dieser Durchsicht der Unebenheiten läßt sich folgendermaßen zusammenfassen: Als Spuren von Zweisträngigkeit lassen sich deuten: die Doppelung der Einleitung, die zwei Redebefehle und die beiden Vordersätze $z u V 8 b$ in $V 7$ und $V 8 a$. Das reicht nicht aus, um die Verknüpfung zweier ursprünglich selbständiger Erzählungen anzunehmen.

Zahlreich sind hingegen Hinweise auf eine nachträgliche Bearbeitung eines Grundtextes. Um diesen wieder zu gewinnen, schlagen wir zwei Wege ein:

- Der V 16 hat offenbar durch die Oberarbeitung die einschneidenste Veränderung erfahren, aber nicht durch Eingriff in seinen Wortbestand, sondern durch Verlust seiner Schlußposition und damit seiner Funktion als Urteilsspruch. Von dieser ursprünglichen Bedeutung aus soll versucht werden, den Duktus einer Erzählung aus dem vorliegenden Bestand zu eruieren, welche ihrer inneren Logik gemäß zu V 16 hinführt.

- Anschließend soll versucht werden, durch terminologische Untersuchung den Bearbeiter zu identifizieren.

Dem Urteilsspruch von V 16 entsprechen sehr wohl die Redegänge vor Gericht VV 11-15, überflüssig wirkt nur der sehr allgemein gehaltene Appell V 13; auffällig sind: der vom Kontext abweichende Gebrauch des Verbums שמע, hier nicht im Sinn eines Rekurses auf Ohrenzeugenschaft, sondern von "Gehorsam" und die zahlreichen terminologischen parallelen in $V 3^{1}$.

jahr falle, sondern später. Richtig ist, daß die Erzählung in der heutigen Gestalt historisch Auseinanderliegendes zusammenbringt, aber eben ohne dies auch erzählerisch deutlich zu machen.

1 Hinzu kommt ein inhaltliches Bedenken, das schon DUHM z.St. geäußert hat; er hält es für "ein wenig zweifelhaft, ob Jer so leichtherzig über die Möglichkeit einer Besserung und so optimistisch über deren Wirkung gesprochen hat". DUHM begnügt sich dann aber mit der Auskunft, "der ehrliche Baruch ... hat seine Worte ... so wiedergegeben, wie er sie auffaßte". Sinnvoller als der Hinweis auf Baruchs Biederkeit, für die wir keinerlei Bewei- 
Zum Bericht, wie es zur gerichtlichen Auseinandersetzung kam VV 1-10, kann festgehalten werden: Von den beiden erkannten Einleitungsformulierungen muß jene von $V 2$ ursprünglicher sein.

Der Auftrittsbefehl entspricht anderen erzählerischen Passagen des Jeremiabuches; der Auftrittsort muß hier genannt sein, da im Folgenden immer wieder auf "dieses Haus" hingewiesen wird und Priester und Propheten als anwesend vorausgesetzt werden.

Die beiden Aufforderungen zum Reden: "rede zu" und "sage" können durchaus zum Grundbestand gehören. Von den beiden Nennungen des Redeinhalts V 2 und VV 4-6 hat die zweite eher Anspruch, für ursprünglich gehalten zu werden. Bei der Gerichtsverhandlung steht offensichtlich ein Einzelwort zur Debatte. Die Beschuldigungsfrage V 9 verweist auf $V 6$ als Streitobjekt.

Die dem Propheten mitgeteilte Reflexion Jahwes über mögliche Folgen der Verkündigung $V 3$ hat nicht nur in 36,3 ein terminologisch sehr nahestehendes Pendant, sondern weckt ein Interesse an Erfolg oder Mißerfolg der Botschaft, das in der Geschichte vom Prozeß selbst nicht befriedigt wird.

Von den VV 4-6 ist der mittlere bereits oben als Glosse erkannt worden. Aber auch $V 4 b$ wird nicht zum ur-

se haben, ist die Erinnerung an das Prophetenbild, das HERRMANN, Die prophetischen Heilserwartungen im AT 189, als Spezifikum deuteronomistisch geprägter Texte des Jeremiabuches erarbeitet hat, daß nämlich "dort, wo Jeremia im Rahmen dieser Texte das Wort ergreift, nicht die absolute prophetische, von Gott dem Propheten aufgetragene Botschaft als unausweichliche Forderung dominiert, sondern der Prophet vielfach vor Alternativen stellt, die vom Volk oder der angeredeten Gruppe eine eigene selbständige Entscheidung verlangen, für die der Prophet nicht mehr verantwortlich ist. Diese Form der prophetischen Alternative hat zwar in der klassischen Prophetie ihre Vorbilder, ist aber an den betreffenden Jeremia-Stellen zum Prinzip erhoben und in den Einzelheiten eine Alternative deuteronomistischer Konzeption". Ahnlich THIEL passim. 
sprünglichen Bestand gehört haben. Weder die Beschuldigungsfrage $V 9 a$ noch die Anklagerede der Priester und Propheten nennen eine Bedingung für das von Jeremia angesagte Unheil. Wäre die Unterschlagung des Konditionalsatzes eine absichtliche Verzeichnung des Tatbestandes im Sinne einer Verschärfung, würde man von der Verteidigung eine explizite Richtigstellung erwarten ${ }^{1}$.

Von den beiden Vordersätzen $z u \quad 8$ wird wohl $V 8 a$ später sein. Terminologisch zeigt er Ahnlichkeiten mit den jüngeren Elementen von $V 2$. Inhaltlich setzt er eine längere Rede voraus, deren feierliches Ende berichtet wird.

Aufgrund dieser Beobachtungen soll nun eine literarkritische Ausfilterung eines ursprünglichen Grundbestandes der Erzählung graphisch dargestellt werden.

Jer 26

2 So sprach Jahwe:

1 Im Akzessionsjahr Jojakims, des Sohnes des Joschija, des Königs von Juda, erging dieses Wort von Jahwe her, sprechend:

"Stell dich in den Hof

des Hauses Jahwes und

rede zu (den Leuten aus)

alZen städten Judas, die

kommen, um im Haus Jahwes anzubeten,

alle worte, die ich geboten habe, zu ihnen zu reden; Zaß nichts weg!

3 Vielleicht hören sie und kehren um, ein jeder von seinem bösen Weg, so daß ich mich des Unheils gereuen lasse, das ich ihnen anzutun vorhabe wegen der Bosheit ihrer Taten,

4 und sage zu ihnen:

'So spricht Jahwe:

$1 \mathrm{Vgl}$. oben Anm. 2 S.23f. 
Wenn ihr nicht auf mich hört, so daB ihr in meinem Gesetz wandelt, das ich euch vorgelegt habe,

5 so daß ihr auf die Worte meiner Knechte, der Propheten, hört, die ich unermüdlich zu euch sende, ohne daß ihr gehört hättet, (dann gilt:)

6 ich mache dieses Haus wie schilo und diese Stadt mache ich zum Fluch für alle völker der Erde." "

7 Als die Priester und Propheten

Jeremia diese Worte im Hause Jahwes reden hörten

da ergriffen ihn die und das ganze Volk

8 und als Jeremia zu Ende geredet hatte alles, was Jahwe ihm zum ganzen Volk zu reden geboten hatte,

Priester und Propheten und das ganze Volk

indem sie sagten:

"Du mußt sterben!"

9 "Warum hast du im $\mathrm{Na}$ -

men Jahwes prophezeit:

Wie Schilo wird dieses

Haus sein, und diese

Stadt wird wüst sein,

daß keiner mehr darin

wohnen kann."

Da versammelte sich das ganze Volk um Jeremia im Haus Jahwes.

10 Und als die oberen Judas von diesen Dingen hörten, da stiegen sie vom Palast des Königs in den Tempel hinauf und setzten sich am Eingang des neuen Tempeltores nieder.

11 Da sprachen die Priester und Propheten au den oberen und dem ganzen Volk: "Des Todes schuldig ist dieser Mann, denn er hat gegen diese stadt prophezeit, wie ihr es mit eigenen ohren gehört habt."

12 Da sprach Jeremia zu allen oberen und zum ganzen

Volk: 
"Jahwe hat mich gesandt gegen dieses Haus und gegen diese stadt all die Worte zu prophezeien, die ihr gehört habt.

14 Ich aber, seht, ich bin in eurer Hand; macht mit mir, was euch gut und recht dünt.

15 Doch seid euch bloB bewuBt, daß ihr, wenn ihr mich tötet, unschuldiges Blut über euch und über diese stadt und ihre Bewohner bringt, denn in Wahrheit hat Jahwe mich zu euch gesandt, vor euren Ohren all diese Worte zu reden."

16 Da sprachen die Oberen und das ganze Volk zu den Priestern und Propheten:

"Dieser Mann ist nicht des Todes schuldig, denn im Namen Jahwes

hat er zu uns gesprochen."
13 Nun aber bessert eure Wege und eure Taten und hört auf die stimme Jahwes, eures Gottes, so daB sich Jahwe des Unheils gereuen läßt, das er über euch gesprochen hat.
, unseres Gottes,

17 Da erhoben sich einige von den Ältesten des Landes und sprachen zur ganzen Versammlung des Vol kes:

18 "Micha, der Moraschtiter, ist in den Tagen Hiskijas, des Königs von Juda, als Prophet aufgetreten und hat zu ganz Juda so gesprochen:

'So spricht Jahwe der Heerscharen: Der Zion wird zum Acker umgepflügt und Jerusalem ein Trümmerhaufen werden und der Tempelberg zur Waldeshöhe'

19 Haben ihn denn Hiskija, der König von Juda, und ganz Juda getötet? Haben sie nicht Jahwe gefürch- 
tet, und Jahwes Angesicht besänftigt, so daß Jahwe sich des Unheils gereuen ließ, das er über sie gesprochen hatte?

Wir aber sind dabei, großes Unheil auf uns zu laden!"

20 Es trat noch ein weiterer Mann als Prophet im Namen Jahwes auf, Urija, der Sohn des Schemaja aus Kirjat Jearim, und prophezeite gegen diese stadt und gegen dieses Land,ganz wie Jeremia.

21 Und als der König Jojakim und all seine offiziere und all seine oberen seine Worte hörten, da suchte der König ihn zu töten, aber Urija hörte davon und, da er sich fürchtete, floh er und kam nach Ägypten.

22 Da sandte der König Jojakim [Männer nach Ägypten] den EInatan, den Sohn des Achbor und Männer mit ihm nach Ägypten.

23 Und sie holten den Urija aus Agypten heraus und brachten ihn zum König Jojakim; der ließ ihn mit dem Schwert hinrichten und seine Leiche auf den Friedhof der gemeinen Leute werfen.

24 Doch Achikam, der Sohn Schafans, bewahrte Jeremia davor, in die Hand des Volkes zu fallen, das ihn töten wollte.

\section{Das Resultat dieses Arbeitsganges kann for m -} $m \ddot{a} \beta i g$ beschrieben werden als Isolierung einer in sich geschlossenen Erzählung. Ihre Elemente sind:

- Ein Auftrag Jahwes zur Verkündigung einer Gerichtsanssage VV $2 \mathrm{a}^{+} \cdot 4 \mathrm{a} .6$,

- ein Bericht über ein anschließendes Gerichtsverfahren, bestehend aus

- einer Verhaftungsnotiz VV $7.8 \mathrm{ba}^{+}$,

- einer vorgerichtlichen Beschuldigung VV 8bB.9a,

- einer Notiz vom Zusammentreten des Gerichts VV 9b.1a.

- drei gleichförmig eingeleiteten Redegängen vor Gericht, nämlich: A n k 1 a g e durch Priester und Propheten, adressiert an die Richter (Obere und 
Volk) V 11, Ve $r$ e $i d i g u n g$ Jeremias, adressiert an die Richter, $F r$ i s $p r u c h$ durch die Richter, adressiert an die kläger $V 16$.

Reden dominieren, sind aber klar erkennbar als notwendige, dem Ablauf eines Geschehens eingeordnete Elemente einer Erzählung. Eine Bestimmung der $G$ a $t \quad t \quad u n g$ kann erst versucht werden, wenn inhaltliche Beobachtungen dargestellt sind. Viele bisherige Interpretationen haben Kap 26 zu rasch mit den Erzählungen von Kapp 19/ $20 ; 27 f ; 29$ und 36 parallelisiert. Nun ist tatsächlich festzustellen, daß hier jedesmal ein Auftrag Gottes an Jeremia einen Konflikt ausiöst.

Gerade aber im Vergleich hebt sich die Eigenart dieser Konflikterzählung ab. Ein menschliches Gericht fällt in Kap 26 die Entscheidung, während in den anderen Geschichten Jahwe selbst sein Wort bestätigt und den Widersachern Strafe ansagt. Oberhaupt verlagert sich in unserer Geschichte der Schwerpunkt auf die $P$ e $r$ s 0 Jeremias. Als weitere Besonderheit bleibt festzuhalten: die Gegner treten nur in Gruppen auf und sind namenlos 1 .

Singulär ist vor allem, daß dieser Konflikt als ein Prozeß vor Gericht ausgetragen wird. Ober welchen juristischen Tatbestand aber wird hier verhandelt?

Antwort ist zu erwarten von jenen Elementen, die oben als vorgerichtliche Beschuldigungsfrage ( $V$ ), als Anklagerede (V 11), als Verteidigungsrede (VV 12-15) und

1 Kap 26 ist die einzige Einheit des Jeremiabuches, in der Priester und Propheten als eigene Doppelgruppe in dieser Reihenfolge (Priester zuerst) genannt werden. Sonst begegnet diese Reihenfolge nur in längeren Aufzählungen, vgl. 2,8.26; 4,9; 8,$1 ; 13,13 ; 18,18 ; 29,1 ; 32,32$.

Für den Propheten selbst treten - in den poetischen Orakeln die Priester hinter den Propheten zuriick. 
als Urteil (V 16) bestimmt wurden. Die Schuld heißt: Im Namen Jahwes weissagen: "Wie Schilo wird dieses Haus sein und diese Stadt wird wüst sein, daß keiner mehr darin wohnen kann." Oder: "gegen diese Stadt weissagen".

Der Strafantrag wird vom Angeklagten und der Urteilsinstanz zurückgewiesen durch Anerkennung, daß Jahwe den Propheten gesandt habe oder: daß er im Namen Jahwes geredet habe.

In der Diskussion über die Bestimmung des Deliktes wird meist Kap 7 bemüht, um klar zu machen, daß Jeremia "ein Dogma, ein Sacrum" verletzt habe ${ }^{1}$. Als möglichen Hintergrund des Urteilsantrags sieht man einen Rechtssatz, wie er in 1 Kön 21,10.13 erkennbar wird: "Wer seinem Gott flucht, muß sterben." Der Rekurs auf die Beauftragung durch Jahwe wäre dann als Berufung auf Befehlsnotstand $z u$ verstehen.

Die Prozeßmaterie kann aber auch ganz anders gedeutet werden: Das Urteil akzeptiert nicht ein Entlastungsargument des Jeremia, sondern anerkennt seine Echtheit als Prophet. Daß Jeremia beansprucht, im Namen Jahwes zu reden, hat auch die Beschuldigungsfrage ausdrücklich gesagt. Aber offenbar war der Inhalt, die Stoßrichtung der Botschaft, der Grund gewesen für eine Bezweiflung der Echtheit der Sendung, die dann vom Angeklagten eindringlich und erfolgreich beteuert wird.

Sucht man im Alten Testament nach einer Parallele, bei der eine menschliche Instanz über die Echtheit eines Propheten zu Gericht sitzt, stößt man auf Dtn 18,20 "Der Prophet, der sich vermessen sollte, in meinem Namen ein Wort zu reden, wozu ich ihn nicht zu reden beauftragt habe [oder welcher im Namen anderer Götter spricht] -

1 Vgl. RUDOLPH z.St., sowie BOECKER ebd. 95, SCHULZ, ebd. 120. 
sterben muß dieser Prophet!" Zweierlei ist zur Interpretation dieses Textes festzustellen:

Bei dem Propheten, um den es in Dtn 18,15-22 geht, handelt es sich nicht um einen reinen Gesetzeslehrer und Mahner, sondern mindestens auch um einen Verkündiger des Künftigen. Das ergibt sich aus dem Gegensatz zu Dtn 18, 14 und aus den späteren Zusätzen Dtn 18,21.22. Zweitens meint Dtn 18,20 nicht, daß J a $h$ we einen solch vermessenen Propheten mit dem Tode bestraft ${ }^{1}$, sondern es wird eine Rechtsnorm für eine menschliche Gerichtsinstanz genannt (vgl. Dtn 17,$22 ; 22,25 ; 19,12 ; 21,22$ ), wenn auch nicht in der klassischen Form altisraelischer Rechtssätze.

Der in unserem Prozeßbericht vorausgesetzte Tatbestand entspricht in folgenden Punkten der im Dtn aufgestellten Norm: Es geht um das "Reden im Namen Jahwes", um das Vorhandensein oder Fehlen einer Sendung bzw. Beauftragung, um eine menschliche Gerichtsinstanz, die entscheiden muß, und es geht um dasselbe Strafmaß: Tod im Falle der eigenmächtigen Verkündigung. Unter Verkündigung ist an beiden Stellen nicht das gesamte prophetische Auftreten verstanden, sondern ein konkretes Wort. Die Grunderzählung von Jer 26 ist also eineapologetische Erzählung von einem "Lehrzuchtverfahren", bei dem

1 Anders verhält es sich in Ez 14,1-11. ZIMMERLI hat in seinem Aufsatz, Die Eigenart der prophetischen Rede des Ezechiel 1-26 sowie in BK XIII z.St. dargestellt, daß der Prophet hier sakralrechtliche Terminologie aufnimmt. Mindestens der erste der beiden disputierten Fälle zeigt durch die Nennung des "Fremdlings",daß seine Formulierung in vorexilische Zeit zurückgehen muß. Sollte auch die den Propheten betreffende Norm altes Rechtsgut darstellen, wäre hier aber nicht Blutgerichtsbarkeit über einen Propheten einer menschlichen Instanz übertragen. Jahwe selbst sorgt für das Ende des Propheten, der sich vergangen hat ( $\mathrm{vgl}$. den Konflikt Jeremia - Hananja Jer 27f!). ZIMMERLI erwägt (ebd. z.St.), den menschlichen Richtern könnte eine Verpflichtung auferlegt gewesen sein, einen Delinquenten, auf den der Fall von Ez 14,9 zutraf, zu exkommunizieren. 
die Anklage der Priester und Propheten gegen die Legitimation des Jeremias zurückgewiesen wird.

Wie steht es um die $H$ i s $t o r$ i $i t a ̈ t$ des berichteten Prozesses? Es ist nicht zu bezweifeln, daß Jeremia in einem Maß im gesellschaftlich-politischen Leben gestanden hat, daß offizielle Instanzen sich mit ihm $z u$ befassen hatten. Daß es dabei zu ernsthaften Auseinandersetzungen mit juristischen Konsequenzen gekommen ist, darf angesichts von Kapp $19 / 20$ und 29 als sehr wahrscheinlich gelten. Aber gerade im Vergleich mit solchen Texten erheben sich Einwände gegen die Historizität eines Verfahrens, wie in Kap 26 erkennbar. Was der Bericht an historischen Reminiszenzen bietet, ist ausgesprochen dürtig. Es treten zwar so ziemlich sämtliche Stände auf, aber sie sprechen alle wie im Chor. Es fehlen alle Einzelakteure, alle Elemente der Polemik; Jeremia setzt sich in seiner Verteidigung mit seinen Widersachern überhaupt nicht auseinander.

Die Geschichte bleibt farblos, die Darstellung schematisch.

Man wird überhaupt fragen, ob solche "Lehrzuchtverfahren" in Israel je praktiziert worden sind. Es ist uns kein ähnliches Beispiel bekannt. Schon der Ergänzer,der in Dtn die VV $21 \mathrm{f}$ dazugesetzt hat ("Wenn du denkst: Woran sollen wir ein Wort erkennen, das der Herr nicht gesprochen hat? - Das Wort, das der Prophet im Namen Jahwes spricht, das aber nicht eintrifft, dies ist das Wort, das Jahwe nicht gesprochen hat; in Vermessenheit hat es der Prophet gesprochen."), war sich der Unmöglichkeit bewußt, Falschprophetie juristisch festzustellen. Er hat denn auch bloß mehr die Empfehlung anzubieten, man brauche sich vor einem solchen - nicht eintreffenden - Wort nicht zu fürchten. (Unter der Hand ist dabei offenbar der Falschprophet fraglos zum Unheilspropheten geworden!) 
Ein praktikables Modell, der Falschprophetie mit juristischen Kategorien beizukommen, ist im AT nirgends berichtet ${ }^{1}$. Eine Inquisition für Propheten mit anerkanntem Recht, Todesstrafen $z u$ verhängen, ist nirgends nachzuweisen. Allenfalls kann man aus Jer 20,1f und 29,26f auf ordnungsrechtliche Kompetenzen von Tempelaufsichtsbeamten gegenüber mißliebigen und ungebärdigen Propheten schließen. Tötungen von Propheten (vgl. das Schicksal Urijas 26,20-23, sowie die Verfolgungen, denen Jeremia durch Dorfgenossen aus Anatot, durch hohe Beamte und durch Könige ausgesetzt war; zu Jer 2,30 siehe unten $z$. St.) gelten nirgends als Machenschaften einer Inquisition, und Jeremia selbst versucht nie, gegen seine prophetischen Gegner ein Verfahren anzustreben, um ihre Illegitimität festzustellen. Unsere Grunderzählung weiß denn auch nichts zu sagen über das Wie der Urteilsfindung.

Aus der Erstgestalt von Jer 26 können wir nur entnehmen, daß ein zunächst nicht weiter identifizierbarer Erzähler daran interessiert ist, Jeremia als einen Propheten darzustellen, dessen Echtheit im Sinne deuteronomischer Forderungen amtlich festgestellt worden sei. Als Bestreiter der Echtheit werden die Priester und die Propheten (in dieser singulären Formulierung als Doppelgruppe) genannt. Anlaß der Bestreitung ist das Gerichtswort, das dem Tempel das Schicksal Schilos ${ }^{2}$ ankündigt.

1 Wenn man im Grundbestand von Dtn 13,1-2 mit ROSE, Ausschließlichkeitsanspruch Jahwes 19-50 vordeuteronomisches Rechtsmaterial annimmt, mag es allenfalls einmal eine Forderung der Todesstrafe für prophetische Einladung zu Fremdgötterdienst gegeben haben. Vgl. aber auch HOSSFELD/MEYER, Prophet gegen Prophet $148 \mathrm{f}$.

2 Daß hier auf die Zerstörung Schilos durch die Assyrer Bezug genommen wird und nicht auf ein Ereignis aus der Zeit der frühmonarchischen Philisterkriege belegt mit archäologischen und literarischen Erwägungen PEARCE, Shilo and Jer VII 12,14.15, S.105108. 
Dieses Wort entspricht in $h$ a $1 t 1$ i $c h$ Jer 7,12 . 14 und bildet die einzige Klammer zwischen der Grunderzählung von Jer 26 und der sogenannten Tempelrede Jer $7,1-15^{1}$. In welcher Form dieses - gewiß authentisch jeremianische ${ }^{2}$ - Tempelwort dem Verfasser bekannt geworden ist, läßt sich kaum mehr feststellen. Er kann es jedenfalls ebenso variieren, wie der Autor von 7,1-15.

Die Pauschalisierung der Gegnerschaft und die Ausweitung der Drohung vom Tempel auf Jerusalem (mit universalem Echo V 6 und Entvölkerung der Stadt V 9) läßt auf eine Entstehungszeit der Erzählung nach der Zerstörung schließen.

\section{Die Bearbeitungszusätze}

Die auffälligsten neuen Sinnakzente sind im Anhang VV 17-24 zu finden. Entscheidend ist, daß V 16 das Urteil mit. Freispruch als ehemaliger Schlußvers eingeebnet und zum Votum einer Gerichtspartei gemacht wird. Es geht nun offenbar nicht mehr um die Legitimationsfrage. Dem Bearbeiter ist der Prozeß vielmehr Station auf dem Leidensweg eines Propheten. Die prekäre Lage eines Angeklagten scheint ihm typisch für das Geschick eines Jahwe-Boten. Aus dem konkreten Wort, das den Anlaß zur Gerichtsverhandlung gegeben hat (VV 6.9) wird nun eine Wiederholung der Gesamtverkündigung $(V 2 a \beta b)^{3}$ und eine Gesetzes-

1 Zur Tempelrede vgl. jetzt THIEL, Redaktion 101-119 und ROSE, Ausschl ießlichkeitsanspruch Jahwes 213-251.

2 Vgl. THIEL, Redaktion 112-115, wo ein rhythmischer Grundbestand von $V 14$ rekonstruiert wird.

3 oblicherweise folgt dem Auftrittsbefehl ein Redebefehl und ein wörtliches Zitat der Botschaft. Das Jeremiabuch kennt aber auch Berichte, in denen Auftrittsbefehl und Redebefehl einerseits, Botschaftsempfang andererseits, getrennte Akte sind. 13 und 35 wird der Prophet mit Aktionen beauftragt, deren Sinn ihm erst später durch eine Jahwerede enthül lt wird. In 18,1 und 19,2 wird expressis verbis beim Auftritts- und Redebefehl ein künftiger Wortempfang angesagt. Diese Ankündigung geschieht mit einem Verb 
vermahnung ( $V$ 4b). Jeremias Gegenspieler ist das Volk, das nicht hören will, das schon als Mitakteur bei der Verhaftung eingeführt, von Jeremia $V 13$ gemahnt und von Vertretern der Altesten VV 17-19 gewarnt wird, indem man ihm das Gegenbild Judas zur Zeit Michas vorhält ${ }^{1}$. Doch nimmt das Volk auch diese Mahnung nicht an. Allerdings wird die Halsstarrigkeit des Volkes, die Abweisung der Botschaft und des Boten und damit die Gefährdung seines Lebens nicht in Weiterführung der Gerichtsverhandlung dargestellt. Es wird vielmehr VV 20-23 das Schicksal eines Berufskollegen erzählt, ein Schicksal, das - so soll doch wohl nahegelegt werden - auch Jeremia droht. Die Absicht, Urija mit Jeremia zu parallelisieren, ist deutlich erkennbar: "Da trat noch ein anderer als Prophet auf ..."; auch seine Verkündigung erfolgt "im Namen Jahwes" und geht "gegen diese Stadt und dieses Land". Zu allem Oberfluß wird auch noch ausdrücklich erwähnt, seine Worte hätten denen des Jeremia entsprochen. Wie im Fall Jeremias hören die Fürsten von seinen Worten.

Die literarische Tendenz, Urija als deutliche Entsprechung zu Jeremia darzustellen, ist um so verständlicher, als das erzählte Material sich in mindestens einem Punkt ${ }^{2}$ gegen dieses Unterfangen sperrt: Offensichtlich geht es hier um nicht beliebig gestaltbare hi-

in Präfixkonjugation. Im Gegensatz dazu wird in 30,2 und 36,2 wie an unserer Stelle der Botschaftsempfang mit einer Verbform der Suffixkonjugation ausgedrückt, was aus dem Kontext (vor allem von 36,2 ) nicht anders verstanden werden kann, als daß hier eine Wiederholung der gesamten Verkündigung gemeint ist.

1 Die im Griechischen ungewohnte Disgruenz eines vorangestellten Verbs im Numerus V 19 scheint auf eine hebräische Vorlage mit einer Abfolge: Verb im sg. - Mehrzahl von Subjekten - Verben im pl., hinzuwe isen.

2 Sollte es im Prozeß gegen Jeremia um Anwendung des Rechtssatzes: "Wer seinem Gott flucht, muß sterben" gehen, ergäbe auch die Hinrichtungsart Urijas (Tod durch Schwert) keine Parallele. Es wäre nach 1 Kön 21,10.13 Steinigung gefordert. 
storische Information. Die im Jeremiabuch singulären Offiziere des Königs, die Figur des Elnatan ${ }^{1}$ und die Einzelzüge, die über Urijas Ende berichtet werden, können kaum erfunden sein. Wenig zur Absicht des Zweiterzählers paßt aber vor allem, daß es ja der König ist, der Urija beseitigen $1 a ̈ ß t$.

Im Schlußvers 24 kehrt der Erzähler zu Jeremia zurück und tut ganz so, als sei es im bisherigen Verlauf der Geschichte immer um dessen Bedrohung durch das Volk gegangen. Offensichtlich konnte er aus Treue zur historischen Information die Aktivität des Königs im Falle Urijas nicht unterschlagen. Um das Auftreten Jojakims nicht allzu befremdlich erscheinen $z u$ lassen, hat er schon in V 19 "ganz Juda" den König Hiskija zur Seite gestel1t.

Die Argumentationsweise des vorhergehenden Abschnitts widerspricht der methodischen Forderung, daß von der Form zum Inhalt fortzuschreiten sei. Sie wurde im vorliegenden Fall gewählt, um deutlich zu machen, daß strukturelle Oberlegungen zum Kapitel einerseits zur Entdekkung einer sinnvollen Erstgestalt geführt haben und andererseits auch die Bearbeitung als zielstrebiges und planvolles Geschäft erkennen lassen.

Ausgangspunkt war also keine vorgefaßte Meinung über einen bestimmten Schatz von Vokabeln oder Vokabelkombinationen, die als angeblich untrügliche Leitfossilien die Diagnose einer - wie auch immer etikettierten - Redaktionsschicht erlauben sollen.

1 Die Erwähnung Elnatans fehlt in G, ganz im Gegensatz zur sonst zu beobachtenden Tendenz, Namen zu ergänzen; vgl. TOV, Critique textuelle $192 \mathrm{f}$. Mögl icherweise haben die Obersetzer sein Verhalten an dieser Stelle für unvereinbar gehalten mit seiner Einstellung in Kap 36, wo er zu den Oberen gehört, die bei Baruchs Vorlesung erschrecken und den König von seiner frevlerischen Zerstörung der Rolle zurückhalten wollen. G hat überhaupt im erzählerischen Abschnitt des Kapitels stärker eingegriffen und den Abschnitt straffer gefaßt. 
Wenn wir uns nicht in einem Gestrüpp von Subtilitäten verheddert haben und das Resultat eine gewisse Schlussigkeit beanspruchen darf, können nun aber doch einige über das anstehende Kapitel hinausgehende Erwägungen die Erwartung für die weiteren Analysen vorstrukturieren.

In den Bearbeitungszusätzen häufen sich Formeln ${ }^{1}$, die eine Reihe von Texten im Jeremiabuch prägen und die seit dem vergangenen Jahrhundert immer wieder in Listen erfaßt worden sind. Ihre ungewöhnliche Verbreitung und ihre Verwandtschaft mit ähnlichen sprachlichen Gebilden im Dtn wie den Büchern Jos - 2 Kön sind verschieden erklärt worden. Hier sind ganz summarisch die wichtigsten Deutungsversuche genannt und kritisiert:

- Die Annahme, Jeremia habe die Bücher der sogenannten "früheren Propheten" verfaßt, ist von der historischen Kritik angesichts der dominierenden sprachlichen und theologischen Differenzen aufgegeben worden ${ }^{2}$.

1 Umfangreiche Listen der geläufigsten Formeln mit ausführlicher Diskussion sind nun leicht zugänglich zu finden bei WEIPPERT, Prosareden, passim, so daß meine eigenen Wortstatistiken knapp gefaßt werden können.

- Kombinationen von צוה צו mit Verbal- und Nominalformen von haben ihren Schwerpunkt im Jeremiabuch in von HYATT, Deuteronomic Edition und THIEL, Redaktion als deuteronomistisch bezeichneten Passagen (vgi. 1,7.17; 26,2.8; 7,23; 11,3f.8; 26,2; $29,23 ; 35,14 ; 38,27 ; 51,59)$.

- "Umkehr eines jeden von seinem bösen Weg" in 18,$11 ; 25,5 ; 15,15$; $36,3.7$. Variationen in 18,$8 ; 15,7 ; 23,14$.

- "Jahwe läßt sich des Bösen gereuen, das er plant (tut)" 18,8. $10 ; 42,10$.

- Die "Bosheit der Taten" 4,4; 21,12; 23,2.22; 25,5; 26,3; 44,22.

- "In der Tora (Jahwes) wandein" Jer 32,$23 ; 44,10.23$ und in spätalttestamentlichen Texten Pss 119,1; 78,10; 2 Chron 6,16; Neh 10,30; Dan 9,10.

- "Die Tora, die Jahwe NN vorlegt" Jer 9,12; vgl. Dtn 4,8; Dan 9, 10 sowie Jer 31,23 ; Lev 26,46.

- "Bessert euren Weg (und eure Taten)" Jer 7,3.5; 18,11; 26,13; 35,15 .

- "Auf Jahwes Stimme (nicht) hören" 3,$25 ; 7,23.28 ; 38,20 ; 42,6$. $13.21 ; 43,4.7 ; 44,23$.

2 Begünstigt wurde die Entstehung dieser Hypothese vermutlich 
- Ein e p o c h e n typischer Prosastil des ausgehenden 7. und beginnenden 6 . Jahrhunderts kann aufgrund der schmalen Quellenbasis nicht rekonstruiert werden. (Die Lachischbriefe helfen da auch nicht weit.)

- Merkmale eines $G$ a $t$ t u n $g$ s $t i l s$ von predigtartigen Reden können nicht erklären, weshalb sich dieselben sprachlichen Kennzeichen in der erzählerischen Prosa wiederfinden.

- Die Annahme charakteristischer Eigenarten einer bestimmten Q u 11 e kann die Streuung der Formeln ebensowenig erklären.

- So bleibt zunächst als plausibelste Hypothese die Annahme, die (oder der) Verfasser der Prosareden habe $(n)$ auch die poetischen Stücke gerahmt, die erzählenden Prosaeinheiten bearbeitet und für jene Edition verantwortlich gezeichnet, die dem Jeremiabuch im wesentlichen sein heutiges Gepräge gegeben hat ${ }^{1}$.

\section{Zusammenfassung}

Unsere auf ein einzelnes Kapitel konzentrierten Beobachtungen haben eine mindestens zweistufige Entstehung von Jer 26 plausibel gemacht ${ }^{2}$.

durch die traditionelle rabbinische Lehre von Jeremias Autorschaft für die Königsbücher, eine These, die in der dogmatischen Vorstellung wurzelt, prophetische Autoren seien Verfasser der sogenannten historischen Buicher.

1 WEIPPERT, Prosareden, hat die Differenz zu Dtn und deuteronomistischem Geschichtswerk an Untersuchungen des Formelschatzes und seiner Verwendung herausgearbeitet. Die sprachliche und theologische Eigenständigkeit der bei THIEL und anderen als deuteronomistisch bezeichneten Passagen ist festzuhalten. Die Schwächen der Arbeit von WEIPPERT liegen unseres Erachtens zum einen in zu wenig differenzierten Begriffen des "Deuteronomischen" und des "Deuteronomistischen", zum andern darin, daß die Streuung, nämlich die Häufung der Formeln in der Prosa und ihr Fehlen in den poetischen Stücken sowie die Gleichartigkeit der Formeln in den Reden und in den redaktionellen Passagen unerklärt bleiben.

2 Zu V $5 \mathrm{vgl}$. HOSSFELD/MEYER, Der Prophet vor dem Tribunal $47 f$. 
Der Grundbestand ergab eine geschlossene Einzelerzählung. Eindeutige formale und inhaltliche Parallelen haben wir nicht gefunden. Ein größerer literarischer Rahmen ist von der inneren Logik her nicht erforderlich. Vermutungen über solche Zusammenhänge (eine Erzählung über Jeremias "amtlich" festgestellte Echtheit k ö $n$ $t$ e natürlich eine Spruchsammlung eingeleitet oder abgeschlossen haben) bleiben ein Ratespiel ohne kompetente Jury. Baruch oder einen anderen Augenzeugen wird man nicht als Verfasser bemühen duirfen. Das Interesse der Erzählung geht dahin, zu berichten, wie Jeremia als echter, von Jahwe gesandter Prophet durch obrigkeit und Volk mittels eines Prozesses anerkannt worden sei. Zunächst scheint zwar nur der eine Spruch, der dem Tempel Jerusalems das Schicksal Schilos ankündigt, Gegenstand der Prüfung zu sein. Aber das im Grundbestand der Tempelrede ebenfalls überlieferte Wort wird hier durch Ausweitung der Unheilsaussage auf die Stadt und ihre Bewohner und durch die Ankïndigung universaler Resonanz (26, 6b) zum Exempel jeremianischer Unheilsbotschaft stilisiert. Der I $n h$ a $1 t$ der Unheilsverkündigung scheint Anlaß der Bestreitung der prophetischen Echtheit zu sein, die Priester und die Propheten gelten als Jeremias Kontrahenten. Was daran historisch ist, wird die Wortüberlieferung ergeben müssen.

Die Bearbeitung verlagert den Interesseschwerpunkt von der Anerkennung des echten Propheten auf das Schicksal des verfolgten Propheten. Sie zeigt eine Neigung zu "Reihenbildung". Jeremia wird mit dem kanonisierten Propheten Micha sowie mit Urija verglichen ${ }^{1}$. Die gesamte

1 Auf eine Hypothese zur Gattungs- und Traditionskritik der Urija Kurzbiographie kann hier angesichts der schmalen Textbasis und im Hinblick auf unsere spezielle Fragestellung verzichtet werden. Zweifel an der historischen Zuverlässigkeit des Berichts sind viel weniger angebracht als bei der Grunderzählung von Jeremias Prozeß. 
Verkündigung des Propheten gerät in Konflikt mit dem gesamten Volk. Die damit erzeugte Spannung wird im Kapitel selbst nicht gelöst. Der Inquisitionsprozeß wird zur Episode, die fürs erste noch glimpflich verlief; aber die Gefahr ist nicht endgültig gebannt. Man erwartet einen größeren erzählerischen Zusammenhang, vermutlich von einer Art "Leidensgeschichte" 1 .

Beobachtungen zu stereotypen sprachlichen Wendungen, ihrer festen Verankerung in der Zweitfassung von Kap 26 und ihrer charakteristischen streuung über das Jeremiabuch hin begründen die Vermutung, der Zweiterzähler sei zugleich der Verfasser oder Bearbeiter der sogenannten Prosareden und der Herausgeber eines Jeremiabuches.

Man wird an das 1 iterarische Profil dieses Bearbeiters keine allzu hohen Ansprüche stellen dürfen. In Kap 26 lernen wir ihn als Sammler und Bearbeiter vorgegebener Stoffe und Texte kennen. Die Erzählung vom Propheten vor dem Tribunal lag ihm offenbar schriftlich vor. Mit der "Kurzbiographie" Urijas mag es sich ähnlich verhalten. Die Form, in der ihm bekannt wurde, daß ein Mann namens Achikam zu Jeremias Parteigängern und Fürsprechern zählte,ist kaum mehr zu ermitteln.

1 Eine älteste jeremianische Leidensgeschichte ist wohl im Grundbestand von Kapp 37-45 zu finden. Vgl. KREMERS, Der leidende Prophet. Einzelerzählungen wie die Ersterzählung von Kap 26 wurden nachträglich ihrem Duktus angepaßt. 

"Ich habe sie nicht gesandt, ich habe sie nicht aufgeboten und habe nicht zu ihnen gesprochen." Jer 14,10-16 
Die exemplarische Untersuchung eines Textes der erzählenden Oberlieferung hat eher ein Stück "Gemeindetheologie" als biographische Informationen enthült. "Jeremia - wahrer Prophet" erschien als Anliegen einer Einzelerzählung, "Jeremia - verfolgter Prophet" als Thema einer sammeinden Bearbeitung.

Es soll nun geprüft werden, ob die oberlieferung der Propheten w o $r$ e einen ähnlichen Transformationsprozeß erkennen läßt.

Die Schwierigkeiten der Analyse beginnen mit der Abgrenzung der Einheit. Man wird bei Spruchsammlungen hauptsächlich auf Gliederungssignale und spezifischen Formelgebrauch achten missen.

Die eigenartige Formel Jer 14,1 "was als Wort Jahwes erging an Jeremia bezüglich der großen Dürre" gleicht den Oberschriften in 1,$2 ; 7,1 ; 11,1 ; 18,1 ; 21,1 ; 25,1$ sowie den Buchtiteln Hos 1,1 ; Joel 1,1; Mi 1,1; Zef 1,1; Ez 1,3; Hag 1,1 und Sach 1,1. Die Vermutung liegt nahe, daß hier eine oberschrift über die Kapp 14-17 zu finden ist. Die noch größere formale Nähe zu den Oberschriften von drei jeremianischen Fremdvölkerworten 46,$1 ; 47,1$; 49,34 kann Indiz dafür sein, daß, was jetzt einen $A b-$ schnitt der ersten Buchhälfte einleitet, schon am Kopf einer vorredaktionellen Sammlung gestanden hat und vielleicht auf Jeremia selbst zurückgeht ${ }^{1}$.

Seit DUHMS vernichtenden Zensuren für die Diaskeuasten und Ergänzer ${ }^{2}$ hat die Exegese keine große Lust mehr

1 Vgl. NEUMANN, Das Wort, das geschehen ist 192-205.

2 Gerade im vorliegenden Abschnitt spart DUHM nicht mit Qualifikationen wie "unnütze Zusätze", "metrisch lästig", "ganz thörichter Einsatz". Die Uberschrift "Wort Jahwes" über einer Einheit mit mehreren sprechenden Subjekten $k$ a $n n$ Gedanken1osigkeit sein, drïckt aber wohl eher ein andersartiges Verständnis von "Gotteswort" aus. 
gezeigt, Gründen für Abgrenzung und Bauplänen redaktioneller Einheiten nachzugehen ${ }^{1}$.

Die Abgrenzung der ursprünglichen Einheit nach unten ist bis in jüngste Kommentare hinein umstritten: Nach 15 , 9 setzen den Einschnitt: KEIL, DUHM, GIESEBRECHT, ROTHSTEIN, CORNILL, CONDAMIN, NOTSCHER, LAMPARTER, DENNEFELD, AESCHIMANN, WEISER, CUNL IFFE-JONES, PATERSON, COUTURIER, z.St.

Einen Neueinsatz nach 15,4 sehen: SCHMIDT, VOLZ, RUDOLPH, GELIN, MCNAMARA, WAMBACQ z.St. Die Entscheidung wird von der Beurteilung der Einheitlichkeit oder Zusammengesetztheit des Textes und seiner Strukturgesetze abhängen. Das Bild, das die Forschung hier liefert, könnte kaum disparater sein.

KEIL sieht hier "nicht eine Einzelrede, sondern gleich den früheren Stücken eine Zusammenfassung von Vorträgen und Aussprüchen über die Verderbtheit des Volkes.. ..." Aufgrund derselben Anschauungen und desselben Gedankenkreises sei aber jede Zerlegung abzulehnen. Ein anderes übergreifendes Prinzip wird nicht namhaft gemacht.

Eine redaktionelle Sammlung sogar sehr verschiedenartiger Aussprüche zur Illustration der Wirksamkeit Jeremias gelegentlich einer Dürre sind Kapp 14-17 für Erbt.

1 GRAF hatte zu dieser Frage noch auf die Parallelität im Aufbau zwischen Kapp 11-13 und 14-17 hingewiesen: Erst Strafandrohungen 14,7-15,9 // 11,6-17, dann Klage über das eigene Leid 15,10$21 / / 11,18-12,6$, end ich durch Sinnbilder 16,1-8 // 13,1-14 Wiederkehr zu weiteren Aussichten auf das Strafgericht und allgemeinere Betrachtungen 16,9ff // 13,15ff. Man vergleiche dazu jetzt THIEL, Diss. 654: "11,1 - 12,6; 18,1-23; 19,1-20,18 (vielleicht auch 14,1-15,21) weisen eine parallele Abfolge der Elemente auf: Anlaß zur prophetischen Verkündigung, Gerichtspredigt, evtl. mit folgendem Gerichtsspruch, anschließende Verfolgung des Propheten und seine Klage. Man darf vermuten, daß D mit dieser Komposition so etwas wie einen typischen Vorgang der prophetischen, genauer: der jeremianischen Verkündigung zeichnen wollte und dabei in Anlehnung an die ältere, besonders die berichtende Oberlieferung auf den ursächlichen Zusammenhang zwischen Verkündigung und Leiden Jeremias hinwies." Vgl. auch RIETZSCHEL, Urrolle 122-125. 
Zwei Reihen verschiedener Stücke findet HITZIG in $(12,4)$; 14,1-9;14,19-22 einerseits und dem Rest, der allerdings von sekundären Zusätzen durchsetzt sei,andererseits. Vor allem passe das Fürbittverbot schlecht zu dem dann doch gesprochenen Gebet. CORNILL übernimmt HITZIGS These von den zwei Reihen. 14,2-10;14,19-15,1 haben es mit einer Duirre zu tun, 14,12-18 und 15,2-9 mit Schwert, Hunger und Pest.

Das Gelenk und die Klammer für den Redaktor habe das Motiv des Hungers in 14,18 gebildet. NOTSCHER nimmt eine Zweiteilung zweier paralleler Gedankenreihen 14,1-16 und 14,17-15,9 in Form eines Zwiegesprächs an.

DUHM sieht in 14,1-15,9 eine redaktionelle Einheit; Ergänzer haben ein Gedicht Jeremias 14,2-10 + 17f + 15, 5-9 neben kleinen Zusätzen mit einem ihrer typischen Einsätze 14,11-16 versehen, wegen ihrer merkwürdigen "Vorliebe für die Polemik gegen die Propheten"; die Gelegenheit dazu habe man "an den Haaren herbeigezogen, denn der Wassermangel gab gewiß keine Veranlassung zu einem Angriff auf die Propheten". Einem jüngeren Ergänzer schreibt er 14,19-15,4 zu, das als Dublette mit 14,11-16 konkurriere, den Ausgangspunkt "Dürre" besser im Auge behalte und sich damit als jünger erweise. Allerdings gesteht er selbst: "Freilich kann eine solche Entscheidung nur subjektiven Charakter haben."

Für ROTHSTEIN ist der Prosacharakter von 14,10-16 Grund zur Elimination, zumal hier von Düre nicht die Rede, die redaktionelle Verklammerung also nicht sehr geglückt sei.

CONDAMIN hält die Prosateile für authentisch, wenn auch möglicherweise sekundär eingefügt. "Mais ils sont tout à fait dans le sujet, le ton et le style des écrits de Jérémie."

VOLZ entdeckt in 14,1-15,4 ein kunstvolles und von Anfang an planvoll intendiertes Nebeneinander von Lied und Rede mit Jahwe, dem Propheten und dem Volk als re- 
dend und handelnd im Wechsel. Ihm folgt RUDOLPH, wobei er mit dem Hinweis darauf, daß "die entscheidenden Erkenntnisse dieses Kapitels ... in der Zwiesprache zwischen Gott und dem Propheten gewonnen" werden, eine Charakterisierung als Liturgie ablehnt. Diese Interpretationsmöglichkeit war von MOWINCKEL in die Diskussion eingeführt und zugleich abgelehnt worden. (Schon ERBT fand in 14,1-10 den Stil einer Liturgie und nahm an, Jeremia parodiere ein Klagefest des Volkes.) WEISER nahm diesen Versuch auf und deutete $14,1-16 ; 14,17-15,4$ als "teilweise formal aber nicht sachlich gleichlaufende Volksklagen", die zusammen mit den jeweiligen Zurückweisungen der Fürbitte als kultische Szenen zu verstehen seien. REVENTLOW meint, Indizien nennen zu können, welche die ganze Einheit als eine große Düreliturgie nach genau festgelegtem liturgischem Formular deuten lassen, hat aber keine Zustimmung gefunden ${ }^{1}$.

Versucht man in diesem Durcheinander von Meinungen eine verantwortbare Entscheidung zu treffen, sind folgende Gesichtspunkte festzuhalten: Das Nebeneinander von Poesie und Prosa kann noch kein Kriterium für Ausscheidung von Versen bilden.

Prophetisches Auftreten im Rahmen einer Klageliturgie ist eine Möglichkeit, mit der auch bei Jeremia zu rechnen ist. 14,2-9 weist die Merkmale einer Volksklage auf, nach der das prophetische Orakel zu erwarten ist ${ }^{2}$. Nur ist das Wissen um den Ort der prophetischen Antwort nicht mit Jeremia in Vergessenheit geraten, um erst wieder im 20. Jahrhundert entdeckt zu werden. Da der Beweis

1 Liturgie 149ff. Zur Kritik siehe RUDOLPH z.St.: zur grundsätzlichen Auseinandersetzung mit REVENTLOWS Methode siehe BERRIDGE, Prophet, People, and the Word of Yahwe.

$2 \mathrm{Vgl}$. GUNKEL / BEGRICH, Einleitung in die Psalmen 137f; PATERSON z.St. ist durchaus recht zu geben: "In strict accord with ritual practice comes the prophetic oracle." 
immer weniger gelingt, daß Redaktoren und Ergänzer yon Natur aus Dummköpfe sein müssen, ist durchaus damit zu rechnen, daß sie, was sie für wichtig halten, auch an ausgezeichneter Stelle im Text zu plazieren wissen. Ihre Handschrift ist aber nicht nur an ungeschickten Obergängen, sondern auch an ihrem charakteristischen Vokabular, ihrer Phraseologie, ihrer typischen Theologie, aufspürbar.

Mit solchen Kriterien kommen folgende Verse und Versteile für eine Zuweisung an einen Redaktor infrage: $V$ 12b mit der Trias: "Schwert, Hunger und Pest". Sie begegnet in formelhafter Zusammenstellung fünfzehnmal im Jeremiabuch, und zwar in Zusammenhängen, in denen Gestaltung durch die Redaktion noch anhand zusätzlicher Merkmale nachweisbar ist 1 .

Auffällig aber ist schon die Ich-Bericht-Einleitung $\checkmark$ 11a. Diese Formel ${ }^{2}$ dient in nicht-redaktionellen Passagen (1,7.12.14) zur Wiederaufnahme nach einem Stück, das mit ריהי דבר יהוה אלי eingeleitet wurde. Die Redaktion braucht sie, um selbständig gestaltete Berichte einzuleiten und zu gliedern $(3,6.11 ; 9,12 ; 11,4.9)$. Dies bestärkt die Annahme der redigierenden Hand in 14,11.14; $15,1^{3}$. Oberraschend wirkt in $V 10 b$, daß nach der Botenformel, mit der in $V$ loa Gott als in direkter Rede sprechend eingeführt wird, von Jahwe in 3. Person gesprochen wird. REVENTLOW ${ }^{4}$ will hier die Gattung des "deklaratorischen Urteils" finden 5 .

1 Neben unserer Stelle noch $21,7.9 ; 24,10 ; 27,8.13 ; 29,17 f ; 32,24$. $36 ; 34,17 ; 38,2 ; 42,17.22 ; 44,13 ; \mathrm{vgl}$. HOLLADAY, Prototype $361 \mathrm{f}$. THIEL, Diss. 299; ausführlich: WEIPPERT, Prosareden 149-191. Der Nachweis eines spezifischen Gebrauchs der Formel und ihrer Elemente im Jeremiabuch scheint durchaus gelungen. Wenn aber daraus die Folgerung gezogen wird, daß "der Deuteronomist nicht der Verfasser ... sein kann" (191), wird man auch hier bedauern, daß mit einem pauschalen Begriff $d$ e $s$ Deuteronomisten gearbeitet wird und die $H \ddot{a} u f u \mathrm{ng}$ der Belegstellen in einer spezifischen $S c h$ i $c h t$ des Jeremiabuches übersehen wird, die nicht $n u r$ anhand des Vokabelbestandes als redaktionell zu erweisen ist. 
Abgesehen davon, daß solche sakralrechtliche Feststellungen nur im Munde von Priestern bezeugt sind ${ }^{1}$, widerrät die Einleitung von $V 10$ einer solchen Deutung. RUDOLPH führt die auffällige Form von $V$ lob auf die Tatsache zurück, daß hier (Teile von) Hos 8,13 wortwörtlich zitiert werden. Nun hat allerdings schon VOLZ festgestellt, daß auch dort die Rede von Jahwe in 3 . Person im Kontext als störend empfunden wird. WOLFF hat aber die Bedenken ausgeräumt mit dem Hinweis auf das öftere Vorkommen solchen Personen-Wechsels im Hoseabuch "be $i$ obergängen zu lehrsatzähnlichen Formulierungen" ${ }^{2}$.

Eine Entscheidung darüber, ob das Zitat von Jeremia selbst oder erst von der Redaktion an die jetzige Stelle gesetzt wurde, $1 a ̈ \beta t$ sich kaum treffen. Auch V 12a, der keinerlei redaktionelle Terminologie aufweist, ist thematisch von Hosea abhängig.

Das Fürbittverbot $V 11$ hingegen findet sich wörtlich gleichlautend in den von der Redaktion gestalteten Texten 7,16 und $11,14^{3}$. Nun könnte einer der drei Texte die Grundstelle für eine spätere obertragung des Fürbittver-

2 Vgl. WILDBERGER ebd. 42-46.

$3 \mathrm{Vgl}$. THIEL zu den genannten Stellen.

4 Liturgie 164.

5 Wie erfinderisch REVENTLOW sein kann, wenn er auf die Suche nach Indizien für kultische Haftpunkte geht, mag das folgende Zitat drastisch verdeutlichen: "Außer dem Weinen (בכה) hat ohne Zweifel auch das Heulen (היליל ) seine Wurzel im Fruchtbarkeitskult", ebd. 157. Da kann man nur noch die Gegenhypothese aufstellen: Das Heulen hat seine Wurzel in der Lektüre exegetischer Literatur ...

1 Lev 1,$4 ; 7,18 ; 19,7 ; 22,25.27$; die Aufnahme sakralrechtlicher Terminologie bei Ezechiel erlaubt noch keine Obertragung auf ein vorexilisches Prophetenamt; vgl. zu Ez 18 ZIMMERLI, BK AT XIII; ferner DERS., "Leben" und "Tod".

2 WOLFF, BK AT XIV, 1, S.174.

3 Daß das Fürbitt $v$ e $r$ b o $t$ auch 15,2 stehe - so REVENTLOW, ebd. 165 - ist mindestens eine Ungenauigkeit. Dort ist nur von der $A b-$ weisung die Rede. 
botes gebildet haben. 7,16 kommt dafür kaum in Frage, denn hier sitzt dieses Element nur sehr locker im Kontext und wäre durchaus entbehrlich. Zudem ist die Sicht der Einheit 7,1-8,3, die THIEL entwickelt hat, schwer1ich zu widerlegen: "Beachtet man aber, daß sich in 7,18,3 nahezu alle wichtigen Themen von $D$ - ausgenommen die Pseudopropheten-Polemik - versammelt finden, so wird man zu dem Schluß geführt, daß $D$ in dieser ersten großen, von ihr gestalteten Rede eine Art Summe der Verkünigung Jeremias in der Pointierung geben wollte, die ihr wichtig erschien" 1 .

Ebenso unvermittelt steht das Fürbittverbot in 11,14. Am besten in den Kontext paßt es zweifellos in 14,11 . Aber auch hier ist es durchaus entbehrlich. (Man beachte auch, daß die den Vers abschließende Form nur in redaktionellen Texten auftaucht: 21,$10 ; 24,5.6 ; 39,16 ; 44,27$.

Mit 14,13 beginnt der Abschnitt, der es mit den falschen Propheten zu tun hat. Er hat die Form eines Dialogs des Propheten mit Gott. $V 13$ beginnt mit einem Klageruf und bietet Jahwe die Tätigkeit von Heilspropheten als Entschuldigungsgrund für das Verhalten des Volkes an. Dabei wird die Botschaft dieser Propheten zitiert, ohne Botenformel-Einleitung, obwohl der Inhalt sich als angebliche Jahwerede zu erkennen gibt $(7 \Omega s)^{2}$. V 14 gibt in Form einer Jahwerede ein theologisches Urteil über diese Propheten. In dreifacher Weise wird dabei ihre Legitimation bestritten; ihre Tätigkeit wird mit dem part. nif. und dem part. hitp. von נבא und drei Nominalverbindungen sowie mit dem Nomen שקר in Frontstellung charakterisiert.

1 THIEL, Diss. 221.

2 Auch in 27,(9).14.16 wird - im Gegensatz zur vorredaktionellen Hananja - Geschichte - den Pseudopropheten diese Einleitungsformel vorenthalten. 
Wortstatistischer Exkurs

A) Zu den Verbalphrasen mit שלח דבר ; צוה ;

1. Ich habe sie nicht gesandt, vgl. 23,21.32; 27,15; 29,9 ; ferner 28,$15 ; 43,2$;

2. und habe sie nicht aufgeboten, 29,23;

3 . und habe nicht gesprochen zu ihnen, 23,21 .

ad 1)

Von den insgesamt 86 Vorkommen dieser Wurzel können zunächst die 24 Belege mit Formen des Intensivstammes ausscheiden, weil hier eine klare Sinndifferenz gegeben ist. Besondere Beachtung verdienen Stellen, wo Jahwe Subjekt ist. Allerdings ist zu beachten, daß keine Formunterschiede feststellbar sind zwischen den Fällen, wo Jahwe jemand sendet und den Stellen, wo die Aktivität eines Königs 1 oder eines offiziers genannt werden. Ausscheiden dürfen die Fälle, wo das Volk von Jahwe aufgefordert wird, Erkundungen einzuholen $(2,10 ; 9,16)$. Nicht in Betracht kommen ferner Stellen, wo als objekt eine Sache genannt ist $(1,9$ die Hand; das Schwert 25,16.27; e in Brief 29,1;29,25); allerdings ist hier eine Einschränkung zu treffen: Das Jeremiabuch kennt selten mb zu einer Tätigkeit, die mit $\rangle+$ inf. $(19,14)$ ausgedruckt wird, wohl aber die Wendung

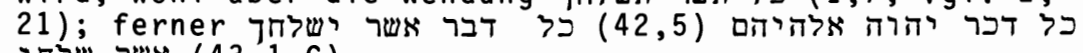
אשר שלחו $(43,1 \mathrm{G})$.

Eine Sendung jahwes wird auch in Bezug auf Nebukadnezzar ausgesagt $(43,10 ; 25,9)$. Hier wird aber die Beziehung auf das personale objekt durch bs ausgedruickt. (Vgl. 16,16 mit zweimaligem $\pi$ it + ).

Neben der uns im Folgenden interessierenden Sendung von Propheten durch Jahwe verdient noch Erwähnung die Formulierung von 23,38. Hier geht es um eine Befehlsübermittlung von Jahwe an das Volk ohne explizite Vermittlung durch Propheten was wohl von der Prophetenbeauftragung nicht allzuweit abgeruickt werden darf. Auch diese Formulierung hat ihre formale Parallele im innermensch1ichen Bereich: 29,28.31 (Jeremia läßt den Verbannten etwas ausrichten).

Nicht übersehen solite man ferner die Tatsache, daß auch eine Beauftragung Jeremias durch das Volk zu einer Anfrage an Jahwe mit derselben Vokabel beschrieben

121,$1 ; 29,3 ; 36,21 ; 37,7.17 ; 38,14$ Zidkija; 26,22 Jojakim; 40,14 der König von Ammon,39,13 Nebusaradan; 36,14 die Fürsten. 
werden kann 42,6.9.20.

Die häufigsten Wendungen mit חלש finden sich allerdings in Zusammenhängen, in denen eine Sendung eines Propheten durch Jahwe ausgesagt ist $(7,25 ; 25,4 ; 26,5$; 29,$19 ; 35,15 ; 44,4 ; 1,7 ; 25,15.17 ; 26,12.15 ; 42,5 ; 43,1$; in den ersten 6 Fäl]en geht es um die kontinuierliche Reihe von Prophetenl, bei den letzten 7 Stellen geht es um die Sendung Jeremias) bzw. bestritten wird $(14,14.15$; $23,21.32 ; 27,15 ; 29,9$, hier geht es um Legitimationsbestreitung einer nameniosen Mehrzahl von Propheten; 28,15 analog um Hananja; 29,31 um Schemaja; 43,2 wird mit derselben Wendung Jeremias Sendung bestritten). 28,9 wird das Eintreffen des Wortes als Erkenntniskriterium statuiert für die Jahwesendung von Heilspropheten.

Versucht man diesen Befund überlieferungsgeschichtlich zu gliedern, läßt sich Folgendes feststellen: Eine gleichmäßige, von anderen Verwendungen formal abhebbare Verwendung von iל für Prophetensendung gibt es nicht2.

Der Terminus $1 \ddot{\beta} \beta t$ sich in den "Berufungsberichten" eines Jesaja 6,8 und Ezechiel 2,3 f; 3,6 und im Zusatz Jes 48,16 nachweisen. Häufig wird die Verwendung erst im Jeremiabuch. Ez 13,6, wo von nicht gesandten Propheten die Rede ist, dürte eine von Jeremia abhängige Nacharbeit am Ezechielbuch formuliert haben ${ }^{3}$. Haggai (Hag 1,12) und Sacharja (Sach 2,12f.15; 4,9;6,15) gelten als von Jahwe gesandt, ebenso wie ihre Voriäufer (Sach 7,12).

In älteren Texten ist mit Formen von חל die Sendung Elijas (2 Kön 2,2;4,6), Natans ( 2 Sam 12,1) und Samuels ( 1 Sam 15,$1 ; 16,1,13$ ) ausgedrückt. Die Sendung Moses wird (in Ex 3,10.12.13.14.15=E) so gekennzeichnet 4 .

Was die Verwendung im Jeremiabuch anbelangt, legt die Analyse nahe, 1,7 dem authentischen Material zuzuweisen. $26,12.15$ sowie 42,5 dürten weitere Belege für den Gebrauch des Terminus zur Bezeichnung der jeremianischen Beauftragung in vorredaktionellem, erzählerischem Material darstellen. Zur Bestreitung der gegnerischen Legitimation scheint der Prophet selbst oder eine vordeuteronomistische Redaktion (siehe unten) die Negation von 4 in 23,21 angewendet zu haben. Die Bearbeiter haben diesen Sprachgebrauch aufgenommen $(25,15.17$ PD), vor allem in der Prophetenpolemik $(14,14.15 ; 23,32 ; 17$, $15 ; 29,9)$.

$1 \mathrm{Vgl}$. HOSSFELD/MEYER, Der Prophet vor dem Tribunal $47 f$.

2 Vgl. RICHTER, Berufungsberichte 156-158.

$3 \mathrm{Vgl}$. HOSSFELD/MEYER, Prophet gegen Prophet 126-142.

4 Ahnlich Jos 24,5; für J vgl. Ex 7,16; Num 16,28f; ein Nachklang der Sendung Moses findet sich noch 1 Sam 12,8; Dtn 34,11 und im Zusatz Mich 6,4. 
ad 2)

Die Wurzel 1 si.findet im Jeremiabuch Anwendungen voller grammatikalischer Varianten in der Bezeichnung des Sach-wie des Personalobjekts. Die in Auftrag genommene Person wird bezeichnet durch an das Verb angefugte Suffixe $(1,7 ; 1,17 ; 7,22 ; 13,5.6 ; 14,14 ; 23,32 ; 26,2$; $29,23 ; 32,35 ; 35,8.10 ; 35,16 ; 38,27 \mathrm{G} ; 50,21)$ bzw. durch תs + suff. ((7,23 (2x);11,4;13,5;27,4(?);35,18)) oder durch $ת$ + Nomen $(11,4 ; 17,22 ; 32,13 ; 35,14 ; 36,5$. $26 ; 38,10 ; 51,59)$, selten durch $>(32,23 ; 47,7)$ oder עy $(35,6)$.

Sachobjekte werden mit $\mathrm{m}(1,7.17 ; 7,23 ; 35,16)$, mit 7 s + Relativsatz $((7,23 ; 7,31 ; 11,4(2 x) .18 ; 19,5$; $29,23 ; 32,35 ; 35,14 ; 36,8 ; 38,27 ; 51,59))$ bzw. את אשר + Relativsatz $(26,2.8)$, כאשר + Relativsatz $(13,5 ; 17$, 22), כשל + Relativsatz (35,10.18; 50,21), je e inmal mit על ל ל אל אר $(7,22)$ und Relativsatz $(35,8)$ verbunden. Tätigkeiten werden mit $>+$ inf. $(11,8 ; 13,6 ; 32$, $23 ; 36,8.26)$ oder mit למאר + direkter Rede verknüpft $(35,6 ; 27,4 ; 32,13 ; 36,5 ; 38,10) .35,22$ zeigt eine Form ohne Sach- und Personalobjekt; ähn1ich 37,21 .

In den 39 belegten Fällen ist $22 \mathrm{mal}$ Jahwe Subjekt von צוד, $5 \mathrm{mal}$ Jeremia, $6 \mathrm{mal}$ Jonadab, $4 \mathrm{mal}$ ein judäischer oder babylonischer König. Ein nach Subjekten spe$z$ ifizierbarer Sprachgebrauch ist auf morphologisch-syntaktischer Ebene nicht feststelibar.

Auffällig sind die beiden einzigen Vorkommen, in denen einem Personalobjekt keinerlei Sachobjekt entspricht: 14,$14 ; 23,32$, wo also von einer nicht näherhin definierten Inpflichtnahme von Personen in generellem Sinn gesprochen wird.

Untersucht man die Verteilung des Wortgebrauchs auf die Zugehörigkeit zu den verschiedenen Schichten hin, ist festzustellen: Die ganz überwiegende Masse der Belege gehört der Redaktion an. Schränkt man die Belege auf die Fälle ein, in denen Jahwe der Befehlgeber ist, bleiben (nach THIEL) nur gerade 13,5f und 26,2.8 für den vorredaktionellen Bereich übrig. Davon stehen die ersten beiden Stellen in einem jener Selbstberichte des Propheten, die dringend einer neueren eingehenden Untersuchung bedürfen. Die Belege aus 26 ( 2 und 8 ) sind nach unserer oberzeugung ebenfalls redaktionel11.

Die Häufung der Belege in der Redaktionsschicht hat nichts Oberraschendes an sich. מצוה ist "das tragende deuteronomistische Wort für 'Gesetz'"2; für die Verben

1 Siehe oben S. 30-33.

2 LOHFINK, Hauptgebot 55. 
im Promulgationssatz gilt: צרה "beherrscht das Feld vollständig" 1 .

Zwei Feststellungen verdienen notiert $z u$ werden:

- Der Deuteronomiker scheint der erste gewesen zu sein, der das Ergehen des Wortes Gottes mittels verbaler Formen von דבו in die zwei Akte zerlegt hat: Gott befiehlt dem Propheten - der Prophet spricht, was Gott geboten hat 2. Die Redaktion dürfte ausgehend von Dtn $18,18.20$ die heutige Form von Jer 1 gestaltet haben ${ }^{3}$.

- Die Verwendung der Wurzel s zur Charakterisierung einer "Berufung", einer "Bestallung" oder eines "Aufgebots" von Propheten ist Eigenschöpfung der Redaktion. In diesem Sinn sind ja wohl Formulierungen zu deuten, die צוד mit einem Personalobjekt versehen, aber weder Sachobjekte noch Tätigkeit spezifizierend beifügen ${ }^{4}$.

Die Durchsicht dieser Stellen, in denen vom צו + Personalobjekt die Rede ist, legt nahe, in dieser Wendung nicht das fallweise Aufbieten zu einem konkreten Auftrag ausgedrückt zu sehen, sondern die Einsetzung zu einem Amt; eine solche Einsetzung ist von Propheten ausserhalb von Jer 14,14 und 23,32 nirgends ausgesagt. Wichtig ist, daß hier offenbar nicht ein oberschreiten der Kompetenz in einem bestimmten Einzelfall angeprangert, sondern die Legitimation $z u$ einem Amt grundsätzlich bestritten wird. Indizien einer Vergrundsätzlichung der Polemik werden wir unten wieder finden.

ad 3)

Eine bloße Vokabelstatistik der Belege für die Wurzel דבר דi. mit Gott (Jahwe oder Elohim) als Subjekt und Menschen als Adressaten, bezeichnet durch $3 \times+N_{0}-$ men oder suff., ist wenig ergiebig. Ertragreicher durfte eine Untersuchung werden, die das Reden und Sprechen Gottes zu Menschen unter Einbeziehung der verbalen Syno-

1 LOHFINK, Hauptgebot 59; eine Skizze zum Gebrauch von מצוה und צרה bietet LIEDKE im Anhang zu: Gestalt und Bezeichnung alttestamentlicher Rechtssätze 187-195.

2 Um einen Jahwebefehl an einen Propheten, ausgedrückt mit צרה geht es auch 1 Kön 13,9.21; eine Datierung dieser Erzählung ist kaum mögl ich; vgl. HOSSFELD/MEYER, Prophet gegen Prophet 21-27. Allerdings geht es hier nicht um einen Redebefehl, sondern um den Auftrag, etwas zu tun, bzw. zu unterlassen.

3 Vgi. THIEL, Diss. z.St.

$4 \mathrm{Vgl}$. Num 27,19: "Setze ihn (Josua) ein vor ihren Augen"; ähnlich Dtn 3,$28 ; 31,14.23$; zu vergleichen ist ferner: Jahwe bestellt $\mathrm{Da}$ vid zum Nagid 1 Sam 13,$14 ; 25,30 ; 2$ Sam 6,21 ; Richter werden bestellt 7,11; $1 \mathrm{Chr} 17,10$; Hirten 7,7;1 Chr 17,6; Salomo zum 
nyme und der Varianten der Partikel, mit denen grammatisch die Adressenbezeichnung verbunden werden kann ( $I$; לא; ; stand nähme. Im Hinblick auf unser Thema wäre dann eine Auswahl jener Texte zu treffen, in denen Instanzen vorkommen, die das Wort weiter zu vermitteln haben. Diese Stellen sind aber mit den Versfragmenten in den Konkordanzen nicht in den Griff zu bekommen; ein einzelnes morphologisches grammatisches Phänomen kommt als Indikator nicht in Frage. So haftet denn den folgenden Ausführungen etwas Zufälliges an.

Immerhin erlaubt eine Durchsicht der 48 Vorkommen der Wurzel דבר pi. im Jeremiabuch mit Jahwe als Subjekt 1 eine Reihe von Fragen und Vermutungen.

- Ein besonderes Gewicht auf die Tatsache des Redevorganges scheinen die Relativsätze "das Wort, das Jahwe geredet hat" anstelle eines bloßen "das Wort Jahwes" legen $z u$ wollen $(10,1 ; 25,13 ; 30,2 ; 36,4)$. Ahnliches gilt von der Bekräftigungsformel "denn ich (bzw. Jahwe) habe (bzw. hat) gesprochen" $(4,28 ; 34,5 ; 13,15)$.

Daß der Redevorgang als solcher ins Blickfeld getreten ist, bezeugt die Tatsache, da $\beta$ auch über die Kongruenz von Reden und Tun Aussagen gemacht werden $(40,3$ "er tat, wie er geredet hatte"), ferner, daß der Erfolg des Redens in grundsätzlicher Weise thematisch wird (ich redete - ihr wolltet nicht hören, vg1.7,13;22,21+; $35,14.17)$, der Inhalt in nominalen Wendungen charakterisiert wird ( רעד 11,17;16,10;18,8;19,15;26,13.19; הדבר 35,$17 ; 36,31 ; 40,2$; 33,14; מרוב 18,20; 36,7 ). Zu diesem Redevorgang kann dann auch die Person eines Mittlers interessieren; Jahwe redet durch (ביד ) Jeremia; der Vorgang kann als ein iteratives Geschehen dargestellt werden ("seit dem Tag, da ich zu dir zu sprechen angefangen habe ...b bis auf den heutigen Tag 36,4. Vgl. dazu $1,2 f$, wo offenbar dieselbe Vorstellung zu Grunde liegt). Der enge Konnex zwischen Denken, Reden und Tun findet Ausdruck in einer Wendung wie: "bald 'rede' ich... auszureißen und zu zerstören ..." $(18,7.8 .9)$.

Eine überlieferungsgeschichtliche Zuordnung dieser Vorstellungen ist hier nicht möglich. Die in unserem Zusammenhang interessierende Problematik des legitimen und illegitimen Mittlers scheint sonst nirgendwo mit

Nagid 1 Kön 1,35; 1 Chr 22,12, vgl. ferner Jes 10,6;13,3; 45,12; Neh 5,$14 ; 7,2$.

1 Insgesamt kommen verbale Formen der Wurzel דרבר pi. 108mal vor; ein Vergleich: Im textmäßig fast gleichlangen Jesajabuch sind es $48 \mathrm{mal}$. 
derselben Terminologie abgehandelt zu werden. (Vgl. Num 12,2-8; ferner Hos 12,11 !)

So bleibt zum direkten Vergleich zu 14,14 nur 23, 21, wo in einem vielleicht authentischen Jeremiawort ebenfalls der Gesprächskontakt von Jahwe her dementiert wird. Als Sinn ergibt sich aus der Parallele dasselbe, was in 14,14 aus dem Kontext zu erschließen ist.

\section{B) Zur Verwendung von כבא}

Zur Charakterisierung der prophetischen Tätigkeit werden in 14,14 die Partizipien nif. und hitp. der Wurzel נבא verwendet (aus V 15 kann dazu genommen werden). Die partizipialen Wendungen scheinen eine Vergrundsätzlichung der Polemik zu bezeugen. Nicht eine einzelne Tat, der Status der Angegriffenen wird disqualifiziert. Ansätze zu einer solchen Sicht liefert schon das עשה ש finiten Verbformen ausgedrückt. Eine Sinndifferenz zwischen part. nif. und hitp. Iäßt sich unserem Vers nicht entnehmen 1 .

Den fünf hitp.-Formen stehen im Jeremiabuch 35 nif.Formen der Wurzel נבא gegenüber. Sie begegnen in morphologischer Vielfalt und in syntaktisch, redaktionsgeschichtlich und sachlich verschiedenartigen Zusammenhängen.

Es sind neben Formen der Praefix- und Suffixkonjugation Partizipien und Infinitive zu belegen. Die nachfolgende Liste dokumentiert die wichtigsten syntaktischen Variationen; neben dem absoluten Gebrauch $(19,14 ; 23,21$; 26,12) finden sich:

a) בבא als Verbum dicendi mit folgendem zur Einleitung einer direkten Rede: $32,3(26,18)$.

b) Angabe des Adressaten mit $3 \times 26,11$ oder 26,20 bzw. beidem zusammen 28,8 .

c) Angabe des Adressaten mit $>+$ dat. commodi $(14,16$; $23,16 ; 27,15 ; 29,31)$.

d) Angabe eines Sachobjekts im acc. הדברים האלה 20,1, 23,26, השר 23,32. Vgl. dazu die Verwendung im Relativsatz 25,$13 ; 18,6)$.

1 Das hitp. wird noch verwendet 23,$13 ; 26,20 ; 29,26.27 .23,13$ ist authentisches Jeremiawort; 26,20 ff mag der Redaktion als Notiz vorgelegen haben; die Verwendung für Urija widerrät jedenfalls einer Deutung, die der hitp.-Form von 3 J als solcher einen negativen Beigeschmack beimessen will; 29,26f gehört einer vorredaktionellen Schicht an. 
e) Angabe eines Themas mittels $>28,9$.

f) Bezeichnung der legitimierenden Autorität mit

$$
\begin{aligned}
& \text { בבעל 2,8 } \\
& \text { בשקר } \\
& \text { בשם יהוה 11,21 } \\
& \text { 14,15 בשמי }
\end{aligned}
$$

g) Ausdruck einer Folge mittels eines Konsekutivsatzes, eingeleitet mit למען .

h) Kombinationen
d) $+f)$
שקר בשמי בשי בירי
14,14
c) $+f)$
להם בשקר
f) + d)
בשמי שקר בשר שיר
10,6
b) + d)

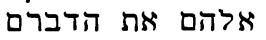
23,25
f) $+a)$

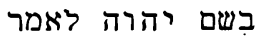
25,30
d) + c)
בעל 26,9
f) $+e$

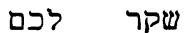
c) + a)
בשמי לשקר לאמר (a) לכמר
$27,10.14$
d) + c)
לכם לאר לאר למר ליד
27,15
27,16
f) $+c)$
c) + f) +
שקר לכם לכמר
27,16
c) + a)
בשקר לכס לכם
d) לכם בשמי שקר שמי לאם
29,9
29,21
לכם לשמר ישרי
27,19 .

Subjekt ist 9 mal Jeremia $(11,21 ; 19,14 ; 20,1 ; 25,13$. $30 ; 26,9.11 .12 ; 32,3)$, je einmal Micha von Moreschet $(26,18)$, Urija ben Schemaja 26,20 , die früheren Propheten 28,8, der Heilsprophet 28,9 , $18 \mathrm{mal}$ ist es eine namenlose Mehrzahl von (Falsch-)Propheten $((2,8 ; 5,31 ; 14$, 14. 15.16 ; 23,16.21.25.26.32; 27,10.14.15 (2x). 16 (2x); $29,9 ; 37,19)$ ); je einmal Paschhur ben Immer 20,6, Schemaja von Nehelam 29,31, Hananja ben Asur 28,6; Ahab ben Kolaja und Zidkija ben Maaseja 29,21.

Zur redaktionsgeschichtlichen Zuweisung ist zu sagen: Nif.-Formen der Wurzel נבא werden verwendet in redaktionellen 1 wie vorredaktionellen Passagen, und zwar sowohl in poetischen wie prosaischen Texten, in Fremdwie Selbstberichten sowie in redaktionell ausgebauten Redestücken.

Ein schichten-oder quellenspezifischer Formgebrauch war nicht festzustellen. Die schmale zahlenmäßige Basis reicht dazu nicht aus. Auffällig ist immerhin der Gebrauch des Partizips. Von den insgesamt 23 Vorkommen solcher Formen im Alten Testament stehen nur 7 außerhalb des Jeremiabuches. Von den 16 Belegen bei Jeremia gehö-

1 Unterscheidet man mit THIEL eine deuteronomistische und eine nachdeuteronomistische Redaktion, sind Belege aus beiden Schichten beizubringen. 
ren 12 sicher der Redaktion an; 32,3 dürfe - nach THIEL - postdeuteronomistisch sein. Als authentisch kommen höchstens $23,25 \mathrm{f} .32$ in Frage. (Vgl. unten $\mathrm{Z} . \mathrm{St}$.)

Das Resultat dieses Abschnitts des Exkurses lautet damit: Vielfalt der Formen, kein auffälliger gleichbleibender Formelgebrauch, keine Differenz zu parallelen hitp.-Formen, kein spezifischer Gebrauch für eine bestimmte Schicht, keine Differenzierung der Tätigkeit von wahren und falschen Propheten mittels Formen von נבא, Wahrscheinlichkeit für die Zuweisung von Partizipien zur Redaktion.

C) Nominalverbindungen

Die inhaltliche Charakterisierung der pseudoprophetischen Botschaft erfolgt in drei Nominalverbindungen.

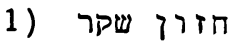

2) 1

3) ותמית לבם לילם

ad 1)

Tindet sich als Bezeichnung prophetischen offenbarungsempfangs vor Jeremia be $i$ Hos 12,11 ; Hab $2,2 f$; Mich 3,6 ; Jes 1,1 ; Ob 1 ; Nah 1,1 , wobei allerdings die Vorkommen in Buchüberschriften nicht ohne weiteres als vorjeremianische Belege gelten können. Das entsprechende Verb ist bei Jeremia nicht belegt. Ober die Authentizität der Parallelstelle 23,16 wird unten zu handeln sein.

ad 2)

קסם ; aus der Notwendigkeit einer Näherbestimmung mit אל (ähnlich bei כ כ ב Ez 13,6.7.9; 21,34; 22,28 ; שר Ez 21,28; חל Ez 12,24) wird man schiießen durfen, daß die mit verbalen und nominalen Formen von DOP bezeichnete Form der Orakeleinholung zunächst noch keine negative Bewertung fand 2 . Anders müßte man den

1 M fügt zwischen קסם und eine Copula ein. Sie düfte erst zu einer Zeit entstanden sein, da Achtung anheimgefallen ist.

$2 \mathrm{Vgl}$. auch den a in der Ständereihe Jes 3,2 in durchaus respektabler Gesellschaft. 
Tatbestand deuten, wenn nachzuweisen wäre, daß der sekundäre Katalogl mantischer Praktiken in Dtn 18,10-11 der Jeremiaredaktion schon vorgelegen hat. Die beiden weiteren Belege für Formen von a p 27,9 und 29,8 sind ebenfalls redaktionel1. Eine Abhängigkeit von Dtn 18 in der jüngsten Fassung ist auch hier nicht zu erkennen.

ad 3)

; d der Ausdruck findet sich in 23,26 wieder und könnte dort authentisch oder eine Kombination aus 8,5 (תרמית) und 23,16 (תרז ) sein (siehe unten ).

Dreifach wie das Dementi ihrer Legitimation wird die Disqualifikation des Inhalts der Falschprophetenbotschaft formuliert. Die Wortwahl ist aber so, daß weder historische Anschaulichkeit noch juristische Präzision in der Festlegung des Tatbestandes erreicht wird. Man wird dann den rhetorischen Aufwand als Indiz für die Vehemenz werten müssen, mit der hier ein theologisches Urteil in einer offenbar brisanten Frage gefällt wird: Die Propheten haben nicht nur sporadisch versagt, sie haben keine Sendung; ihr Tun ist Lüge und steht in der Nähe von Götzendienst ( לילי) .

Auf das Konto rhetorischer Wirkung wird man dann auch die Gestaltung von V $15 f$ zu setzen haben: Mit לכi und Botenformel wird die Strafankündigung eingeleitet, wobei zunächst die Anklage in Form eines Exzerpts aus $\checkmark 14$ sowie den VV $12 f$ wiederholt wird, um dann in Entsprechung dazu die Folgen zu formulieren. In $V 16$ wird die Gerichtsansage auf das Volk als Adressaten ausgeweitet; es begegnet in den VV $15 f$ die stereotype redaktionelle Phraseologie und Thematik: direkter Obergang von der Botenformel in die Jahwerede schon in der Adresse ${ }^{2}$; רעב ; חרב ;הנבאים הנבאים; Partizipialformulierungen; + Aufzählung; die Verweigerung des Begräbnisses als Strafe ${ }^{3}$.

1 Vgl. SEITZ, Redaktionsgeschichtliche Studien zum Deuteronomium 236.

2 Vgl. 11,21; 12,14, DUHM ebd. 181. 
$\checkmark 17 a$ a leitet dann zur folgenden $\mathrm{Klage}$ des Propheten über. Auffällig ist dabei, daß der Redaktor durch seine Verknüpfung auch diese Worte des Propheten auf einen Jahwebefehl zurückführt. VV $17 \mathrm{a} b .18$ schildern tatsächlich das Gericht, aber eben nicht in Form eines Drohwortes im geprägten Sinn des Begriffs. Nach einem weiteren Stück der Volksklage VV 19-22 folgt einer neuen Ich-Bericht-Einleitung eine erneute Ablehnung der Fürbitte (vgl. 14,10.12a).

\section{Zusammenfassung}

Eine vollständige Analyse der Einheit ist hier nicht beabsichtigt. Was der Redaktion vorlag, war wohl ein Ganzes, bestehend aus Volksklage, Jahweantwort durch den Propheten mit Ablehnung des Fastens wie der Opfer sowie prophetischer Klage, die das Gericht beschreibend antizipiert. Dem Volk muß also durch den Propheten seine Kultunfähigkeit bescheinigt werden. Die Heilsgeschichte ist an ein Ende gekommen. Jetzt wird Jahwe der Schuld gedenken und die Sünde ahnden ( $V 10)$. Das Bittgebet, das darauf hinzielte, Jahwe zu bewegen, der sünde nicht zu gedenken, war gescheitert ( $\mathrm{vgl}$. Hos $8,13 !)$. Bei allen kultischen Assoziationen, die bei einzelnen Begriffen dieser Formel mitschwingen mögen ${ }^{1}$ ist es doch völlig undenkbar, daß ein solcher Satz, der Heilsgeschichte und Kult aufhebt, $g$ e $l \ddot{a} u f i g$ e $s$ Element eines wiederholbaren Ritus gewesen sein könnte. Denkbar ist, da $\beta$ Hosea $^{2}$ hier Pate gestanden hat für die theologische Er-

$3 \mathrm{Vgl} .7,32 ; 8,1.2 ; 19,11$; alle redaktionell; 25,33 postdeuteronomistisch; Prototyp 16,4.6 oder 22,19.

1 REVENTLOW ebd. $164 \mathrm{f}$.

2 Vgl. auch Am $7 ; 8$. 
kenntnis des Jeremia, daß jetzt das Gericht in voller Radikalität hereinbrechen muß.

In sachlich zutreffender Weise hat der Redaktor diesem Kontext ein grundsätzliches Fübittverbot Jahwes an den Propheten eingefügt. Seine Handschrift war erkennbar an der Phraseologie, an der Prosa mitten in poetischem Kontext, an den Einleitungen und Oberleitungen.

Einiges an theologischer Absicht ist dabei deutlich geworden: die Ablehnung der Fürbitte wird zu einem Fürbittverbot. Die Legitimation der angegriffenen Propheten wird grundsätzlich, mit deklamatorischem Aufwand und dogmatischen Formulierungen bestritten. Wo dabei noch der Anschein der Konkretheit eines Zusammenstoßes erweckt werden soll, nämlich dort, wo diese Propheten angeblich zitiert werden ( $V$ 13), wird nicht das spezifische Thema der Volksklage anläßlich einer Dürre angesprochen, sondern vom Schwert (also vom Krieg) und vom Frieden geredet. Es geht offensichtlich nicht darum, daß Propheten bei irgendeiner Buß- und Klagefeier etwas $z u$ wenig massiv Jahwes Forderungen verkündet hätten, sondern um das Versagen der Prophetie anläßlich des bevorstehenden Gerichts, der Zerstörung Jerusalems. Die Schuld der Propheten tritt in diesem Abschnitt so sehr in den Vordergrund, daß nur noch von der Mitstrafe des Volkes, aber nicht mehr von seiner Mitschuld (wie etwa 5,31) die Rede ist.

Störend wirkt im jetzigen Zusammenhang, daß 14,18 noch von der Deportation der Propheten die Rede ist, obwohl ihnen zuvor in 14,15 ausdrücklich Ausrottung durch Schwert und Hunger angesagt worden ist. Auch dieser Anstoß wird behoben, wenn man sieht, daß gerade dieser $V$ 18 für die Redaktion mit ein Anlaß gewesen sein wird für die Lokalisierung einer massiven Prophetenpolemik in unserem Abschnitt. 

"Sie heilen den Schaden meines Volkes leichthin indem sie sagen:

Heil, Heil, wo es doch kein Heil gibt. Jer $2,8.26 .30$

$4,9.10$

$5,12-14$

$5,30.31$

6,9-15 
Historisch-biographisches Rückfragen nach der Auseinandersetzung Jeremias mit anderen Propheten hat sich als schwieriger erwiesen, als zu erwarten war. Das apologetische und hagiographische Interesse der überliefernden Kreise ist deutlich geworden (Kap 26). Aber auch fortdauernde Aktualität einer Frontstellung gegen Falschpropheten war zu erkennen in dem rhetorisch-polemischen Aufwand, mit dem die Redaktion die authentische Spruchüberlieferung in Kap 14 angereichert hat.

Es gilt nun im Folgenden, einschlägige authentische Jeremiaworte und ihre redaktionelle Rahmung und Interpretation in den ersten sechs Kapiteln des Buches aufzuspüren, die vermutlich das älteste Spruchgut enthalten. In Kap 2 sind die drei Verse 8. 26. 30 zu untersuchen.

Te $x t k r$ i $t$ i $c h$ bildet nur der letzte der drei Verse ein ernsthaftes Problem, das aber erst im Zusammenhang mit der Auslegung angegangen werden kann.

Sollen die uns interessierenden Verse nicht aus dem Zusammenhang gerissen werden, muß versucht werden, den Kontext zu charakterisieren. Dabei stößt man auf massiven Dissens der Ausleger sowohl hinsichtlich der Abgrenzung wie der Einteilung und der Charakterisierung der Einheit bzw. der Einheiten ${ }^{1}$.

DUHM entfernt 2,4-13;3,6-12a.14-18 und einige kleinere Einschiebsel und findet dann im Rest eine eng verbundene Serie von kleinen Dichtungen mit identischem Metrum und vorzüglicher Disposition. Mit seinem Kommentar beginnt in der Exegese ein neues formales Verständnis

1 Eine Einheit von 2,1-3,5 nehmen an: GRAF, HITZIG, KEIL, DENNEFELD, LAETSCH, AESCHIMANN, DAVIDSON, CUNLIFFE-JONES, WAMBACQ, PATERSON z.St. Die Korrektheit der heutigen Kapitelabgrenzung verfechten GIESEBRECHT, ROTHSTEIN, VOLZ, KOBERLE, NOTSCHER, KROEKER, GELIN, LAMPARTER, BRIGHT, RUDOLPH, WEISER, COUTURIER, MCNAMARA Z.ST. 
des in Kap 2 vorliegenden Materials als (Teil einer) Anthologie.

Die älteren Ausleger hatten hier in stärkerem Maße eine durchstrukturierte Einheit gesehen. So findet etwa HITZIG, daß die Einheit 2,1-3,5 "in ihrer geschlossenen Vollständigkeit den Charakter einer erstmaligen Herzensergießung mache, in welcher alle seit langem aufgelaufenen Beschwerden Jahwes gegen Israel ohne Rückhalt dargelegt werden". KEIL sieht hier Jeremias erste Rede und eine Skizze seiner Grundgedanken. GRAF meint, V'V 2 und 3 "bilden gewissermaßen den Text zu der von $V 4$ an folgenden Strafrede". Es hat sich aber der Eindruck durchgesetzt, daß man es mit einer Reihe von ursprüglich selbständigen, teilweise sogar nur torsohaft erhaltenen ${ }^{1} \mathrm{Ge}-$ dichten zu tun hat ${ }^{2}$.

Exkurs

Allerdings ist gerade in jüngster Zeit nochmals ein Versuch unternommen worden, eine über bloße Sammlung thematisch und formal ähnlicher Gedichte hinausgehende höhere Einheit aufzuzeigen. Ausgehend von den Beobachtungen metaphorisch verwendeter juristischer Terminologie, die KOHLER erlaubt hatten, einerseits die hebräische Rechtsgemeinde 3 plastisch zu beschreiben und andererseits auf 4 den Umfang rechtlicher Redewendungen be $i$ Deuterojesaja 4 aufmerksam zu machen, und im Anschluß an GUNKEL 5 sucht GEMSER 6 nachzuweisen, Jeremia 2,1-4,4 (unter Ausschiuß

1 BRIGHT z.St.

2 Man vgl. etwa CHALLENOR z.St., der das Kapitel eine Anthologie mit Variationen über e in Thema nennt oder McNAMARA z.St., der zwar Kap 2 den Titel "Jeremias erste Predigt" gibt, dann aber doch verschiedene Neueinsätze im Text feststellen muß. Ahnlich AUGÉ z.St. "un cicle de petites profecies".

$3 \mathrm{Vgl}$. KOHLER, Der hebräische Mensch.

4 DERS., Deuterojesaja.

5 GUNKEL/BEGRICH, Einleitung in die Psalmen 329.

6 The Rîb - or Controversy - Pattern in Hebrew Mentality 131. 
des Einschiebsels 3,6-18) stehe in einer prophetischen Tradition, die Jahwes Vorgehen gegen sein Volk in der Form eines Rîb, eines Rechtsstreites, darstelle. Die Elemente, die von einer solchen Konzeption zeugen, werden aufgezählt. Aber es geht GEMSER nich.t eigentlich um den Aufweis einer Gattung, in deren Rahmen jene Elemente ihren Platz fänden, die anderen Autoren als disparat und als Hinweis für die Zusammengesetztheit des Textes erscheinen. Seine Absicht ist vielmehr, festzustellen, daß "the frequency and diversity of application of the rîbphraseology in the 0ld Testament reveals a frame of mind, and not only a way and means of expression"1. Weiter gehen HUFFMON 2 und HARVEY 3 . Während ersterer sein Interesse nur auf Jer 2,4-13 richtet, analysiert letzterer Jer 2,2-37 und bezeichnet diesen Text als einen der "textes reconnus comme Rîb par la plupart des auteurs qui s'y sont attachés"4. Es wird dabei versucht, die einzelnen Verse als fest verankerte Glieder eines Rîb-Pattern zu deuten, dem ein spezifischer Sitz im Leben, nämlich die Gerichtsverkündigung im Bundeskult, entsprochen habe ${ }^{5}$. Aber die Glieder dieser angeblichen Gattung werden so vage beschrieben, daß außerordentlich Verschiedenartiges in ihr Platz hat, und das meiste auch fehlen kann, somit also ein Instrument zur Feststellung von Einheit oder Zusammengesetztheit, yon Torsohaftigkeit oder Integrität nicht gegeben ist 6 .

Eine Abgrenzung wird mit anderen Mitteln versucht werden müssen. Nach vorn bietet die Oberschrift 2,1.2aa ein klares Indiz für einen Neuansatz, weil an dieser Stelle auch ein thematischer Einschnitt zwischen 1,19 und 2,2aßb ff. gegeben ist. (Man beachte das נאם יהוה in 1,19 und den neuen Adressaten von 2,2aß.)

1 ebd. 136.

2 HUFFMON, The Covenant Law suit in the Prophets 285-295.

3 HARVEY, Le "Rîb-Pattern" 172-196.

4 ebd. 177.

5 Man vgl. zur kultischen Verwurzelung der prophetischen Gerichtsrede: WORTHWEIN, Der Ursprung der prophet ischen Gerichtsrede 116 HESSE, Wurzelt die prophetische Gerichtsrede im israelitischen Kult?; WESTERMANN, Grundformen prophet ischer Rede 50-57. Ferner SKINNER, Prophecy and Religion $66 \mathrm{f}$.

6 Zur Kritik vgl, auch PERLITT, Bundestheologie im Alten Testament 132-134. 
Allerdings ist schon DUHM, CORNILL und GIESEBRECHT der Unterschied $z$ wischen dem in der Einleitung genannten Adressaten, nämlich Jerusalem, und dem in der Folge angesprochenen Israel bzw. den Israeliten, aufgefallen. DUHM hält die Einleitung ${ }^{1}$ für das Werk eines späten Diaskeuasten, der Kapp 2-6 zu einer Predigt zusammenfassen wollte,und der im Buch bereits vorliegende Einleitungsformeln imitiert habe. WILDBERGER zweifelt ebenfalls an der Ursprünglichkeit der Formel. "Es scheint sich auch hier um einen kurzen Eigenbericht zu handeln. Er ist aber so allgemein gehalten, daß man an seiner Echtheit zweifeln muß. Sonst wird der Prophet immer in eine bestimmte Situation hineingestellt. Es wird ein bestimmter Befehl erteilt. Wir werden darum gut tun, auch in diesem Fall G zu folgen, die das zweite Kapitel einfach mit ko amar jahwä beginnen 1 äßt" 2 .

Wenn THIELS Darstellung von Kap 1 als einer redaktionellen Einheit richtig ist (und vor allem $V 7$ und $V 9$ dem Bearbeiter zuzuweisen sind), und man die Beobachtung WILDBERGERS ${ }^{3}$ dazunimmt, daß nach der Selbstbericht-Einleitungsformel ("Und es erging das Wort Jahwes an mich") weitere Worte an den Propheten persönlich mit "und es sprach Jahwe zu mir" angeschlossen werden, könnte man dieselbe Abfolge von Einleitungsformeln in 2,1 und 3,6 als Indiz für dieselbe gestaltende redaktionelle Hand werten. Es läßt sich jedenfalls noch eine ganze Reihe von Hinweisen zusammentragen für die Vermutung, daß

1 Sie fehlt (noch?) in G.

2 WILDBERGER, Jahwewort 26. Diese Darstellung ist aber unpräzise, da $G$ der Botenformel ein hal ElזEv vorausschickt, was wohl doch auf eine vollere Einleitungsformel in der Vorlage hinweist. Man wird eine solche auch (mit CORNILL) erwarten dürfen, da mit Kap 2 deutlich eine jener größeren Einheiten beginnt, die übl icherweise eine ausführliche Oberschrift tragen.

3 ebd. 24. 
Kapp $2 f f$. aus verschiedenartigem Material gestaltet worden sind. Da sind einmal Störungen des Rhythmus, die schon DUHM analysiert und zum Anlaß von literarkritischen operationen genommen hat ${ }^{1}$. Auffällig sind und gegen eine ursprüngliche Zusammengehörigkeit sprechen:

- Der Neueinsatz in 2,4 und der AbschluB von V 3 mit J יהוה ; allerdings kann diese Formel als liturgisches Bekräftigungselement oder Zusatz eines "zeilenschindenden Abschreibers"2 gedeutet werden. Hier trifft sie aber zusammen mit einer neuen Adresse. Mag man die Aufforderung zum Hören und die Botenformel noch mit dem Botschafterstil eines Rechtsstreitformulars, in dem der Prophet als Jahwes Anwalt auftreten kann, in Verbindung bringen, der obergang von pluralischer zu singularischer Anrede ist doch auffällig ${ }^{3}$;

- die Reste einer Oberschrift in $3,1^{4}$;

- der häufige Bildwechsel in den folgenden Abschnitten ${ }^{5}$.

1 Die Gefahren dieses Arguments sind oft betont worden. Man kann CORNILLS diesbezügliche Sätze nach 70 Jahren nur mit Wehmut lesen: "In der hebräischen Metrik sind wir nach meiner festen oberzeugung vor der Hand noch in einem Provisorium; es wäre zu wünschen, daß wir möglichst bald zu einem Definitivum kämen!" VII. Vielleicht führt hier der Vergleich mit ugaritischen Texten weiter. Vgl. LORETZ, Die Spruiche Jeremias 109.

2 DUHM z.St.

3 Allerdings tut man sich schwer, mit ERBT z.St. in 2,1-3 ein eigenes, vollständiges Orakel zu finden, das in die Zeit zu datieren sei, da Joahas nach Joschijas Tod nach Agypten deportiert wurde. Allzuvieles muß für eine solche Interpretation "erahnt" werden.

4 Vgl. RUDOLPH z.St.

5 DUHM hat diese Tatsache als Merkmal des jungen Poeten gedeutet, welcher der Fülle seiner Eindrücke noch nicht richtig Herr werde. Ahnlich AUGE: "l'exuberància un poc folla d'imatges que s'hi no$\mathrm{ta}$, es comprenen molt millor en un escriptor jove ..." z.St. ERBT z.St. hingegen meint aus diesem Tatbestand auf ein redaktionelles Mosaik schließen zu können. Auch BRIGHT z.St. rechnet mit teilweise torsohaftem Material, das unter thematischen Gesichtspunkten hier zusammengestückt worden sei. 
Die Möglichkeit redaktioneller Bearbeitung von Kap 2 hat sich uns zur Wahrscheinlichkeit erhoben. Da die Auslegung des gesamten Kapitels nicht unsere Aufgabe ist, konzentrieren wir uns auf die Frage, ob VV 8. 26. 30 einer bestimmten redigierenden Hand zugewiesen werden muissen oder zum vorgegebenen Material gehören.

Jer 2,8

Die Priester fragten nicht: Wo ist Jahwe, und die mit der Tora umgehen, erkannten mich nicht, und die Hirten sind abtrünnig geworden von mir, und die Propheten weissagten im Baal, und denen, die nicht helfen können, liefen sie nach.

Der Vers illustriert Israels Abfall, von dem im vorhergehenden Vers die Rede war, anhand der Vergehen führender Gruppen. KEIL urteilt: "Die Aussagen über die einzelnen Stände bilden nach der richtigen Bemerkung von HITZIG einen Klimax." CORNILL weist darauf hin, daß der Kontext hoseanische Prägung zeige 1 , und Hosea des öftern gegen Priester polemisiert habe. Dagegen steht zunächst die Beobachtung DUHMS: "Wie die Priester, so werden auch die 'Hirten', die Könige und ihre Beamten $(23,1 \mathrm{ff})$ von den Ergänzern des $B$. Jeremia ständig angegriffen" ${ }^{2}$. Tatsächlich treffen wir auf diese Aufzählung von Ständen in Variationen noch in folgenden redaktionellen Texten: 8,1; 13,$13 ; 17,25 ; 32,32 ; 44,17.21^{3}$. Ein noch nicht formelhafter Gebrauch einer Ständereihe findet sich in 4,9 (vgl. unten). Nun hat HOLLADAY ${ }^{4}$ nachgewiesen, daß es der Arbeitsweise des jeremianischen Redaktors entspricht,

$1 \mathrm{Vgl}$. GROSS, Die literarische Verwandtschaft Jeremias mit Hosea.

2 ebd. 19.

3 Vgi. THIEL, Diss. 131.

4 HOLLADAY, Prototype and Copies 351-367. 
authentische Stellen des näheren und ferneren Kontexts abwandelnd aufzunehmen. Das terminologische Material von 2,8 läßt sich denn auch ohne große Schwierigkeiten aus authentischen Jeremiatexten ableiten.

1. Der erste Vorwurf an die Priester findet sich wenige Zeilen vorher als Vorwurf an die Vätergeneration ( $v$ 6).

2."Diejenigen, denen die Handhabung der Tora aufgetragen ist 1 , ließen es an Erkenntnis Jahwes fehlen."Dies ist der Hauptvorwurf, den schon Hosea gegen die Priester erhoben hat ${ }^{2}$. Nun läßt sich aber nicht nur eine geistige Verwandtschaft zumal des jungen Jeremia zu Hosea nachweisen, sondern auch die Redaktion hat offensichtich vorjeremianische Texte als Prototypen verwendet ${ }^{3}$. Allerdings läßt sich im konkreten Fall keine direkte textliche, sondern nur eine topische Verwandtschaft nachweisen.

3. Die Hirten "fielen von mir ab" trifft wie der erste Vorwurf an die Priester kein spezifisches Standesvergehen, sondern ist ein formaler theologischer Begriff für Sündigen ${ }^{4}$.

1 Wohl auch die Priester; LAETSCH z.St. hält sie für eine eigene Gruppe: die Vorgänger der Schriftgelehrten. Mit RUDOLPH z.St. halten wir dies für nicht sehr wahrscheinlich. CODY, Priesthood 116, beschreibt die Verbindung von Priesteramt und Tora wie folgt: "The giving of tora by priests does not appear in any texts earlier than the eight century or early ninth century (Hos 4,6 ; Mich 3,11 ; cf. also $2 \mathrm{Kgs} 12,3$ ), but from that time on down to the Exile it is closely associated with priests (Dtn 31,9.26; Jer 21,8; 18,18; Ezek 7,26; Zeph 3,4)". Vgl. auch PLOGER, Priester und Propheten 157-192, bes. Anm. 5.

$2 \mathrm{Vgl}$. WOLFF, Wissen um Gott 182-205.

3 HOLLADAY ebd. 364-366.

$4 \mathrm{Vgl}$. PORUBCAN, Sin in the 01d Testament $24 \mathrm{ff}$. 
4. Der Vorwurf an die Propheten: "Sie weissagten im Baal" ist Generalisierung einer Anklage, die 23,13 die Propheten Samarias trifft. Der Topos "Baal" ist für das Jeremiabuch (in hoseanischer Tradition) theologischer Generalnenner für alles Götzendienerische. Die Identifikation von בעל ${ }^{1}$ erlaubte den Redaktoren die Formulierung dieses Vorwurfs an die Adresse der Jerusalemer Propheten ${ }^{2}$.

Der zweite, parallel zum ersten gebaute Teil des Prophetenvorwurfes verwendet als Synonym für Baal לא יועלו aus 2,11b und zur Charakterisierung der prophetischen Tätigkeit הלך אחרי, eine Wendung, welche die Redaktion in authentischen Texten vorgegeben gefunden $(2,2 ; 2,23.25)$ und häufig selbst verwendet hat ${ }^{3}$.

Eine Information über konkretes Fehlverhalten der angegriffenen Stände erhalten wir hier also nicht, vielmehr wird in theologischer Begriffssprache ein Urteil gefällt. Man darf hier an THIELS Darstellung erinnern, mit der er die redaktionelle Verbenreihe 1,10 charakterisiert: "Diese Weise zu reden, formelhaft wie umfassend, theologisch gefüllt wie konzentriert, vor allen Dingen aber prinzipiell-allgemeingültig, ist eines der Charakteristika von D" 4 .

1 Siehe unten zu 5,30f.

2 Neben konkreten Ausdrücken für Götzenopferkult ("dem Baal Höhen bauen" 32,35; 19,5; oder "Al täre errichten" 11,13; "den Baalen opfern" 11,17 ; 32,29b; 7,9) kann Israels gesamtes Verhalten als Verletzung des Hauptgebotes genannt werden: "hinter den Baalen herlaufen" 2,13; 9,13; "bei den Baalen schwören" 12,16; "Jahwes Namen wegen des Baal vergessen" 23,17. Jer 2,23 zeigt, daß das Volk sein Treiben keineswegs als Baalskult versteht, sondern Jeremia diese theologische Qualifikation ausspricht gegen den Willen des Volkes.

32,$5 ; 7,6.9 ; 8,2 ; 9,13 ; 11,10 ; 13,10 ; 16,11.12 ; 25,6 ; 35,15$; jüngerer Zusatz ist wohl 3,17; zur Verwendung der Terminologie im deuteronomistischen Bereich vgl. LOHFINK, Das Hauptgebot $76 \mathrm{f}$ und ROSE, Ausschließlichkeitsanspruch $21 \mathrm{ff}$. 
Sollte sich diese Interpretation redaktioneller Zusätze an weiteren Texten bestätigen, so düften die abwertenden Urteile ${ }^{1}$ der Vergessenheit anheimfallen. Der bewuBte oder unbewußte Zwang mancher Ausleger, möglichst viele Verse für den authentischen Jeremia meinen retten $z u$ sollen, erübrigt sich dann.

Jer 2,26

Wie ein Dieb sich schämt, wenn er ertappt wird,
so müssen sie sich schämen [das Haus Israel],
sie selbst, ihre Könige, ihre Oberen
und ihre Priester und ihre Propheten.

Der Vers zeigt erneut eine Liste von führenden Ständen. DUHMS Urteil, daß das Metrum überladen sei, wird von CORNILL geteilt ${ }^{2}$. Allerdings schlägt dieser vor, eher $27 a \beta$ als Glosse aus $32,23 \mathrm{zu}$ deuten. Nun weist aber in 32,16-44 so vieles auf die Redaktion hin, daß an eine Abhängigkeit in dieser Richtung nicht zu denken ist. Die Vorliebe der Bearbeiter für einen Ausbau der Anklage und Applikation auf die führenden Schichten ist uns schon begegnet. Hier verrät sich ihre Handschrift auch durch eine formale Eigenheit: "Der Gebrauch des Pronomen separatum zum nachdrücklichen Anschluß an Vorausgegangenes darf als ein Spezifikum von D bezeichnet werden" 3 .

4 THIEL, Diss. 120.

$1 \mathrm{Vgl}$. DUHM, "Reiner Wasserguß zum edlen Wein" ebd. 54. CORNILL, "Ein seniles Geschwätz" ebd. XLV.

2 Ahnlich urteilen GIESEBRECHT, ERBT, VOLZ, RUDOLPH und sogar WEISER z.St.

3 THIEL, Diss. 139. 
Jer 2,30

Vergeblich habe ich eure Söhne geschlagen, Zucht wollten sie nicht annehmen.

Es fraß das [...] Schwert eure Propheten wie ein reiBender Löwe.

Der Vers bietet zunächst textkritische Schwierigkeiten. vier Probleme sind zu klären:

a. לשרא הכיתי את בניכם

mit inhaltlichen Erwägungen und ohne Anhalt in der Textüberlieferung wird eine Anderung des Ausdru'cks "eure Söhne" in "eure Väter" vorgeschlagen ${ }^{1}$. Der vorliegende Text 1 äßt sich aber durchaus ohne Anderung verstehen. "Eure Söhne" hat hier den Sinn von "Angehörige eures Volkes".

b. מוסר לא לקחר.

G 1iest 2. pl., was GRAF übernimmt. Aber die nachträgliche Umsetzung in Anrede ist plausibler als der umgekehrte Vorgang. Der Obersetzer hat vielleicht seiner allzu starren Logik zuliebe korrigiert, weil er sich sagte, von den Erschlagenen ${ }^{2}$ sei sinnvollerweise kein Lernprozeß mehr zu erwarten.

c. Für חרבם

bietet G bloßes $\mu a x a c \rho \alpha^{3}$. HITZIG findet dies "undeutlich und fehlerhaft". Andere, z.B. DUHM, CORNILL, AESCHIMANN, LAMPARTER, halten dies für ursprünglich. Am massivsten greift EHRLICH in den Text ein und konjiziert . Eine Entscheidung kann erst im Zusammenhang mit der vierten Schwierigkeit getroffen werden.

1 So z.B. EHRLICH, GIESEBRECHT, ROTHSTEIN, BHK ${ }^{3}$ z.St.; die noch weitergehenden Textänderungen von LOEWENCLAU, Zu Jeremia II 3o, lehnt RUDOLPH z.St. zurecht ab. Er selbst möchte "Väter und Söhne" lesen.

2 Das griechische Verb bedeutet in G "erschlagen".

3 Im Gegensatz zu BHK ${ }^{3}$ hält BHS diese Variante nicht mehr. für erwähnenswert, obwohl sie von $L$ und $S$ gestuitzt wird. 
d. נביאכם

Der Textbefund ist eindeutig. VOLZ will in נביאי ändern. Soweit ich sehe, ist ihm darin niemand gefolgt ${ }^{1}$. Im allgemeinen versucht man mit dem vorliegenden Text zurande zu kommen und greift dabei zu etwas gequält wirkenden Erklärungen. So meint NOTSCHER "E u $r$ e Propheten" stünde hier, weil sie zum Volk gesandt seien ${ }^{2}$, oder weil sie $f$ ü $r$ das Volk wirken ${ }^{3}$. Auffällig bleibt, daß hier offenbar die einzige frühe Stelle vorliegt, wo wahre Propheten durch ein Suffix als Israels Propheten bezeichnet werden ${ }^{4}$.

Der Vers wird meist als Anspielung auf eine Prophetenverfolgung verstanden, wobei die früheren Ausleger sich noch die Mühe machten, historische Belege für ein solches Vorkommnis zu suchen. GRAF trägt folgende Stellen zusammen: 1 Kön 18,4.13; 19,10.13; 2 Chr 24,2off; vielleicht 2 Kön 21,16; Josephus ANT $X$. 3,1; Jer 26,23.

HITZIG verweist auf Neh 9,26 und Mt 23,37. Meist aber wird angenommen, unter den Opfern des Blutbades, das Manasse nach 2 Kön 21,16 veranstaltet habe, seien auch viele Propheten gewesen ${ }^{5}$. Dagegen ist Folgendes einzuwenden: Für Prophetenmorde unter Manasse gibt es keine Indizien in historischen Quellen. Die These von der Tötung aller Propheten durch Israel muß als theolo-

1 Halbwegs vielleicht KOBERLE z.St., wenn er unscharf übersetzt: "Das Schwert fraß bei euch die Propheten."

2 BB z.St.

3 EB z.St.

4 Man vgl. später Neh 9,32 "Unsere Propheten". Meist hat eine Determination durch Suffix oder ein Bezugsnomen wie z.B. "Jerusalem" oder "dein Vater und deine Mutter" pejorativen Beigeschmack; vgl. Klgl 2,14; 2 Kön 3,13; 1 Kön 22,23.

5 So z.B. GIESEBRECHT, VOLZ, ROTHSTEIN, KOBERLE, NOTSCHER, DENNEFELD, BRIGHT, WAMBACQ (welcher zusätzlich auf AscIs5, IV und Justin, Dial Tryph $\S 120$ MG 6,756 verweist) z.St. 
gische Aussage im Gewand einer historischen Behauptung verstanden werden ${ }^{1}$. Die späten Legenden, etwa vom Martyrium des Jesaja, verdanken ihre Entstehung eher diesem Theologumenon als historischer Information.

Nun hat schon DUHM der erwähnten geläufigen Interpretation eine andere entgegengesetzt: In $V 30 b$ werde gar nicht das Volk eines Verbrechens angeklagt, vielmehr verweise Jahwe auf eine seiner erfolglosen Strafmaßnahmen gegen Israel. Nimmt man die Lesart von $G$ als urspruinglich $a n^{2}$, so ist diese Deutung durchaus möglich. Jedenfalls verfängt die ausdrückliche Gegenargumentation CONDAMINS nicht: 1. könne der Tod von falschen Propheten nicht als Strafe verstanden werden und 2. sei nicht einzusehen, durch wen denn solche Propheten getötet worden sein könnten, wenn nicht durch das Volk. Einmal sollte man die Unterscheidung von wahren und falschen Propheten gar nicht vorschnell an den Text herantragen. Die Propheten werden hier einfach hingestellt als jemand, dessen das Volk bedarf, als Autoritäten, die geschätzt werden und deren Verlust wie deren Fehlen man etwa in den Klageliedern oder Psalm 74,9 beklagt. Daß Propheten gewaltsam beseitigt wurden, wenn sie einer offiziellen Religionspolitik, wie sie von Assur oder Agypten diktiert werden konnte, gefährlich wurden, ist durchaus denkbar. Daß das Volk dies als Strafe Gottes verstand, leuchtet dann ebenfalls ein. Verständlich ist aber auch, daß ein späterer Glossator den Sinn des Verses unter der Prämisse des erwähnten Theologumenons vom gewaltsamen Geschick der Propheten hat umdeuten können. Das strafende Schwert (Jahwes) wurde nun zum mordenden Schwert jenes Israel, das seine Propheten verfolgt. Derselbe oder ein anderer

1 Vgl. STECK, Israel und das gewaltsame Geschick der Propheten.

2 Es ist kaum ein Grund einsichtig zu machen, weshalb G ein Possesivpronomen hätte unterdrücken sollen. 
Glossator mag dann auch den anschließenden beifälligen Ausruf ${ }^{1}$ beigesteuert haben:"Ihr seid dieses Geschlecht, schaut euch das Wort Jahwes an!" Der Satz fällt jedenfalls rhythmisch aus dem Rahmen, redet im Gegensatz zum Kontext von Jahwe in dritter Person und fordert zum Sehen, d.h. doch wohl zum genauen Lesen des Gotteswortes $a u f^{2}$.

\section{Zusammenfassung}

Kap 2 hat sich uns als Teil einer redaktionellen Einheit erwiesen. Ob schon bei einer Sammlung der Texte vor der Bearbeitung durch die Herausgeber (etwa anläßlich des Diktats der Urrolle oder deren erweiterter Zweitausgabe Jer 36,2.4.28.32. oder durch anonyme Tradenten) Eingriffe in den Bestand vorgenommen wurden, ist kaum mehr zu ermitteln. Gerade in den uns interessierenden Versen waren Spuren der Tätigkeit der uns bekannten Editoren erkennbar.

Inhaltlich gilt von VV 8.26: Was im authentischen Kontext als Anklage gegen Israel erhoben bzw. als Strafe über das ganze Volk angedroht wird, erfährt eine besondere Applikation auf die führenden Stände. In $V 8$ wird ihr Verhalten in theologischer Begriffssprache qualifiziert. Der theologisch interpretierende Charakter der Bezeichnung ihres Tuns als Baalsdienst läßt kaum mehr begründete historische Vermutungen $z u$, auf welche Art Jeremias Berufskollegen in heterodoxe religiöse Unternehmungen verwickelt gewesen sein könnten.

1 So DUHM, RUDOLPH u.a. z.St.

2 WEISER z.St. sieht hier eine Aufforderung, das sichtbare Gotteswort in der Heilsgeschichte zu betrachten. 
$\checkmark 30$ verrät nichts von einem Konflikt zwischen Propheten. Nach unserer Deutung wurde in diesem authentischen Vers ursprünglich nicht das Volk angeklagt, Propheten ermordet zu haben; vielmehr wird ein gewaltsamer Tod von Propheten als Verlust gedeutet, durch den Jahwe sein Volk bestraft habe. Von $f$ a $l s c h$ e $n$ Propheten ist hier (noch) nicht die Rede.

Jer $4,9.10$

9 Und es wird sein an jenem Tage - Spruch Jahwes da geht zugrunde der Mut des Königs und der Mut der Fürsten, und es erschrecken die Priester und die Propheten erbeben.

10 Und sie werden sagen: "Ach, Herr, Jahwe, wie hast du uns getäuscht, indem du sprachst: Heil wird euch sein! Und nun geht uns das Schwert an die Gurgel!"

Auch diese beiden Verse bieten $t e x t k r$ t $i s c h$ e Probleme. Umstritten sind zwei Fragen:

a. Das einleitende רִ̣ in $V 10$ wird von einigen Auslegern umpunktiert in ?ָמָר? , was dann unpersönlich ubersetzt wird ${ }^{1}$; andere punktieren 2 Die Textänderung findet einen schwachen Anhalt in der Textuberlieferung: $G^{L}, G^{A}$ und die arabische Version bieten einen Plura ${ }^{3}$. Eine Entscheidung ist erst unten im Zusammenhang mit Oberlegungen form- und redaktionskritischer sowie inhalticher Art möglich.

b. Plausibel ist die Vermutung, daß die offensichtliche Oberlänge des ersten Teils von $V 10$ auf das Konto

1 So HEUSLER, EWALD, CONDAMIN z.St.

2 So z.B. DUHM, CORNILL, GIESEBRECHT, ROTHSTEIN, YOLZ (dessen Anderungsvorschläge noch weitergehen), PEAKE, RUDOLPH, NOTSCHER, WEISER, PATERSON, GELIN, AESCHIMANN u.a. 
eines Abschreibers geht, der ein לנר durch die Wendung aus V 11 לעם הזה רלירשלם ersetzte 1 .

Die Hauptschwierigkeiten der Interpretation beginnen auch hier mit der A b g r e n u n g des Textes: KEIL läßt die Einheit mit 4,3 beginnen und mit 4,31 enden. Was den Anfang anbelangt, ist ihm - soweit ich sehe - niemand gefolgt. Viel häufiger wird ein Neuansatz in 4,5 angenommen. Ein relatives oder absolutes Ende des Abschnittes wird meist in 4,31 gesehen. Die ausführlichste Auseinandersetzung mit älteren Auffassungen bietet CONDAMIN, der rund 50 Exegeten und Historiker zu Wort kommen läßt, um die liturgische Struktur und den geschichtlichen Hintergrund $z u$ klären. Er findet schließlich in 4,5-6,30 ein großes Gedicht mit einer dreiteiligen Anlage, wobei jeder Teil genau 50 Verszeilen umfaßt. Aber dieser Versuch hat wenig Anklang gefunden. Auch 1iterarkritische Operationen aus metrischen Grüden vermochten im allgemeinen nicht zu überzeugen ${ }^{2}$.

Was zunächst wie ein thematisch einheitliches Gedicht erscheint, als Flugblatt (VOLZ) oder als private Aufzeichnung (RUDOLPH) konzipiert, macht angesichts der Einleitungsformeln, der Unterschiede im Metrum wie in der Thematik eher den Eindruck einer nachträglichen Komposition mehrerer ursprünglich selbständiger Einheiten ${ }^{3}$.

Die Einleitungsformeln in $V 9$ und $V 11$ geben das Recht, die VV $9 f$ als selbständiges Stück vom Kontext

3 Ungenau pauschal isieren BLANK z.St.: "The Greek ..." und AESCHIMANN z.St.: "les LXX et les versions ..."

1 Anders REVENTLOW, Liturgie 97.

2 So wollte etwa DUHM z.St. 4,9-11a eliminieren, weil sie aus dem Versmaß fallen und "nur etwas poetisch gefärbte Prosa" darstellten. CORNILL greift massiv in den Text ein, um Stichen zu bekommen, die seinen Vorstellungen vom Normalmaß entsprechen.

$3 \mathrm{Vgl}$. AESCHIMANN z.St.: "Toute une série d'oracles qui mettent en scène l'ennemie qui vient du nord." 
abzuheben ${ }^{1}$. Allerdings besteht kaum ein Grund, diese Verse Jeremia abzusprechen. Die Reihe von Ständen wird hier noch keineswegs stereotyp aufgezählt. Vielmehr kommt dieser Text als "Prototyp" für die späteren Abwandlungen durch die Redaktion in Betracht.

Die oben offengelassene Frage, ob $V$ lo Selbstzitat Jeremias oder vorhergesagter Ausspruch der Propheten sei, wird meist mit inhaltlichen oberlegungen beantwortet.

Wer hier mit $M$ einen Ausspruch Jeremias sieht, wie vor allem die alten Kommentare, greift zu Erklärungen wie HITZIG: "Vers 10 ist Weissagung dieser Propheten,... welche Jeremia jetzt, wo zuerst die Betrüger entlarvt werden, ein letztes Mal, der bisherigen öffentlichen Meinung sich fügend, als Wort Jahwes hinnimmt." Bereits bei GRAF findet sich auch schon der theologische Erklärungsversuch mit dem Hinweis auf Jahwes Allkausalität, wie sie 1 Kön 22 zum Ausdruck komme ${ }^{2}$. Der individualpsychologisch-biographischen Sicht HITZIGS kommt unter den neueren Auslegern WAMBACQ am nächsten, wenn er schreibt: "Eerlijk en rechtschapen als hij was, had hij nog niet ingezien dat niet alle profeten, die zich op Jahwe beriepen, in feite door Jahwe waren gezonden." Der Behauptung von VOLZ, daß solche Deuteversuche gekünstelt wirken, läßt sich kaum ausweichen.

Die jüngste ausdrückliche Verteidigung von $M$ findet sich bei REVENTLOW ${ }^{3}$. Nachdem für den Abschnitt 4,5-12

1 Vgl. schon GIESEBRECHT z.St., der hier ein vierhebiges Tristich findet, welches sich auch formal yom Qinametrum der Umgebung abhebt; isoliert steht der Versuch ERBTS z.St., 4,10 als ein Einzelstuick den Denkwürdigkeiten Jeremias zuzuweisen.

2 Ahnlich KEIL z.St.; vgl. BRIGHT z.St.; paradox wirkt, wenn LAETSCH z.St. zum Nachweis, daß Jahwe auch falsche Propheten schicke, neben 1 Kön 22 auch Jer 14,13 und 23,17 nennt, wo ausdruicklich die Sendung durch Jahwe bestritten wird. ebd. 97. 
Kategorien "einer persönlichen Lyrik" als einem Werk "antiker Sakralliteratur" 1 inadäquat abgetan sind, wird als Erklärungsraster ein "festes agendarisches Formular" postuliert, dessen Elemente aus zum Vergleich herangezogenen Texten wie Kap 14 rekonstruiert werden. Darin soll V 4,10 denselben Stellenwert wie die Fübitte in 14,13 einnehmen. "Ach, Herr, Jahwe ..." wird als Kurzform und Kern einer Klage gedeutet und daraus wird auf kultische Situation geschlossen.

Aber auch dieser Erklärungsversuch vermag - neben anderen offenkundigen Schwächen ${ }^{3}$ - das völlig isoliert stehende Element eines Selbstberichts zu Beginn von $v 10$ nicht zu deuten. So bleibt die Wahrscheinlichkeit, daß ein Abschreiber die 1. sg. an Stelle der 3. pl. gesetzt hat, weil für ihn nach Auswe is von 1,6 und 14,13 (vgl. 32,17 sowie Ez 4,$14 ; 9,8 ; 11,13 ; 21,5$ ähnlich Jos 7,7 und $\mathrm{Ri}$ 6,22) der Klageruf "Ach, Herr, Jahwe" zur typischen Wendung geworden war, mit der ein Prophet seine Einwände in Selbstberichten einleitete ${ }^{4}$.

Das Verschwinden des ursprünglichen Plurals scheint so verständlich. Die spärlichen Zeugen dieser Form in Versionen mögen auf eine theologische Korrektur zurückgehen, die aber hier einmal auch das textkritisch Richtige trifft.

Damit bleibt die Frage, ob $V$ lo unmittelbar an das letzte Glied der Ständereihe in $V 9$ anknüpft und also ein Zitat speziell der dort genannten Propheten sein will, oder ob alle vier Gruppen als Sprecher zu denken sind.

1 ebd. 96.

2 ebd. 130.

$3 \mathrm{Vgl}$. die Kritik bei BERRIDGE, Prophet, People, and the Word of Yahweh sowie GROSS, "Prophetisches Amt".

4 Schon CORNILL z.St. hat richtig gesehen, daß auf solche Einwuirfe an den übrigen Stellen immer eine Erwiderung Gottes folgt, hier aber $V 11$ den vorhergehenden Vers zu ignorieren scheint. 
Ein vorschnell und freihändig gezeichnetes Bild der Falschpropheten als Heilspropheten hat schon allzu oft den Blick auf den Text verstel1t 1 .

Versucht man eine provisorische Antwort von Paralleltexten her, 1 äßt sich,Späteres vorwegnehmend,sagen: Es begegnen Texte ${ }^{2}$, die zeigen, wie Jeremias Blick im Verlauf einer Polemik gegen führende Stände sich auf die Propheten als seine Hauptkontrahenten konzentriert. Ebenso aber wird auch deutlich werden ${ }^{3}$, daß die in V 10 ausgesprochene Heilszuversicht, deren Vernichtung angesagt wird, auch ohne soufflierende Falschpropheten artikuliert werden kann.

Gegen spezielle Vergehen von Berufskollegen scheint Jeremia in 4,9.10 nicht zu polemisieren; ihnen wird mit den übrigen Vertretern der Oberschicht zusammen angesagt, daß sie den festen Boden unter den Füßen verlieren, und daß ihre Illusionen wie Seifenblasen platzen werden.

Jer $5,12-14$

12 Sie haben Jahwe verleugnet

und gesagt: "Nichts ist mit ihm", und: "Nicht kommt über uns Unheil", und: "Schwert und Hunger bekommen wir nicht zu spüren".

13 und: "Die Propheten werden zu Wind", und: "Das Wort ist nicht in ihnen".

14 Darum: So spricht Jahwe, der Gott der Heerscharen:

$1 \mathrm{Vgl}$. REVENTLOWS zutreffende Kritik, Liturgie $121 \mathrm{f}$.

2 Vgl. unten zu Jer 6,9-15.

$3 \mathrm{Vgl}$, unten zu Jer 5,12-14. 


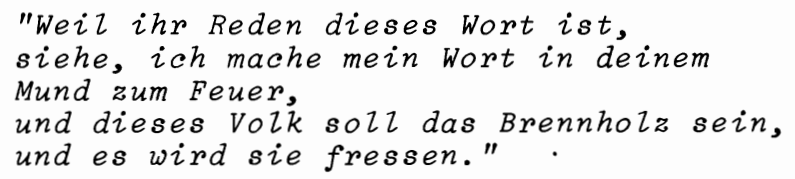

EHRLICHS Urteil über $V 13$ sei der Analyse vorangestellt, um von vorneherein den hypothetischen Charakter der zu erwartenden Resultate bewußt zu machen: "Dieser Vers ist heillos entstellt. Der Ausdruck יהיר לרוד ist beispiellos und namentlich bei persönlichem Subjekt kaum denkbar. Ferner, von der Ausdrucksweise in רהדבר איז בהם abgesehen, kann es für Leute, die nach $V 12$ JHVH verleugneten keinen Unterschied gemacht haben, ob JHVH in den Propheten sprach oder nicht. Endlich ist der Schlußsatz völlig unverständlich" 1 .

\section{Exkurs}

$A n l a B z u t e x t k r i t$ i $t h$ e $r$ Diskussiongeben folgende Formen:
1) לא הרואי in $\vee 12$
2) ביהוה אלהיהם conj. in V 12
3) in V 13
4) in V 13
5) in V 14

ad 1)

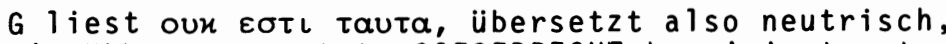
was ein היו voraussetzt. GIESEBRECHT korrigiert entsprechend 2 .

M läßt sich aber durchaus interpretieren, sei es als Aposiopese "d e $r$ nicht..."3, vgl. Zeph 1,12 oder als Gottesleugnung: "Mit ihm ist's nichts"4, nicht im Sinn eines theoretischen Atheismus, aber so wie der Tor Ps 10,4 Jahwes $W i r k$ a m k $i t$ bezweifelt.

$1 \mathrm{Vgl}$. auch die vorsichtigen Vorbemerkungen KOBERLES.

2 Vgl. BLANK z.St.: "It is not so."

3 So DUHM, CORNILL z.St., ähnlich BRIGHT: "Not he." I.e. "He will

4 So RUDOLPH u.a. z.St. do no such thing." z.St. 
ad 2)

G versieht zuplos mit dem Possesivpronomen 3. pl., was CORNILL und VOLZ z.St. veranlaßt, ein Vorlage anzunehmen. Für CORNILL sind zusätzlich metrische Erwägungen ausschlaggebend, weil der Stichos sonst zu kurz erscheint; DUHM z.St. hatte diesem Umstand schon abhelfen wollen durch Konjektur eines inf. abs. כש in Analogie zum Eingang von V 11 , was aber weder in der hebräischen noch der griechischen Textüberlieferung einen Anhalt findet. Ebenfalls aus metrischen Gründen, aber nach abweichender Zählweise wollte schon GIESEBRECHT $z$. St. בי ביהוה Ind den VV 11 und 12 vertauschen und נאם יהוה nach V12a zusetzen. Es wird bei einem non 1iquet bleiben müssen.

ad 3 )

Die Vokalisierung ist auffällig. Die Deutung GRAFS und KEILS Z.St., die hier eine Verbform mit Artikel in Vertretung eines Relativpartikels sehen wollen, scheitert an dem -1 ; so schon CORNILL z.St., der hier ein "infinitivartiges Nomen" analog zu רog 44,21 und Dtn 32,35 findet 2 .

Wahrscheinlich handelt es sich um eine spätere Umvokalisation eines ursprünglichen $77_{7}$. G liest doyos und ergänzt interpretierend ein nuplou. Hieronymus muß nach Ausweis seiner Obersetzungen "responsum sive sermo" bereits eine ungewohnte form vorgefunden haben.

ad 4 )

Die Wendung fehlt in $G$. Da sie auch inhaltlich stört und besser nach der Einlejtung von $V 14$ paßt, soll die Frage ihres Ursprungs in literarkritischen Zusammenhängen unten erörtert werden.

ad 5)

Das Suffix der 2. pl. ist in der Oberlieferung eindeutig bezeugt. Die Gründe für eine konjizierte Anderung in דברם werden unten besprochen.

Das 1 i t e $r$ a $r r i t i s c h$ e Hauptproblem bildet auch hier die Abgrenzung der Einheit. Die in Kommentaren geläufigen oberschriften beziehen sich meist auf eine mehr oder weniger deutlich erkennbare durchlaufende

1 GIESEBRECHT punktiert $\bar{\Psi} \cdot$

2 Vgl. Ges. K. § 520; Kön. § 241h. 
Thematik des ganzen Kapitels; einzelne Abschnitte erhalten dabei ebenfalls inhaltsbezogene Zwischentitel. Selbst DUHM, der in 5,10-17 "wiederum ein jerusalemisches Gedicht" findet, anerkennt eine enge Verknüufung mit dem Vorhergehenden, "wenn die weiblichen Suffixe Vers 10 sich auf die Hauptstadt beziehen, was doch wohl angenommen werden muß, da sonst kein Femininum vorhergeht." Einzig ERBT nimmt unter den älteren Auslegern an, hier seien ziemlich heterogene Elemente redaktionell verknüpft worden. $V 10$ ist für ihn ein Trümmerstück eines Spruches, der ursprünglich zu den Völkersprüchen gehört habe. Kriterium von Abtrennungen ist für ihn eine formkritische Beobachtung: "Der Stil ist ... in solchen Worten meist so, daß auf eine Schilderung des zu tadelnden Zustandes die Drohung folgt". Die Stimmen, die für eine Zusammengesetztheit des Textes votieren, haben sich in letzter Zeit vermehrt. So fand schon NOTSCHER ab $V 15$ "mehrere lose aneinander gereihte Mahn- und Drohworte" 1 und sogar GELIN nimmt ab V 18 "deux additions" an. Am deutlichsten äußert sich BRIGHT in dieser Richtung: Er nennt das Material "highly composite", "made up of originally separate fragments", was am Wechsel der sprechenden und angesprochenen Personen sowie am fehlenden Gedankenfortschritt deutlich werde.

Eine Reihe von Eingriffen in den Text ist nun zu erwähnen, die zum Ziel haben, dem Abschnitt eine ursprüngliche konsistente Form zurückzugeben.

ROTHSTEIN urteilt: "V 11 stört als Wort des göttlichen Ichs den Zusammenhang." Der Vers sei entbehrlich und als Glosse in Anlehnung an 3,1ff erklärbar.

DUHM schlägt vor, in V lob ליהוה als fälschliche Auflösung einer vermeintlichen ursprünglichen Abkürzung

1 EB 2.St. 
י zu verstehen. Damit wäre wenigstens einer der zah1reichen Personenwechsel beseitigt. Aber ein analoges Verfahren kommt aus metrischen Gründen in $V 12$ wohl nicht in Frage.

Obernimmt man GIESEBRECHTS genannte Anregung, בי und ביהוה in den VV 11 und 12 zu vertauschen, erhält man in den VV 10 f ein konsequent in Prophetenrede formuliertes Gerichtswort, während VV 12-14 dann als durchgehend in Jahwerede formulierte Schelt- und Drohrede-Einheit gelesen werden kann.

Eine solche Umstellung bleibt aber doch recht hypothetisch. WESTERMANNS Annahme einer Einheit 5,10-14 muß den Obergang von Prophetenrede zu Jahwerede in "Einleitung" und "Begründung", der in den übrigen tabellarisch erfaßten Beispielen ohne Parallele bleibt, stillschweigend übergehen und das יהוה unterschlagen.

Allerdings darf die Formel באם יהוה nicht ungeprüft als Strukturanzeiger gewertet werden. Inr Zusatzcharakter im Jeremiabuch scheint aus einem Vergleich zwischen $M$ und $G$ oft ziemlich deutlich hervorzugehen. Im vorliegenden Fall bieten eine Reihe von G-Handschriften ein

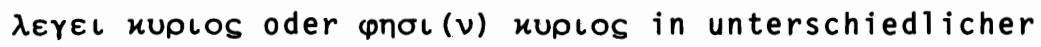
Position, teils nach, teils vor der $v 11$ abschließenden Adresse. Die metrische oberdehnung wird denn auch oft durch Elimination von ניהם יהוה beseitigt ${ }^{2}$.

Schwierigkeiten bieten die letzten drei Wörter von $v$ 13. Zwar ist die generelle Behauptung, sie fehlten in $G$, ungenau ${ }^{3}$. Immerhin fehlt das Sätzchen in gewichtigen

1 Grundformen $124 \mathrm{f}$.

2 So CORNILL z.St., während DUHM 2.St. das textlich gut bezeugte בית יהשראל ובית יהודה ausscheiden will. Mit ungenauer Bezugnahme auf DUHM streicht GIESEBRECHT z.St. den zweiten Teil der Adresse ובית יהודה , ähnl ich VOLZ, RUDOLPH, PATERSON z.St.

3 So ERBT, DUHM z.St., genauer VOLZ Z.St.; siehe jetzt Göttinger Septuaginta 2. St. 
Textzeugen. Es überdehnt den Stichos sehr und ist am besten als Glosse eines Abschreibers zu werten, der, wie schon der Targumist, $V 13 a$ von falschen Propheten verstand ${ }^{1}$.

Die älteren Kommentatoren hatten den Versteil als ein weiteres Zitat des Volkes zu deuten versucht. HITZIG: "also sollte man ihnen thun", d.h. man sollte sie als falsche Propheten behandeln. GRAF: "So wie sie uns verkündigen, möge ihnen geschehen, Schwert und Hunger, womit sie uns bedrohen, möge sie treffen."

Die komplizierten deutenden Umschreibungen sprechen nicht für die Richtigkeit dieser Erklärung. Am meisten Anhänger hat DUHMS Vorschlag gefunden, dieses Sätzchen hinter die Einleitung von $V 14 \mathrm{zu}$ setzen ${ }^{2}$. Ihm folgen NOTSCHER, GELIN, AESCHIMANN, BRIGHT, RUDOLPH ${ }^{3}$.

Nur schwachen Anhalt in der Textüberlieferung findet die Konjektur, welche in V 14a דברכם in ändert ${ }^{4}$ דבם Sie erscheint dennoch plausibe ${ }^{5}$. Zwar hat BOECKER ${ }^{6}$ den Wechsel der angeredeten Person als geläufiges Stilmittel der Reden vor Gericht nachgewiesen; hier aber fällt die einmalige Anrede an das Volk in unmittelbarer Nachbarschaft zur Anrede an den Propheten sehr aus dem Rahmen ${ }^{7}$.

1 So CORNILL, ähnl ich DENNEFELD, WAMBACQ z.St.

2 Ahnlich VOLZ z.St., der in ihm aber auf jeden Fall eine Glosse sieht, die ursprünlich hinter צבאות gestanden habe.

3 GIESEBRECHT z.St. versetzt den ganzen $V 13$ hinter $V 14$, weil er nicht Rede des Volkes, sondern nur Wort Jeremias sein könne. Diese inhaltliche Unvereinbarkeit müßte aber bewiesen und nicht einfach behauptet werden. Zudem würde bei dieser Umstellung der Anschluß von $V 15$ denkbar ungeschickt.

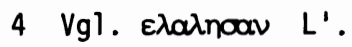

5 Es korrigieren DUHM, ERBT, VOLZ, CORNILL, EHRLICH, DENNEFELD, BRIGHT, RUDOLPH, WEISER, stillschweigend GELIN, LAMPARTER, SKINNER u.a. z.St.

6 Redeformen passim.

7 WAMBACQ 2.St. verweist auf den analogen Fall in 5,19. Hier liegt 
Zusammenfassung

Das argumentum metri causa ist nur vorsichtig anwendbar, etwa bei eindeutiger Oberdehnung eines stichos ${ }^{1}$. Die VV 12-14 sind offenbar als Fragment (eine Adressatenbezeichnung muß vorausgegangen sein) redaktionell in den jetzigen Kontext gebracht worden, wofür auch die Spuren der bearbeitenden Hand in V 11 zeugen. $V 13 b$ dirfte eine Glosse sein, die möglicherweise zunächst nach V $14 a \alpha$ gestanden hat. Mit $V 15$ beginnt eine weitere Weissagung im Präsentativstil ( הנה + suff. + part.), die sich vom Vor hergehenden abheben $1 a ̈ ß t$.

Das Fragment läßt sich formal wie folgt charakterisieren: VV $12 f$ bilden ein Scheltwort in Prophetenrede, bestehend aus einer Tatbestandskonstatierung und 5 Zitaten der Angeklagten. V 14 bietet das Gerichtswort, eingeleitet durch die Begründungspartikel לכ und die Bottenformel; der nachfolgende zweiteilige Gottesspruch statuiert die Entsprechung von Delikt und Folge, wobei mit verbalen und nominalen Formen von דבר gespielt wird.

Der Abschnitt enthält also keine Auskunft über einen Konflikt zwischen Jeremia und Berufskollegen, vielmehr stehen sich hier das Volk und eine von ihnen abgelehnte Mehrzahl von Propheten gegenüber. Nun fällt auf, daß im Jeremiabuch, wo von de $n$ Propheten im Munde Jeremias die Rede ist, meist die falschen Propheten gemeint sind. Es kommt hinzu, daß das zweite und das dritte zitat in

wohl ein weiteres Beispiel dafür vor, daß durch redaktionelle Verknüpfung ursprüngl ich selbständiger Elemente die Numeruswahl durcheinander geriet und die erwähnte Toleranz gegenüber Personenwechsel in Gerichtsreden überstrapaziert wurde.

1 Wir verzichten daher auf die Diskussion entsprechender Konjekturen. Erwähnt seien zusätzlich zu den oben genannten: ivy in $V 12 b$,von DUHM und ERBT z.St. gestrichen, weil zu blaß. (Ditto-

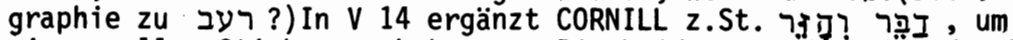
einen vollen Stichos zu bekommen. Die beiden Wörter seien durch Haplographie ausgefallen. 
V 12 eine fast wörtliche Entsprechung im Munde falscher Propheten 14,13 und 23,17 finden. Dies hat verschiedene Ausleger dazu veranlaßt, die Zitate 1-3 in $V 12$ als Echo im Munde des Volkes auf die Verkündigung der Falschpropheten $z u$ verstehen und in $V 13$ nicht eine Fortsetzung der zitatenreihe, sondern eine Reflexion Jeremias zu sehen ${ }^{1}$.

Dagegen ist Folgendes einzuwenden:

- Zitat Nr. 1 hat kein Gegenstück in den Zitaten der falschen Propheten und entspricht vielmehr der Art und Weise, wie die Widerspenstigkeit des Volkes gekennzeichnet wird, nämlich nicht nur Ablehnung der Unheilsbotschaft, sondern Ablehnung von Jahwes Person, vgl. $2,20.25 \cdot 27.31 \cdot u .0 ̈$.

- Zu vergleichen ist auch Am 9,10; Mich 2,6; 3,11, wo der Prophet das Volk, ohne auf heilsprophetische Aktivität von falschen Kollegen zu rekurrieren, sagen läßt: "Das Unheil wird uns nicht einholen und nicht erreichen!"

- Die als Parallelen bemühten VV 24,13 und 23,17 erweisen sich bei näherer Untersuchung (siehe unten) als Formulierungen der deuteronomistischen Redaktion, die sich an zahlreichen Stellen bemüht, eine Tätigkeit falscher Propheten zu zeichnen. Eine Umdeutung von 5,12-14 hat wahrscheinlich das Material für die Gestaltung von 14 , 13 und 23,17 geboten, eine Arbeitsweise, wie sie uns bereits an anderen redaktionellen Stellen begegnet ist.

1 So vor allem SCHMUTTERMAYR, Beobachtungen zu Jer 5,13 S. 215-232, bes. 225; ähnlich, aber mit Verpflanzung des $V 13$ nach $V 14$, schon GIESEBRECHT z.St. Unklar bleibt WEISERS Absicht, wenn er im Text das Zitat mit $V 12$ zu Ende kommen läßt, im Kommentar dann aber doch $V 13$ als Ablehnung der Propheten durch das Volk interpretiert. Verwirrend auch BRIGHT 2.St., wenn er in einer Note zum Abschnitt schreibt: "The people, and specifically the prophets, misrepresent Yahwe in denying that he will bring desaster." Um die Propheten als Falschpropheten geht es hier ja eben gerade nicht. 
- Daß Jeremia von einem intakten Prophetentum sprechen kann, befremdet nicht mehr, wenn wir oben zu Jer 2,30 gesehen haben, daß für ihn eine Unterscheidung von wahren und falschen Berufskollegen keineswegs von Anfang an eine Selbstverständlichkeit war.

- Wenn die Gerichtsansage ausdrücklich das Prinzip statuiert: "Worin man sündigt, wird man bestraft", dann fügen sich die Zitate 4 und 5 sogar am besten in die Scheltrede ein: Das "windige Wort" der Propheten wird zum alles vernichtenden Brand ${ }^{1}$.

Was die Authentizität der Zitate anbelangt, wird man über Vermutungen kaum hinauskommen ${ }^{2}$. Zu erwägen bleibt allenfalls ein Verdacht, ob das Volk eine so präzise theologische Negation der prophetischen Echtheit, wie das 5. Zitat sie beinhaltet, formulieren konnte. Die seltsame Vokalisierung kann späte theologische Stilisierung eines ursprünglichen als terminus technicus für das 0rakel betrachtet zu werden braucht, sondern in Analogie zu Ri 18,7.28; Num 20, 19; 1 Sam 20,21 übersetzt werden kann: "Mit ihnen ist nichts los."

Jer $5,30.31$

30 Entsetzliches und Abscheuliches geschieht im Lande:

31 Die Propheten weissagen im Lügengott; und die Priester geben ihre Weisung im Verein mit ihnen; und mein Volk liebt es so! Aber was wollt ihr machen, wenn damit SchluB ist?

5,3 of bieten eine Reihe von Obersetzungsproblemen, die

1 Vgl. WOLFF, Die Begründung der prophetischen Heils- und Unheilsspruiche 25 .

2 Zur Problematik vg1. WOLFF, Das Zitat im Prophetenspruch 36-129. 
zu verschiedenen textkritischen Konjekturen geführt haben. Da dabei inhaltliche oberlegungen ins Spiel kommen, seien erst die formalen Fragen besprochen.

Nach dem Kontext und עמי zu schließen, sind die beiden Verse in Jahwerede gestaltetes Gerichtswort mit Anklage in $V 30,31 \mathrm{a}$ und einer Frage anstelle einer Formulierung der Strafe in $V 31 b$.

Die Stellung im Kontext ist verschieden gesehen worden. HITZIG urteilt: "Die VV 30.31 bilden hinter dem Schluße V 29 eine Art von Epimetrum, welches die bisher besprochene Sündhaftigkeit des Volkes kurz charakterisiert, sodann nach Hauptzügen sie besondert als falsche Lehre, nach ihr eingerichtete Praxis, und allgemeine Zufriedenheit mit einem solchen Treiben: was Alles zum Untergang reife." KEIL stimmt dieser Charakterisierung ausdrücklich zu. Eine relative Abtrennung vom Vorhergehenden durch einen eigenen Zwischentitel nehmen auch WAMBACQ, NOTSCHER, WEISER vor; CONDAMIN stellt V 29 nach VV $30 f$, um einen gewichtigen AbschluB zu bekommen. COUTURIER findet in der Aufdeckung der Verderbnis der Führenden die Klimax eines von V 26 - V 31 reichenden Sündenkatalogs. GIESEBRECHT will aus metrischen Grüden vor $v 30$ ein 7 שע ergänzen. DUHM sieht schon ab V 18 nur noch Ergänzer am Werk, die mindestens jünger als Tritojesaja sein müßten. Aber darin ist ihm mit Recht niemand gefolgt.

Man wird die beiden Verse als relativ selbständiges Wort beurteilen düren; da die vorhergehende Einheit ihrerseits mit einer in rhetorischer Frageform gestalteten Gerichtsansage schließt, bot sich die Einsatzstelle an. obersetzungsschwierigkeiten entstehen in drei Punkten:
1) בעקר
2) ירדר
3) על יודיהם 
EHRLICH wirft pauschal den Erklärern vor, sie hätten ב instrumental verstanden, während 16,19 wie 2,8 und 27 , 13 eine Bezeichnung für falsche Götter nahelegten. G eb-

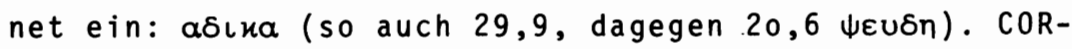
NILL betont die Differenzen im Sprachgebrauch. 3 bezeichnen nach ihm die Autorität, kraft welcher, respektiv in deren Auftrag prophezeit wird ${ }^{1}$. RUDOLPH hält auch in der jüngsten Auflage seines Kommentars daran fest, daß es sich um eine Art Personifikation handle ${ }^{2}$. Man wird mit WAMBACQ zustimmen: "De 'leugen' wordt verpersoonlijkt" 3 .

ad 2)

ROTHSTEIN übersetzt "die Priester aber - sie schalten Hand in Hand mit ihnen" und gibt dann zu: "Die Aussage über die Priester ist geraten; der Text ist verdorben" 4 .

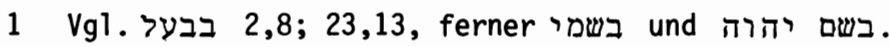

2 Anders KLOPFENSTEIN, Lüge 394. Aber seine Argumente verfangen nicht: Der redaktionelle V 2,8 meint nicht Baalpropheten im Sinn der Elijageschichten, sondern theologisch disqualifizierte Jah-

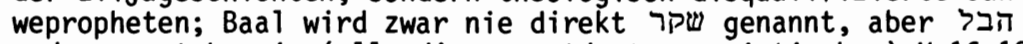
und als Falschgötter-Bezeichnungen in unmittelbarer Nachbarschaft. Daß 23,13f eine Differenz im Sinn einer Steigerung zwischen Samarias und Jerusalems Propheten ausgedrückt sein will, ist nicht zu bezweifeln, aber das besagt noch lange nicht, da $\beta$ das theologische Urteil "Baalsprophetie" nicht auch über Jerusalemer Propheten gesprochen sein könne.

3 Unklar bleibt, ob hier ein moralisches Urteil gefällt wird, ob den Falschpropheten also subjektive Lügenhaftigkeit vorgeworfen wird. Seit QUELL mit der Vorstellung aufgeräumt hat, daß es sich bei innen immer um sittlich verkommene oder minderwertige Subjekte handeln müsse, besteht eine gewisse Neigung, die Tatsache zu übersehen, daß Propheten sehr wohl in ihrer Polemik gegen Berufskollegen zu moralischen Tiefschlägen ansetzen konnten. Man $\mathrm{vgl}$. Jesajas Standardvorwurf der Trunksucht Jes 28,7ff; Michas derbe Verhöhnung der Gegner 3,5-8; Jeremias moral ische Vorwürfe: Ehebruch, in Lügenhaftigkeit wandeln, die Sünder unterstützen 23,14 . 
Wer die M-Form beläßt, interpretiert sie entweder im geläufigen Sinn der Wurzel רדה als "herrschen", "schalten und walten" ${ }^{1}$ und verweist auf die tempelpolizeilichen $(29,24-29 ; 20,1 f$.$) und jurisdiktionellen (26,7 f f)$ Kompetenzen der Priester ${ }^{2}$ oder nimmt ein רדה II an, was nur noch Ri 14,9 bezeugt ist als "(Waben) losschälen" 3 , was dann interpretierend zu einer Sachparallele zu Mi 3,11 stilisiert wird ${ }^{4}$.

Die Vorschläge EWALDS, nach syrischen Parallelen einen Sinn "zur Seite treten" zu postulieren oder DUHMS, ירדר nach dem Aramäischen als "Brot aus dem Ofen schieben" = "in seine Taschen schieben" $z u$ interpretieren (so auch AUGE), haben keine Gefolgschaft gefunden. Am meisten Anklang hat die Konjektur gefunden, statt ירדי >ר $>$ zu lesen 5 .

Allzu raffiniert ist die Konjektur VOLZ's: ידער זרמיה, die man bei fast identischem Konsonantenbestand aber komplizierter Umstellung herstellen kann. Die Wiedergaben alter Versionen mit "klatschen" sind eher Interpretationen als obersetzungen ${ }^{6}$.

$4 \mathrm{Vgl}$. EHRLICH z.St.: "für mich undeutbar".

1 BLANK z.St.: "The priests bear rule"; DENNEFELD z.St.: "Les prêtres gouvernent"; vgl. LAMPARTER, WEISER u.a. z.St.

2 So GIESEBRECHT z.St.; seltsam bleibt allerdings angesichts yon 29 , 24-29 seine Behauptung, die Priester seien bei diesen Aufgaben von Prophetensprüchen abhängig gewesen!

$3 \mathrm{Vgl}$. KBL sub verbo.

4 HOLLADAY, The priests scrape out on their hands 111-113 offeriert einen originellen Obersetzungsvorschlag; er nimmt an, Jeremia "has thus created here a vivid ad hoc antonym for the formula of consecration" (scil. Tמל יד). Englisch möchte er das wiedergeben mit: "unfrock themselves" oder "the priests deconsecrate themselves". Bei allem Respekt vor Jeremias Originalität wird man allerdings zweifeln, ob er neben dem konventionellen Prophetenvorwurf einen so ausgefallenen Angriff auf die Priester formuliert hat.

$5 \mathrm{Vgl}$. HITZIG, CORNILL, SCHMIDT, NOTSCHER, CONDAMIN, SKINNER, GELIN, AESCHIMANN, RUDOLPH u.a. z.St.; WAMBACQS: De priesters onderwerpen zich aan hun gezag! setzt offenbar ein sonst nicht nachweisbares nif. voraus. 
ad 3 )

Neben der eben erwähnten Umstellung von Volz sind drei Obersetzungsmöglichkeiten von den Auslegern erwogen worden, die entweder eine bloße Kumpanei von Priestern und Propheten, eine Abhängigkeit der Priester von den Propheten (sie lehren bzw. herrschen ad nutum prophetarum) oder eine Eigenmächtigkeit der Priester beinhalten.

Für die Deutung: 'ihnen zur Seite' setzt sich jüngst wieder KLOPFENSTEIN ein ${ }^{1}$ mit Verweis auf $\mathrm{Hi} 1,14$; Num 34,4; Ri 11,25; $1 \mathrm{Chr} \mathrm{7,29} \mathrm{und} \mathrm{die} \mathrm{häufige} \mathrm{Bedeutung} \mathrm{von}$ T = Seite ${ }^{2}$. Eine Abhängigkeit der Priester von Propheten (also die Beziehung des suff. auf Propheten), nehmen an: HITZIG (mit dem wenigsagenden Hinweis auf Jes $30,20$. 21); GRAF (als Alternative); CORNILL (? auch Jes 28,7 stünden Priester und Propheten unter einer Decke); GIESEBRECHT, JOHNSON ${ }^{3}$.

Eigenmächtigkeit und Selbstherrlichkeit der Priester (also die Beziehung des suff. auf die Priester selbst) sehen hier ausgedrückt: NOTSCHER ("auf eigene Faust", ebenso LAMPARTER und WEISER); DENNEFELD ("à leur gré"); GELIN ("de leur propre chef"); RUDOLPH ("sua auctoritate").

Eine Entscheidung ist schwierig. Inhaltlich läßt sich Folgendes sagen:

$6 \mathrm{Vgl}$. VOLZ und EHRLICH z.St.

1 "Sie orakeln im Verein mit innen", Lüge 121, vgl. Anm.505 S.394.

2 Vgl. SKINNER, GRAF, ROTHSTEIN z.St.

3 Er verweist auf Jer 33,$13 ; 2 \mathrm{Chr} 23,18 ; 26,13$; Esr 3,10 sowie die Musikergilden in den Chronikbüchern, die unter prophetischer Leitung stehen. JOHNSON, The Cultic Prophet in Ancient Israel 66. 
- Ein רדה wird yon Priestern im Alten Testament nirgends ausgesagt. Wohl aber gehört das "Lehren", "Torageben" $z u$ ihren spezifischen Aufgaben (siehe oben zu Jer 2,8$)^{1}$.

- Das Zweigespann Prophet/Priester tritt im Jeremiabuch auf: a) innerhalb der Reihen von führenden Ständen (2, $8.26 ; 4,9 ; 8,1 ; 13,13 ; 18,18 ; 29,1 ; 32,32$, wovon wohl alle Texte mit Ausnahme von 4,9 der Redaktion zuzuweisen sind), b) als Doppelgruppe 'Prophet und Priester' $(14,18 ; 23,11 ; 23,33.34$; die ersten $z$ wei Stellen sind authentisch, die letzten zwei aus nachdeuteronomistischer Zeit) bzw. Priester und Propheten (26,7.8.11.16); c) im Doppelausdruck vom Propheten bis zum Priester $(6,13=8,10)$.

An keiner der authentischen Stellen $(4,9 ; 6,13 ; 14$, 18; 23,11) wird eine spezielle Polemik gegen ein priesterliches Vergehen laut. Den einzigen Hinweis auf eine spezifische Auseinandersetzung mit Priestern kann man 8 , 8.9 entnehmen: Der Lügengriffel der Schriftgelehrten hat die Tora verdreht.

Aber auch die Redaktion scheint kein besonderes Interesse an Geißelung priesterlicher Vergehen zu haben ${ }^{2}$. In Auseinandersetzungen des Jeremia und in entsprechenden Texten der Redaktion steht der Priester meist im Schatten des Propheten. Auf diesem liegt das Augenmerk. Der Blick scheint sich öfters (vgl. zu 6,9-15 und zu 23)

1 Zum Lehren der Priester vgl. BUDD, Priestly Instruction; zum traditionellen Nebeneinander von Priestern und Propheten in der alttestamentlichen Tradition vgl. PLOGER, Priester und Prophet 157192; zu ירה 179f.

2 DUHMS Bemerkung zu 6,9-15 geht völlig am Tatbestand yorbei: "Die Schilderung und Drohung gilt wesentlich den Priestern, d.h. dem sadducäischen Priesteradel der späteren Zeit. Merkwürdig genug, daß die Ergänzer im B. Jeremia überall die Priester aufs Korn nehmen." 
unwillkürlich von der Doppelgruppe auf die Hauptkontrahenten zu konzentrieren.

5,30f ist die erste authentische Polemik Jeremias im Buch gegen seine Berufskollegen; man wird annehmen müssen, die grundsätzliche Disqualifikation als Baalbzw. Lügendienst stehe erst am Ende einer Kette von Erfahrungen, von denen im Buch noch weitere Spuren zu finden sein werden. Der Schluß von der Stellung im Büch auf den chronologischen Ort im Leben verspricht wenig Zuverlässigkeit. WAMBACQS Urteil z.St. bleibt daher hypothetisch: "Hier is de eerste schermutseling die later een hevige strijd worden zal."

Jer $6,9-15$

9 So sprach Jahwe der Heerscharen:

"Halte gründlich Nachlese, wie am Weinstock, am Rest Israels!

Noch einmal suche $a b$, wie ein Winzer, mit deiner Hand

seine Ranken!"

10 - "Wem soll ich noch zureden, wen beschwören, daß sie zuhören?

Siehe, taub ist ihr ohr, sie können nicht hinhören;

siehe, das Wort[Jahwes] ist ihnen zum Hohn geworden,

sie können es nicht leiden!

11 Ich aber bin voll von meiner Zornesglut, ich kann sie nicht mehr zurückhalten."

- "Gieße sie aus auf das Kind auf der Gasse und auf die Menge der Jugend zugleich. Denn Mann wie Frau werden gefangen, der Greis und der Vollbetagte.

12 Es gehen ihre Häuser an andere über, Felder und Frauen zumal, denn ich recke meine Hand gegen die Bewohner des Landes - Spruch Jahwes.

13 Denn von ihrem Kleinsten bis zu ihrem Größten sind sie alle auf Gewinn aus, 
und vom Propheten bis zum Priester

übt jeder Trug.

14 Sie heilen den Schaden meines Volkes

leichthin indem sie sagen:

Heil, Heil,

wo es doch kein Heil gibt.

15 Sie wurden zu Schanden, weil sie Abscheuliches getan haben;

doch weder kennen sie wahre Scham,

noch verstehen sie es, scheltend Schande aufzudecken.

Darum werden sie mit den Fallenden zu Fall kommen, zur Zeit der Heimsuchung werden sie strauchein hat Jahwe gesprochen.

Die Kommentarliteratur zeigt eine gewisse Neigung, VV 6,9-15 als eine Einheit zu lesen ${ }^{1}$; teilweise werden al lerdings erhebliche literarkritische Eingriffe vorgenommen ${ }^{2}$. Eine Zweiteilung nimmt WAMBACQ vor: 6,9-12a; $12 b-15^{3}$. Als Abgrenzungssignale können die Botenformel $z u$ Beginn von $V 9$ und $V 16$ gelten. Eine Zweiteilung könnte die "Spruch-Jahwes"-Formel Ende V 12 nahelegen. Eine einfache Abfolge Scheltwort-Drohwort ist jedenfalls nicht gegeben. Der vorliegende M-Text zeigt vielmehr folgende komplizierte Form: Der erweiterten Botenspruchformel folgt eine Strafansage in Jahwerede $V 9 a \beta$ und ein Befehl an den Propheten $V 9 b$. In $V 10$ folgt offenbar ein Selbstgespräch des Propheten in Form einer Frage $V$ loaa und zweier anklagender Hinweise $V$ loaß und $V 10 b$, beide eingeleitet mit הנה und fortgefuhrt mit je einer positiven und einer negativen Aussage. V 11 beginnt mit einer doppelten Aussage des Propheten über sich selbst $V 11$ a a und

$1 \mathrm{Vgl}$. HITZIG, GRAF, KEIL, KOBERLE, LAMPARTER, GELIN, NOTSCHER, DENNEFELD, PATERSON, MCNAMARA, AESCHIMANN, LAETSCH u.a. z.St.

2 Vgl. DUHM, CORNILL, ROTHSTEIN, VOLZ, AUGE z.St.

3 ERBT z.St. trennt VV 6,9-10 ab und weist die beiden Verse als Dialog den Denkwürdigkeiten Jeremias zu. VV 11-14 werden - von einer Reihe von Zusätzen befreit - dem "Volkspropheten" zugeschrieben. VOLZ läßt eine erste Einheit mit V 11 aa schließen; WILDBERGER trennt VV 12-15 vom Vorausgehenden, Jahwewort 82. 
fährt fort mit einer Aufforderung eines nicht deutlich gemachten Sprechers (Gottes oder Jeremias an sich selbst) wahrschein1ich an den Propheten $V 11 \mathrm{aB}$ und einer mit Begründungspartikel angeschlossenen strafansage $V 11 \mathrm{~b}$, die in $V 12 a$ fortgesetzt wird. $V 12 b$ gibt sich durch das abschließende Jis als Jahwerede zu erkennen. Die Anführungszeichen zu diesem Zitat lassen sich entweder nach dem einleitenden ' $\supset$ setzen, wenn man das Vorhergehende als Prophetenrede faßt, oder sie lassen sich an den Anfang von V 1laß zurückverlegen, wenn dort ein Befehl Jahwes an den Propheten anhebt. Die VV 13-15 sind Anklage (diese Bezeichnung ist allerdings für $V 15 a$ nicht zureichend; der Halbvers enthält in sich einen Hinweis auf schon ergangene Strafe und eine Begründung) bis $V 15 b a$ und Gerichtsansage, eingeleitet mit לכז und abgeschlossen mit der Schlußformel אמר יהוה V $15 b B^{1}$. Die Unklarheiten, die sich bei einem Beschreibungsversuch ergeben, werden verstärkt, wenn die Differenzen der Textüberlieferung und die Konjekturvorschläge mit in Betracht gezogen werden.

Der Text von G läßt sich ohne große Schwierigkeiten als durchgehende Jahwerede lesen. Dies wird erreicht, indem עי עולי יעוליו in 9 als zwei gleichlautende Imperati-

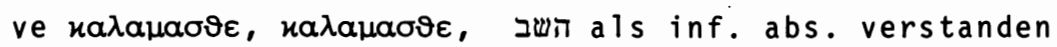

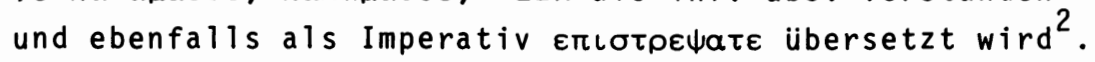
Zwar stört zunächst דבר יהוה in V lob; deutet man es aber

1 Die Formel אמר יהוה, die hier die Einheit abschließt, ist im authentischen Jeremia-Material nicht mehr bezeugt; 6,15 ist mög1 icherweise der Prototyp für ihren Gebrauch bei deuteronomistischen und nachdeuteronomistischen Redaktoren als Zwischen- und Endformel: 30,$3 ; 44,26 ; 49,18$ bzw. $33,11.13 ; 48,8 ; 49,2 ; 46,25$ ?, $\mathrm{vgl}$. den häufigen Gebrauch dieser abschließenden Botenformel be $i$ Amos. WOLFF, Joel, Amos 179.

2 Will man nicht annehmen, daß die Obersetzer ihrer Interpretation zuliebe das suff. in יד ( $V$ gb) unterschlagen haben, könnte es in der Vorlage durch Haplographie ausgefallen oder in $M$ erșt später als Dittographie entstanden sein. 
als terminus technicus für das durch Propheten übermittelte Orakel, läßt es sich auch im Munde Jahwes durchaus verstehen. Anstelle des Imperativs offenbar entweder in 1. sg. Diese glatte Lösung wird als lectio facilior und Interpretation der obersetzer gelten müssen, welche durch ein in M nicht bezeugtes כ bzw. Otl 1 einen engeren AnschluB der Einheit an die vorhergehende hergestellt und die Reihe der Aufforderungen an die Feinde zum Gericht an Jerusalem ( $V 3 f$ ) in $V 9$ um weitere Glieder erweitert hat. Die in $\mathrm{Ri} 20,45$ bezeugte übertragene Verwendung von על על fur "Nachlese halten am fliehenden Feind" mag diese Deutung nahegelegt haben.

In dem Rahmen von $G$ bewegen sich auch die Interpretationen von $V 9$ bei den älteren Auslegern ${ }^{2}$. DUHM hat hier ein neues Verständnis begründet: Für ihn beginnt der Vers mit einer Aufforderung an den Propheten, Nachschau zu halten, ob nicht doch noch eine gute Traube zu finden sei am Weinstock Israels (vgl. 8,13). יערל שארית ישראל hält er für eine Glosse eines Späteren, der auffordern wolle, den eschatologischen Rest Israels sorgfältig aufzuheben. Ohne diese literarkritische operation ${ }^{3}$ mitzumachen, hat die jüngere Auslegungstradition sich diesem Verständnis vielstimmig angeschlossen. Man ist sogar noch einen Schritt weitergegangen in der Deutung der Einheit als Dialog zwischen Jahwe und Jeremia. DUHM ist bei der traditionellen Auffassung von $V 11 \mathrm{a} \beta$ als Selbstaufforderung des Propheten ${ }^{4}$ geblieben (allerdings unter Ersetzung

1 In der Hexapla obelisiert.

2 HITZIG, GRAF, KEIL, GIESEBRECHT z.St.

3 Die auf einem falschen Verständnis von שאר ית als eschatologischem Fachterminus und zweifelhaften metrischen Erwägungen basiert.

4 Vgl. HITZIG, GRAF z.St. 
der Imperativform durch einen aus G erschlossenen inf. abs., den er in erster Person wiedergibt). Jeremia könne Jahwe nicht zu so etwas auffordern. Auch CORNILL begründet die Umpunktierung $z u$ שפ damit, daß weder eine Aufforderung Jahwes an Jeremia, noch eine Bitte Jeremias an Jahwe einen erträglichen Sinn gebe. Das überzeugt nicht; daß Jahweswirkendes Gerichtswort vom Propheten im Inneren aufgestaut und als Grimm im Auftrag Jahwes ausgegossen werden soll über die Adressaten, ist in jeremianischer Vorstellungswelt durchaus denkbar und sinnvoll (vg1. 5,14;15,10.16;23,29).

Was das Verständnis der Einheit als Dialog mit Gottesrede in $V 9$, Prophetenantwort in $V 10.11$ aa und Gottesrede ${ }^{1}$ ab V loaß zu hindern scheint, ist die Tatsache, daß die Prophetenantwort nicht von "Deinem Wort" und "Deinem Grimm", sondern vom "Wort Jahwes" und "Grimm Jahwes" redet. Aber wenn wir oben die Verwendung von "Wort Jahwes" als terminus technicus für prophetisches Orake 1 sogar im Mund Jahwes als möglich erachtet haben, ist dieser Ausdruck auch im Dialog mit Jahwe plausibel. Was die Wendung "Zorn Jahwes" anbelangt, spricht einiges dafür, daß wir es hier mit einer fälschlich als Abkürzung gelesenen und aufgelösten Form eines Abschreibers zu tun haben. Jedenfalls liest $G$ in der Vorlage חמתי und übersetzt tov Эupov nou ${ }^{2}$.

1 Der Einspruch WILDBERGERS, ebd. 56 verfängt nicht; die von VOLZ vorgeschlagene Obersetzung der Einleitung: "So sprach Jahwe Zebaoth" ist nicht nur hier im Jeremiabuch zu belegen, siehe oben zu Kap 26,1.

$2 \mathrm{Vgl}$. zur Frage der Abkürzungen DRIVER, Abbrevations in the Massoretic Text 112-131. Ziel des Artikels ist es, zu beweisen, "that abbrevation must have played a considerable part already in the pre-septuagintal text of the 0.T., al though not nearly to the same extent as it does in medieval manuscripts." 130; an einer Reihe von Beispielen wird nachgewiesen, "that the divine names must once have been abbreviated by the copyists ... The commonest abbreviation for the tetragrammaton seems to have been a single yodh." 119. Soweit ich sehe, wird dabei חמת Jer 6,11 als Bei- 
Kann also $V 10 a$ und $V 11$ a als Prophetenantwort verstanden werden, besteht keine Schwierigkeit, ab $\vee 11 a \beta$ Gottesrede zu lesen. Dann braucht auch V 12b nicht eliminiert zu werden, weil der Prophet rede ${ }^{1}$. Die Wiederaufnahme von Anklagerede VV 13-15ba und erneute Gerichtsansage in $V 15 b \beta$ erfolgt dann in konsequenter Gottesrede.

Die drei letzten VV 13-15 finden sich fast wörtlich in 8,10-12 wieder. Sie passen Kap 6 besser in den Zusammenhang ${ }^{2}$.

Die $i n h$ a $l$ t $l i c h$ Untersuchung kann sich - dem Thema unserer Arbeit entsprechend - auf die VV 13-15 beschränken. Das Augenmerk des Propheten ist zunächst auf die Gesamtbevölkerung gerichtet: vom Kleinen bis zum Großen. Der Vorwurf lautet auf Gewinnsucht. "Gewinn" erhält in weisheitlichen Sentenzen (Spr 1,19; $15,27 ; 28,16$; Ps 119,36$)$ einen anrüchigen Klang. Gewinnsucht wird schon 1 Sam 8,3 El is Söhnen vorgeworfen. Jojakim erhält bei Jeremia diesen Vorwurf 22,17; Israel insgesamt Jes 57,17; die Hirten Jes 56,11; das Volk Ez 33,31; die Beamten Ez 22,27; Jerusalem Ez 22,12; Verachtung des Gewinns macht zum Richteramt tauglich Ex 18,21, vgl. Jes 33,15 .

spiel für eine Fehlinterpretation von $G$ behandelt. Es läßt sich aber mit demselben Recht eine falsche Auflösung einer vermeintlichen Abkürzung durch einen Abschreiber des M-Textes annehmen. Zum Problem der Abkürzungen vgl. ferner vom selben Autor: Once Aga in Abbreviations, vor allem 89 die Hinweise auf Abkürzungen in den Qumranschriftrollen als Bestätigung der Abkürzungstheorie.

$1 \mathrm{BHK}^{3}$.

2 Sie können in Kap 8 Indiz für die Arbeitsweise einer Redaktion sein, deren Handschrift uns schon bisher begegnet ist; hier geht es offensichtlich um eine Komposition, die in einer Reihe von Stichworten die Möglichkeit der Verklammerung beider Texte

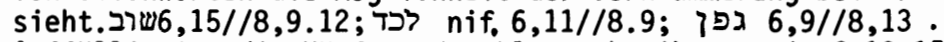
Auffällig ist die Häufung der Pleneschreibungen in 6,13-15. Kap 8 wird zum Teil den älteren Konsonantenbestand bewahrt haben. 
Die Anklage wendet sich dann speziell Priestern und Propheten $z u^{1}$ und bezichtigt sie des Truges. שק kommt 111mal im Alten Testament vor; von den 53 Belegen bei den Schriftpropheten entfallen allein 36 auf das Jeremiabuch. Es taucht in vielfältigsten Kombinationen auf. Einen präzisen Sinn wird man aus dem jeweiligen Kontext zu erschließen versuchen müssen. $V 14$ lautet: "Sie heilen den שבר meines Volkes leichthin."

\section{Exkurs}

Das Nomen שבר hat sich in seiner semasiologischen Entwicklung nie ganz gelöst von der Bedeutung des entsprechenden Verbes "brechen". Die Wiedergabe mit "Schaden" bleibt unpräzis, weil sie nicht zum Ausdruck bringt, daß nicht ein moralischer Defekt, sondern Gerichtsschläge Jahwes bezeichnet werden ${ }^{2}$, das Wort also weniger Schuld-als Strafcharakter hat. Diese Bedeutung ergibt sich auch bei den Stellen, wo im Alten Testament vom

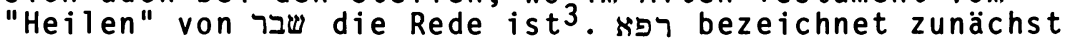
ärztliche Aktivität an Mensch und Tier.

Heilen wird von Jahwe ausgesagt, und zwar im wörtlichen Sinn, daß er Kranken Gesundheit gibt ( $z$.B. Gen 20, 17; Num 12,13 u.ö.), wie auch im übertragenen Sinn, daß er kosmische (Ps 60,4) sowie politische und moralische Schäden (Hos 6,$1 ; 14,5$; Jer 3,22 ; Jes 19,$22 ; 30,26 ; 57$, 18.19 u.ö.) behebt. Die Aufgabe der Heilung ist vor allem Sache Jahwes; seine exklusive Zuständigkeit wird in

1 Aus dem strikt parallelen Aufbau von $V 13$ kann wohl nicht viel geschlossen werden: weder läßt sich "vom Propheten bis zum Priester" als Merismus verstehen (analog zu "von ihrem Kleinsten bis zu ihrem Größten"), noch eine Gleichung Prophet = klein; Priester = groß aufstellen. Dann ist aber auch fraglich, ob man das Delikt "Trug üben" in die Nähe von Gewinnsucht bringen darf.

$2 \mathrm{Vgl}$. Jer 4,$6 ; 4,20(2 \mathrm{x}) ; 6,1 ; 8,21 ; 10,19 ; 14,17 ; 30,15 ; 48,3$; 50,$22 ; 51,54$.

3 In Ez 34,4 und Sach 11,16 ist von der Vernachlässigung des Heilens durch die Hirten Israels die Rede; der Ausdruck bleibt aber innerhalb des Bildes und meint die Sorge um die Gesundheit der anvertrauten Tiere. Das im allgemeinen mit "heilen" wiederzugebende Wort kann auch "reparieren" bedeuten (Jer 19,11). Ez 47,8f redet von der Heilung der "geographischen Wunde Palästinas", dem Toten Meer,durch die eschatologische Tempelquelle. 
Psalmen und prophetischen Texten immer wieder thematisiert (Hos 5,13; Ex 15,26; Jer 17,14 u.ö.).

Der Prophet wird mit dem Heilen Jahwes unter dreifachem Aspekt in Verbindung gebracht:

1) Er wird beauftragt, Jahwe nach dem Ausgang der Krankheit zu befragen (2 Kön 1,2);

2) seine Fürbitte veranlaßt Jahwe, zu heilen (Gen 20,17; Num 12,13);

3) er überbringt - auch unbefragt - Jahwes Beschlüsse über Gesundung oder tödlichen Ausgang der Krankheit ( 2 Kön 20,8; vg1. Jer 30,17;33,6 u.ö.).

Ps 107,20 redet von Menschen, die von Jahwes Wort geheilt worden sind ${ }^{1}$. Dabei läßt sjch an einen Vorgang denken, bei dem ein kranker durch Vermittlung eines fürbittenden Propheten die Zusage der Heilung erhalten hat 2 . "Heilung" durch den Propheten wird man nicht nur die Wunderheilung, sondern schon die obermittlung des Gesundheit verheißenden Wortes genannt haben. Denn solche prophetische Botschaft ist nicht nur Information über kommendes Geschehen, sondern wirkendes Wort.

Jer 6,14 geht es nicht um Heilung der Krankheit eines Individuums, sondern um den "Schaden" des Volkes. Eine heilende Aktivität wird man sich in diesem Zusammenhang so vorzustellen haben, daß nach einem Gerichtsschlag Jahwes (einer Durre, einem Feindeseinfall) der Prophet öffentlich mit der Einholung eines Jahwebescheides beauftragt wurde. Die Erteilung einer positiven Prognose konnte man auf dem Hintergrund der erwähnten Vorstellungen durchaus als "Heilen" bezeichnen.

Dreimal wird Jeremia in den Fremdberichten des Buches beauftragt, Jahwe zu befragen ${ }^{3}$.

1 Es ist von שלח und דבר die Rede.

2 "Kultisch" wird man eine solche Aufgabe des Propheten nicht ohne weiteres nennen können, denn grundsätzlich gilt der Kranke als kultunfähig; der Prophet von Samaria, von dem das israelitische Sklavenmädchen im Dienst der Gemahl in Naamans wei $\beta$, daß er ihren Herrn von Aussatz befreien könnte, wirkt denn auch nicht an einem Heiligtum ( 2 Kön 5 ).

3 Jer $37,1 \mathrm{ff}$ und $42,1 \mathrm{ff}$ dürtten auf alter Oberlieferung basieren, $21,1 \mathrm{ff}$ wird redaktionelle Nachbildung sein. Vgl. THIEL, Diss.z.St. 
37,1ff ist der König Zidkija (587 v.Chr.) mißtrauisch, ob der Abzug des babylonischen Heeres angesichts der heranrückenden Agypter zu einer dauernden Besserung der Lage Jerusalems führt. Ein Beamter und ein Priester sollen Jeremia ersuchen: "Bete doch für uns zum Herrn, unserem Gott!" Jahwe antwortet: "So spricht Jahwe, der Gott Israels: Gebt dem König von Juda, der euch zu mir geschickt hat, um mich zu befragen, folgende Antwort: Das Heer des Pharao, das im Anmarsch ist, um euch Hilfe zu bringen, wird wieder umkehren in sein Land Agypten, und die Chaldäer werden zurückkehren und gegen diese Stadt kämpfen und sie einnehmen und in Flammen aufgehen lassen" $(37,7$. 8). Aus der Antwort Jeremias geht hervor, daß Zidkija sowohl die Fürbitte des Propheten veranlassen, wie auch Jahwe befragen lassen will. Den analogen Vorgang zeigen Jer $21,1 \mathrm{ff}$ und $42,1 \mathrm{ff}$. Es 1 äßt sich überhaupt aufweisen, daß Fürbitte und Befragung zusammengehörige Elemente der mittlerischen Tätigkeit des Propheten sind ${ }^{1}$.

Es ist anzunehmen, daß der Prophet, wenn er Gottes Bescheid einholt, sein ganzes Gewicht dafür einsetzt, ein für seinen Auftraggeber günstiges Urteil zu erreichen; die Auftraggeber andererseits werden selbst alles unternehmen, den Propheten zum Höchsteinsatz zu bewegen, im Vertrauen darauf, daß inm ein gewisser Einfluß auf den Ausgang der Befragung zukommt. Das heißt aber nicht, daß das Ergebnis schon präformiert wurde (vg1. Bileam Num 22, 24 und Am 7). Ober den verständlichen Wunsch des Propheten, einen positiven Bescheid zurückzubringen und die Gefahr, Jahwe die Treue zu brechen, wird noch zu handeln sein.

1 Zum Fürbittauftrag des Propheten vgl. von RAD, Die falschen Propheten 109-120; HESSE, Die Fürbitte im AT; REVENTLOW ebd. 14off.; JEREMIAS, Kultprophetie und Gerichtsverkündigung in der späten Königszeit Israels 140ff; in der Sache differiert die hier vorgelegte Sicht kaum von MACHOLZ, Jeremia in der Kontinuität der Prophetie 306-334. 
Für den zur Debatte stehenden $V$ 14a ergibt sich daraus:

Die Wendung, den "Schaden/Bruch meines Volkes heilen" braucht nicht in einem völlig verblaßten Sinn als "etwas überspielen" oder "etwas übertünchen" oder "bagatellisieren" und damit als Vorwurf gegen die gesamte oberschicht verstanden werden ${ }^{1}$. Die singuläre Formulierung und die noch nachvollziehbare Bedeutungsentwicklung der verwendeten Ausdrücke legen nahe, daß Jeremia hier Propheten im Auge hat. Er wirft ihnen vor, in ihrer "amtlichen" Tätigkeit der Jahwebefragung und Fürbitte leichtfertig das Ende bestehender wie auch drohender Strafaktionen Gottes angeblich in dessen Auftrag zu verkünden.

Der Halbvers 14b legt diesen Vorwurf näher aus: "Indem sie sagen: Heil! Heil! Wo es doch kein Heil gibt!" Die Kurzformel oder besser das Stichwort "Schalom" ist jeremianische Etikette für die derzeitige Tätigkeit der "falschen Propheten". Man wird hier nicht schließen dürfen, daß Jeremias Gegner aus dogmatischen Gründen schon immer nur Heil verkündet hätten. Es geht zunächst darum, daß sie zur Unzeit Heil ansagen und die Heilung einer "Krankheit" versprechen, deren tiefste Krise noch gar nicht gekommen ist. Das illustriert Jer 14,19, eine Klage des Volkes an die Adresse Jahwes wegen einer enttäuschten Hoffnung auf Besserung. Wenn man annehmen darf, daß Jeremia und die Redaktoren in der Beschreibung der Gegner nicht freihändig Zitate erfinden, kann man in Jer 4,10 oder 23,17 den konkreten Wortlaut eines solchen Bescheides wieder finden: "Friede, Wohlergehen kommt auf euch zu!" Die ausgefaltete Form ist im redaktionelien V 14,13 zu finden: "Ihr werdet das Schwert nicht sehen, und Hunger wird nicht an euch kommen, sondern sicheren Frieden gebe ich euch an diesem Ort!" Die Gewißheit, daß

1 Vgl. RUDOLPH z.St. 
es jetzt kein Heil gibt, ist die Grundüberzeugung der Verkündigung Jeremias, vgl. 14,1ob.12a; 16,5. Dies wird dazu geführt haben, daß man in Jerusalem zur oberzeugung kam, man habe in Jeremia das Zerrbild eines Propheten vor sich; so in 38,4, wo der Vorwurf gegen ihn erhoben wird: "Er ist nicht auf das Heil, sondern auf das Unheil dieses Volkes aus!" Dieser Vorwurf braucht nicht ein bloß gesinnungsmäßiges Desinteresse am Heil Jerusalems zu bedeuten, sondern konkreter: Es wird bestritten, daß er die oben dargelegte Aufgabe des Propheten wahrnimmt, mit dem ganzen Gewicht seiner Prophetenpersönlichkeit bei Jahwe für das Wohl des Volkes zu intervenieren.

$\checkmark 14$ zeigt also folgenden Konflikt: Auf der einen Seite Jeremia, der von der oberzeugung herkommt, daß Jahwe sein Heil von seinem Volk weggenommen hat, daß die Krisen in Jerusalem ein Gerichtsanschlag Jahwes sind, eine "Krankheit" ohne die Aussicht auf Genesung. Seine Kontrahenten hingegen versprechen in Jahwes Namen ein baldiges Ende der Krise; Jeremia nennt ihr Vorgehen leichtfertig, wobei nicht sichtbar wird, ob sie persönlich schuldhaft den Ernst der Lage nicht sehen wollen oder nicht sehen können. - Der Adressat von $V 15$ ist schwierig zu identifizieren. Nach Ausweis des Gerichtswortes (sie werden fallen unter den Fallenden, d.h. unter dem Volk) handelt es sich immer noch um eine Gruppe. Die Alternative besteht darin, in dieser Gruppe entweder Priester und Propheten zusammen (vg1. V 13) oder nur die Propheten zu sehen, denen allein der unmittelbar vorhergehende Vorwurf galt ( $V 14$ ).

Eine Entscheidung ist möglich, wenn es gelingt, im $\checkmark 15$ eine gruppenspezifische Anklage zu finden. Das Wort, das wir zunächst mit "zu Schanden werden" und dann mit "sich schämen" wiedergegeben haben ( ברד) hat im hif.den Sinn einer Bestrafung, einer von außen erzwungenen "Scham", einer Bloßstellung und Blamage; im qal kann es 
eine psychische Regung bezeichnen: Reue und Scham ${ }^{1}$. תועבה meint Schändliches, vorwiegend Vergehen des Götzendienstes ${ }^{2}$, die Jeremia dem ganzen Volk anlasten kann. Hingegen wird man הכלים (der inf. nif. in $V 8,12$ nötigt nicht zur Anderung des inf.hif. in $V 6,14$ ) eine spezielle Prophetenaufgabe sehen düfen: "scheltend Schande aufdecken" ${ }^{3}$.

\section{Zusammenfassung}

Im Verlauf des komplexen Gerichtswortes stellt sich eine bemerkenswerte Verengung des Blickwinkels ein: Ist zunächst von der Gesamtheit des Volkes, Groß und Klein, die Rede, so treten in $V 13 b$ allein Propheten und Priester ins Gesichtsfeld. Noch begrenzter ist der Kreis der Adressaten in V 14: Aus der Gesamtheit haben sich die Propheten herausgeschält. Das abschließende Drohwort ordnet die Strafe dieser Gruppe in das Gericht über das ganze Volk ein.

Im Vorwurf an die Berufskollegen werden die Konturen der Auseinandersetzung am schärfsten: Ihnen wird hier leichtfertiger Umgang mit der Heilszusage, was Jeremia als Götzendienst (תרעבה) disqualifiziert, Unfähigkeit zur Reue und Vernachlässigung ihrer Pflicht zur Aufdekkung der sünde vorgehalten.

1 Zur Häufigkeit der Vokabel im Jeremiabuch und ihrer Bedeutung vgl. nun STOLZ, THAT I 269-72 und SEEBASS, TWAT I 568-580.

$2 \mathrm{Vgl}$. Jer 2,$7 ; 16,18 ; 32,35$; der erste der drei Texte dürfte zum vorredaktionellen, authentisch jeremianischen Bestand gehören; gegen DUHM z.St. Zum Gebrauch von תרעבה als theologische Disqualifikation durch die Redaktion vgl. ROSE, Ausschließlichkeitsanspruch $210,248$.

$3 \mathrm{Vgl}$. KLOPFENSTEIN, Scham und Schande nach dem AT 66f, dem wir hier auch in der Obersetzung gefolgt sind. KLOPFENSTEIN erwägt, in כלם hif. geradezu einen alttestamentlichen Fachausdruck für Scheltrede zu sehen, 141f; vgl. Mich 2,6!, ferner Jer 3,3; 3,25; $6,15=8,12 ; 20,11 ; 22,22 ; 31,17$. 
"Hört nicht auf die Propheten!" Jer 23,9-32 
Jer 23,9-32

Neben den Spuren gelegentlicher ${ }^{1}$ Auseinandersetzungen mit anderen Propheten in den ersten sechs Kapiteln bietet das Jeremiabuch einen Abschnitt, der es ausdrücklich mit Berufskollegen zu tun hat. Die Oberschrift לנבאים (siehe unten) stellt die Verse Jer 23,9-32 in Parallele zu 21,1ff "Ober das Königshaus Judas" und macht sie zum 2. Teil eines Diptichons über die führenden Stände. Die Redaktion hat hier offenbar vorliegende Sammlungen aufgenommen, stellenweise glossiert und mit 21,1-10 und 24, 1.10 (zwei sich in vielem ähnelnde Abschnitte!) gerahmt ${ }^{2}$.

Es ist im Folgenden für unser Thema zu prüfen: Erweisen sich 23,9-33 als ursprüngliche Einheit? Ist dies $z u$ verneinen, suchen wir nach formalen Spuren von Bearbeitungsstufen (Glossen, Eingriffe der Hauptredaktion, eventuell Hinweise auf literarische Tätigkeit der Sammler) und fragen dann nach den in den verschiedenen Stufen gemachten Aussagen über den Prophetenkonflikt.

Die Auseinandersetzung mit der Kommentarliteratur soll hier nicht in der ganzen ermüdenden Breite geführt werden. Vielmehr gilt es jetzt zu prüfen, ob die Sicht von der Entstehungsgeschichte des Jeremiabuches, die wir in den vorausgehenden Abschnitten gewonnen haben, sich auch zur Klärung der wichtigsten strittigen Fragen in der Auslegung dieses Kapitels eignet. Es sei zu diesem Zweck zunächst an die bisherigen Ergebnisse erinnert: Im authentischen Spruchmaterial fanden wir Erwähnungen eines Prophetentums, das in Opposition zum Volk, aber nicht zu Jeremia stand $(5,12-14)$ oder - ohne daß die

1 Streuungsgesetze waren nicht erkennbar. Historische Einordnungen konnten nur mit Hilfe inhaltlicher Oberlegungen erwogen werden.

2 Vgl. THIEL, Diss. 380-433. 
Frage der Echtheit berürt wird - Demonstrationsbeispiele für die Ernsthaftigkeit des Gerichtswillens Jahwes geworden war $(2,30 b)$.

5,3of und 6,9-15 hatten dann gezeigt, daß Jeremia bei seiner Gerichtsbotschaft an das Volk auf besonderen Widerstand von Berufskollegen stieß, ihre besondere Verantwortung und Schuld anprangerte und ihnen das Gericht ansagte. Als Adressaten eines eigenen Gerichtswortes sind uns unter den Vertretern führender Stände die Propheten in hervorragender Stellung 4,9f begegnet.

Die Redaktion nahm sowoh1 die Ständepolemik (2,8 Anklage; 2,26 Gerichtsansage) wie die spezifische Auseinandersetzung mit den Propheten auf. Sie redigierte Einzelspruiche, Sprucheinheiten und -fragmente mittels Einleitungs- und $\mathrm{Klammerformulierungen} \mathrm{zu} \mathrm{größeren} \mathrm{Einhei-}$ ten.

Formal zeigte sich 2,8.26 weder präzise Anpassung an den Rhythmus des Kontexts noch reine Prosa. Die redaktionellen Verse in Kap 14 ließen sich in kein Metrum zwängen, gaben aber eine gestalterische Absicht zu erkennen, die man am besten aus rhetorischen Absichten herleitet. (V 14: dreifaches verbales Dementi, dreifache Qualifikation mit nominalen Doppelausdrücken, das Ganze gerahmt von Partizipien von נבא: V 15: sprach1iche Entsprechung von Anklage und Gerichtsansage.) In der Phraseologie zeigten sich stereotype Wendungen einer theologischen Fachsprache und Wiederaufnahmen aus dem authentischen näheren und weiteren Kontext.

Theologisch zog die Redaktion die Linien der authentischen Polemik aus: Die Klage wird ausgebaut und die führenden Stände, vor allem die Propheten, werden theologisch disqualifiziert und als Hauptverantwortliche für den Untergang hingeste11t.

Jer 23,9-32 ist nicht aus einem Guß gestaltet. Trotzdem von einer Einheit zu sprechen, nötigt die Oberschrift. 
לנבאים wäre zwar nach der Punktation von M zum Folgenden zu ziehen und mit "wegen der Propheten" zu übersetzen. Ein solcher Begründungszusammenhang würde aber in Konkurrenz treten $z u \vee 9 b$ : "wegen Jahwe und seinen heiligen Worten". G zieht die Wendung zum Ende von V 6 (VV 7.8 fehlen). Analog $z u 14,1$ ist aber eine Oberschrift zu lesen: "Ober die Propheten". Zu diesem Thema passen aber die VV 9-32 nur teilweise. Vor allem die erste Einheit, VV 9-12, hat es mit einem weiteren Adressatenkreis zu tun: das Land und seine Bewohner, zumal Prophet und Priester:

Jer $23,9-12$

9 "Gebrochen ist mein Herz in meinem Innern, es zittern alle meine Glieder.

Ich bin wie ein Betrunkener,

wie ein Mann, den der Wein überwältigt hat vor Jahwe

und vor seinen heiligen Worten:

10 Führwar, von Treuebrechern

ist voli das Land,

[ja, ihretwegen ${ }^{1}$ trauert das Land, vertrocknen die Auen der Trift; ] ${ }^{2}$

ihr Treiben wurde böse

und ihre Tüchtigkeit unrecht.

$11 \mathrm{Ja}$ selbst Prophet wie auch Priester sind (mir) entfremdet, sogar in meinem Hause fand ich ihre bösen Taten,

Spruch Jahwes.

12 Darum wird ihnen ihr Weg zum schlüpfrigen Grund, auf dem sie in der Finsternis stürzen und fallen:

denn ich bringe Unheil über sie

im Jahre ihrer Heimsuchung,

spruch Jahwes."

1 Zur Vokalisierung siehe BHS.

2 Zur Glosse vgl. die Auslegung und Anm. 1 S.117. 
Die Einheit beginnt mit prophetischen Außerungen des Entsetzens ( $V$ 9). VV 10.11 sind Anklage, auf die in V 12 , eingeleitet mit לכז, das Gerichtswort folgt. Das Besondere ist die Einleitung der Einheit. Die Außerungen des Entsetzens erfuhren hauptsächlich drei Erklärungen:

1. Jeremia als "harmloser, unverdorbener" Juingling vom Lande erschrickt, wie er die Korruption selbst in den höchsten Kreisen Jerusalems entdeckt (WEISER, RUDOLPH). Diese individual-psychologische Erklärung verlegt deshalb (seit VOLZ) dieses Wort in die Frühzeit des Propheten.

2. Die Wendung "wegen Jahwe und seiner heiligen Worte" bewog WEISER, hier einen Wortempfang im Tempel ana$\log z u$ Jes $6 \mathrm{zu}$ vermuten, wo der Prophet angesichts der Heiligkeit Jahwes mit Schrecken die Kluft zwischen dem heiligen Gott und dem sündigen Menschen erfährt. Hinweise auf einen kultischen Sitz im Leben findet auch JEREMIAS aufgrund der Parallele Hab $3,16^{1}$.

3. HILLERS ${ }^{2}$ zeigt die Verwandtschaft von $23,9 \mathrm{mit}$ einer geprägten Form der Reaktion auf schlimme Nachricht. Es wird nach HILLERS' Ausführungen nicht mehr gelingen, aufgrund von Beobachtungen am Wortgebrauch einen bestimmten Sitz im Leben zu rekonstruieren. Die Reaktion auf schlimme Nachricht in verschiedensten Lebenssituationen wird überall mit ähnlichen Wendungen ausgedrückt. Die Schilderung der eigenen psychosomatischen Symptome ("Mein Herz zerbricht, meine Glieder zittern, mein Haupt zerfließt in Tränen" u.ä.) gehört neben dem unartikulierten

1 JEREMIAS, Theophanie 107: "... dann wird trotz des geringen Belegmaterials der Schluß erlaubt sein, daß es speziell Kultpropheten waren, die diese Stilform in Zusammenhang mit dem Offenbarungsempfang benutzten; sie diente offensichtlich dazu, die Guiltigkeit der erhaltenen offenbarung hervorzuheben und ihre Glaubwürdigkeit zu verstärken."

2 HILLERS, Bad News 86-89. 
Schrei zu den elementaren Außerungen eines Menschen, der von Schmerz oder Schrecken getroffen wird.

In Jeremias Worten finden wir solche Schilderungen als Antwort auf ein Gerichtswort oder eine Gerichtsvision $(4,19 ; 6,24 ; 8,18.23 ; 10,19 ; 14,17)$. In den einzelnen Auftritten des Propheten stehen sie in der Mitte oder am Ende, um das ergangene Gericht dramatisch auszumalen, oder eröffnen den Auftritt, um Aufmerksamkeit zu erregen und zugleich den Tenor der Botschaft anzuzeigen (vgl. 4,19;10,19;14,17). Folglich können wir aus 23,9 weder auf Jeremias Sensibilität oder auf "sittliche Entrüstung des unverdorbenen Jünglings" (WEISER) schließen, und das Wort daher auch nicht datieren, noch läßt sich daraus eine kultprophetische Tätigkeit herauslesen; man kann nur die Funktion dieses Verses aufzeigen:

Jeremia will durch die Schilderung seiner Schreckensreaktion den Hörern etwas von jenem Entsetzen mitteilen, das die im Folgenden vorzutragende Gerichtsbotschaft be $i$ ihm ausgelöst hat.

Im Gegensatz zu den anderen Texten, in denen auf die Klageäußerung die Gerichtsschilderung folgt, beginnt der Gottesspruch mit der Anklage, das Land sei voller Treuebruch (V 10).

באת; der hebräische Begriff, der hier den Tatbestand "Treuebruch" anzeigt, wird im Jeremiabuch in einem dreifachen Sinn verwendet:

1. In der wörtlichen Bedeutung von Ehebruch $(5,7 ; 7$, 9; vielleicht 23,14; 29,13 hier als konkreter Vorwurf an zwei namentlich genannte Propheten);

2. in der Bedeutung von Götzendienst im Fruchtbarkeitskult des Baal $(3,8 f ; 13,27)$;

3. ethisch verallgemeinernd als Treulosigkeit (23,9; vielleicht 23,14 ).

Letzere Bedeutung durfte sich auch in unserem Text nahelegen, weil der Vorwurf mit Begriffen wie "Treiben" 
גבורה aufgenommen wird. Diese letzten beiden Begriffe sind sehr allgemein in ihrem Bedeutungsgehalt; es kann ihnen nur entnommen werden, daß es sich in V lob um Urteile über sittliches Tun handelt.

Die Glosse V loaß: "Ja, ihretwegen trauert das Land, vertrocknen die Auen der Trift", unterbricht den Zusammenhang der Anklage; sie nimmt das Gericht vorweg und stellt es als Dürreplage dar ${ }^{1}$.

1 Zur Entstehung der Glosse ist Folgendes zu beobachten:

1. Dürre als Strafe für sittliche Vergehen ist eine dem AT geläufige Vorstellung, vgl. Jes 24,4; Jer 12,4.

2. Das Dürre-Strafmotiv ist im Jeremiabuch zweimal redaktionelle Erweiterung, 12,$4 ; 23,10$. In 12,4 scheint der Einschub einerseits ein neues Interventionsmotiv für Jahwe zu bilden, andererseits Jeremias Bitte um Vernichtung der Frevler eine besondere Dringlichkeit zu geben. Weil der Einschub offenbar geprägtes Gut ist, fügt er sich nicht glatt in den Kontext ein. Aus der Klage über die Glaubensnot des Jeremia wird ein $K l a g e g e b e t$ aus $A n l a B$ einer Dürre. In unserem $V 10$ hat das Stichwort "Treuelosigkeit" die Erwähnung der Duirreplage ausgelöst; vgl. Jer 3,3, wo Jeremia den Gedanken von Hos 2,1-14 aufnimmt, daß Gott den Ehebruch seines Volkes durch Entzug der Fruchtbarkeit des Landes bestraft.

3. Das Dürremotiv kann auch eine Verbindung eingehen mit Darstel lungselementen der Theophanie ( $\mathrm{vgl}$. WOLFF, BK XIV/2 zu Am 1, 2 und JEREMIAS, Theophanie 12f; zur Verbreitung des Theophanieelementes vgl. Jer 25,30 und Joel 4,16 ). Die Formulierung der judäischen Redaktion des Amosbuches in Am 1,2 wird Pate gestanden haben für dieselbe Verknüpfung der Motive in der Septuaginta-Version unserer Einheit: aus den "heiligen Worten" in 23,9 ist hier Jahwes "Pracht und Herrlichkeit" geworden. Der Vorwurf des Treuebruches (V loaa) fehlt, er ist wohl in der Vorlage zur Septuaginta durch Haplographie (Homoioteleuton) entfallen. Die hebräische Glosse V loaß muß schon vorher in den Text eingedrungen sein.

Die Erwähnung von Obeltätern (und damit die Authentizität von $V$ loaa) fordert $V$ lob nicht nur wegen der maskul inen Suffixe, die nicht auf "Land" und "Augen" in V loaß bezogen werden können, sondern auch, weil die Begriffe in lob - vor allem "Unrecht" (vgl. KBL 442) und wohl auch "Tüchtigkeit" - ein moralisches Verhalten beschreiben und damit die Erwähnung von Personen voraussetzen.

Gegen JANZEN, Double Readings 433-447, bes. 437, nehmen wir an dieser Stelle keine lectio conflata an, sondern einen komplizierteren Entstehungsprozeß vom ursprünglichen Text bis zur Septuaginta: 
V 11 bringt zwei neue Anklagen, die offensichtlich eine Steigerung beabsichtigen. Es werden aber keine konkret greifbaren Vergehen genannt; die Delikte sind umso gravierender, als sie von der Personengruppe und an dem ort begangen werden, an die Jahwe besondere Anforderungen stellt. Die Stelle zeugt erneut vom Bewußtsein Jeremias um die besondere Verantwortung seiner Berufskollegen, der Propheten ( $v g 1.5,30 f ; 6,12-15)$, die als profilierteste Gegner seiner Botschaft die Hauptschuld am kommenden Gericht tragen. Ein besonderes Vergehen der Priester ist auch hier nicht genannt. Daß sie miterwähnt werden, mag zwei Gründe haben: 1. Jeremia stammt aus einer Priesterfamilie und stöBt bei seinen Verwandten auf wenig Verständnis $(12,6) ; 2$. geht es hier ja gerade um Vergehen an heiliger Stätte, für die die Priester verantwortlich sind.

Die Schlußformel "Spruch Jahwes" in V 11 (sie fehlt in $G$ sowohl für $V 11$ wie für $V 12$ ) kennzeichnet diesen Vers eigens als Gotteswort, möglicherweise, weil nach Einführung der Glosse $V$ loaß nicht mehr deutlich war, daß die Gottesrede wohl schon mit $V$ loa beginnt. V 11 verlangt aber schon wegen des Ausdrucks "mein Haus" Jahwe als Sprecher. Der Obergang von Prophetenrede zu Gottesrede fällt also hier nicht mit dem Obergang von Anklage zu Strafansage ( $V$ 12) zusammen und wird mit bloßem deiktischem "Fürwahr", ohne Botenformel, markiert. (Eine solche Botenformel ist auchnicht nötig nach Die Einheit endet mit einem Gerichtswort, das die Strafe ankündigt, die offenbar über alle Treuebrecher ergehen soll. Die Formulierung verwendet teilweise singuläre

a) Eine Glosse mit dem Motiv der Dürreplage;

b) Haplographie in der Septuagintavorlage;

c) theologische Gestaltung der Einheit nach Art einer Theophanie

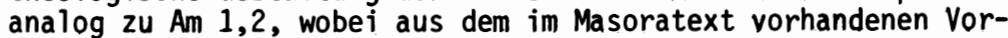
wurf ("ja, ihretwegen trauert das Land, vertrocknen die Auen der Trift") im Griechischen eine Darstellung gestörter Naturabläufe wird. 
Wendungen ${ }^{1}$, die damit verbundenen Vorstellungen hingegen sind wenig originell. Eine besondere Strafe für Prophet und Priester wird wie in 6,15 nicht erwähnt.

Jer $23,13-15$

13 Zwar habe ich bei den Propheten Samarias Abgeschmacktes gesehen:

Sie traten als Baalspropheten auf

und verführten mein Volk Israel.

14 Aber bei den Propheten Jerusalems

fand ich Schauderhaftes:

Ehebruch, Wandel in Trug;

sie bestärkten Ubeltäter,

so daß sie nicht umkehrten

ein jeder von seiner Bosheit;

sie sind mir allesamt geworden wie Sodom, und ihre (d.h. Jerusalems?) Einwohner wie Gomorra.

15 Darum: So spricht Jahwe der Heerscharen über die Propheten:

Siehe, ich gebe Ihnen Wermut zu essen und Giftwasser zu trinken.

Denn von den Propheten Jerusalems

ist übergegangen die Profanation aufs ganze Land.

Verschiedene Gründe sprechen dafür, daß wir es hier mit einer literarischen Komposition zu tun haben, die eigens als Anhang zum vorhergehenden Spruch gestaltet worden ist: Die vorhergehende Einheit bedarf dieser Fortsetzung nicht; sie ist für sich ein abgerundetes Ganzes. Es fehlen Hinweise dafür, daß VV 13-15 innerhalb eines Auftrittes gesprochen wurden. Die Gottesrede, in der der ganze Spruch ergeht, wird nicht eigens eingeleitet; der Sprechende wird vielmehr von $V 12$ her als bekannt

1 ताT nif ist nur noch 2 Sam 14,14 zu belegen. Formen des yerwandten נדח begegnen in redaktionell bearbeiteten Passagen 8,3; 16,$15 ; 23,2 f .8 ; 24,9 ; 27,10.15 ; 29,14.18 ; 32,37$; selten auch אפלה und חלקלקד. 
vorausgesetzt. Die Einheit nimmt zahlreiche Sichworte des vorhergehenden Abschnitts auf: Bosheit, Ehebruch Treuebruch, Entfremdung, Land und das Motiv des beobachtenden Gottes (ich fand, V 11 - ich sah; $V$ 13). Der Wortschatz gibt keinen Hinweis auf die uns bekannte Redaktion. Eine Reihe von sprachlichen Indizien könnten aber doch in diese Richtung weisen:

$\checkmark$ 8a formuliert Anklagen mit einer Reihe von inf. abs., fortgesetzt durch $7+$ perf. Im authentischen Text finden sich, soweit ich sehe, keine analogen konstruktionen. ( $V \mathrm{gl}$. dagegen 7,9.Die Redaktion hat eine klare Vorliebe für Konstruktionen mit dem inf. abs.)

Die Verbindung eines Nebensatzes durch לבלתי hat in authentischen Texten ebenfalls kein Gegenstück. ( Vgl. dagegen 7,$9 ; 16,12 ; 17,23.24 ; 18,10 ; 19,15 ; 26,24 ; 27$, $18 ; 32,40 ; 42,13 ; 44,5.7$ alle redaktionell; daneben einige Vorkommen in Fremdberichten.)

Ein abschließendes Urteil ist nicht möglich. Die Qualifikation des Treibens der Nordreichpropheten als "abgeschmackt", תפלה, ת תל 2u vergleichen; wenn ihnen Baalsdienst vorgeworfen wird, könnte man zwar etwa an die Erzählung von der Auseinandersetzung Elijas mit den Baalspropheten auf dem Karmel (1 Kön 18) denken. Wahrscheinlicher aber ist ein theologisches Urteil gefällt wie in Jer 2,8 (siehe oben). Von der "Verführung meines Volkes" durch Propheten ist noch 23, 32 und 42,20 (beide redaktionell) die Rede; vgl. Mi 3,5. "Abscheuliches", als Bezeichnung für das, was die Jerusalemer Propheten treiben, findet sich noch in 5,30, in einer authentischen Prophetenpolemik.

Die Argumentation mit dem Kontrast Juda/Israel ist der Redaktion geläufig ( $v g l$. vor allem 3,6-11 und 7,1215). Unklar bleibt, ob in $V 14$ beim Vorwurf des "Ehebruchs" der Ausdruck im wörtlichen Sinn zu nehmen ist; der anschließende Vorwurf meint ein sehr allgemeines 
sittliches Urteil und bezeichnet kein spezifisches Berufsvergehen. Die "Bestärkung der Bösewichte, daß sie sich nicht vom Bösen abwenden", meint den Mißbrauch des prophetischen Auftrages sowohl gegenüber einer Gesamtheit wie gegenüber Einzelnen. Die letzte Zeile von V 14 weist eigentümliche Unschärfen auf. Zunächst werden die Propheten und Obeltäter mit Sodom verglichen, dann werden in einem parallelen Glied "seine Einwohner" Gomorra gleichgestellt. Das Suffix lenkt recht ungelenk auf den Anfang des Satzes zurück (Jerusalem). Sodom und Gomorra (seltener Adma und Zebojim, vgl. Dtn 29,22; Hos 11,8) sind geläufige Beispiele für Schuld und Strafe in vorexilischer und exilischer Zeit ${ }^{1}$. Jes 1,10 zeigt dabei, daß der Vergleich auf eine Personengruppe und ein Volk zugleich anwendbar ist: "Höret das Wort Jahwes, ihr Sodomsfürsten! Vernimm unseres Gottes Weissagung, du Gomorravolk!"

Der letzte Versteil von $V 14$ ist damit Anklage wie auch Gerichtshinweis in einem. Die Strafe wird mit traditionellen Wendungen ausgedrückt, die sich fast wortwörtlich in 9,14 (redaktionell) wiederfinden, und vielleicht beidemale auf dieselbe Hand zurückgehen ${ }^{2}$. Jetzt ist das Thema erreicht, das die Oberschrift ankündigt.

Das Gerichtswort $V 15$ endet genau wie die Einheit 23,9-12 mit einer abschließenden Begründung. Sie lautet: "denn von den Propheten Jerusalems ist übergegangen die Profanierung (die Entfremdung von Jahwe) auf das ganze Land." " חנפה , "Profanierung" ist hapax legomenon".

1 Dtn 32,32; Am 4,11; Jes 1,10; Ez 16 Sodom allein passim; Jer 49, $18 ; 40,40$.

2 Mit DUHM u.a. gegen THIEL und RUDOLPH z.St.; zu den verwendeten Bildern vgi. Dtn 29,17; Am 5,7; 5,12; Kigl 3,15 (Jahwe als dämonischer Gastgeber); 3,19.

3 Verbale Formen der Wurzel חנר finden sich außer in Kap 23 im Jeremiabuch nur noch Kap 3 in einem Textzusammenhang, der frappie- 
In authentischen Jeremiatexten war zusammen mit den Anklagen und Gerichtsansagen an die Adresse yon Propheten und Priestern immer auch die Solidarität von Groß und Klein in Schuld $u n d$ Strafe betont worden. Hier nun ist nur noch von der Mit $s t r$ a $f e$, nicht mehr von der Mit s c h u l d des Volkes die Rede.

Der redaktionelle $V 14,13$ hatte zwar die Aktivität der Pseudopropheten noch nicht als Infektionsherd für die Verderbnis des Volkes verantwortlich gemacht, aber der fürbittende Jeremias präsentiert dort bereits dem zürnenden Jahwe ihre Tätigkeit als Entschuldigungsgrund oder mildernden Umstand. In 23,15b wird die Hauptschuld und Erstschuld dieser Propheten expressis verbis formuliert.

Die zusammengetragenen Indizien reichen aus, VV 1315 als redaktionell gestalteten Abschnitt zu qualifizieren. Aber eine eindeutige Entscheidung, ob er seinen Ursprung der Hauptredaktion oder einem älteren Kompositeur eines Prophetenkapitels verdankt, will nicht gelingen.

Jer 23,16-22

VV 16-32 zeigen einen komplizierten Aufbau, ohne daß sich noch so eindeutige Zäsuren wie zwischen $V 12$ und

rende Analogien zu unserem Abschnitt bietet: 3,6-12 "zeigt wenig Diktion von D" (THIEL, Diss. 149). Die Zuweisung zu dieser Schicht läßt sich trotzdem solide begründen. "Besonders auffällig ist der im Sprachgebrauch des Abschnitts dominierende Kontextbezug" (THIEL, Diss.149). Auch hier wird die "Entweihung" des Landes ( $V 9$ ) dem unmittelbaren authentischen Kontext $(3,1.2)$ als Thema entnommen und über sie unter Kontrastierung von Juda und Israel reflektiert. - Der entscheidende Unterschied zu Kap 3 besteht in der poetischen Form von 23,13-15. Aber die sprachlichen und thematischen Hinweise, der nicht eben elegant sich einfügende $V 14 \mathrm{~b}$ mit dem konventionellen SodomGomorra-Vergleich, die Verwendung des auch anderweitig für die Redaktion verfügbaren Gerichtswortes ( $15 \mathrm{a}=9,14$ redaktionel1) legen den Schluß nahe, daß hier redaktionelle Arbeit vorliegt. 
V 13 oder V 15 und V 16 erkennen ließen. Die im Folgenden vorgenommene Abtrennung kann nicht mehr als ein Notbehelf aus arbeitstechnischen Gründen sein.

16 So spricht Jahwe der Heerscharen:

"Hört nicht auf die Worte der Propheten,

die euch prophezeien! 1

Sie machen euch zunichte;

Gesichte des eigenen Herzens werden sie

euch sagen,

nicht aus dem Munde Jahwes ${ }^{2}$.

17 Sie sagen [ $]^{3}$ den Verächtern von Jahwes Wort:

Frieden wird euch sein!

Und jedem ${ }^{4}$, der in verstocktem Eigensinn

wande $2 t^{5}$,

[sagen sie: $]^{6}$

Nicht wird über euch Unheil kommen!

18 Fürwahr, wer immer im Rat Jahwes gestanden hat, der soll sein Wort sichtbar machen; wer hinhören durfte auf seine Worte, soll (sie) hören Zassen?.

1 "Die euch prophezeien" kann aus Dittographie entstanden oder einem Abschreiber als geläufige Formel in die Feder geflossen sein. Möglich ist aber auch, daß eine Redaktion von VV 16-33, die die Propheten mit Partizipien näher zu spezifizieren pflegt, dies schon hier für nötig hielt, um das unerhörte Verbot von $V 16$ auf bestimmte Propheten einzugrenzen.

2 "Aus dem Munde Jahwes" ist möglicherweise falsche Auflösung einer vermeintlichen Abkirzung und zu ersetzen durch: "nicht aus meinem Mund". Nach der Botenformel erwartet man dies. Die Tempuswahl (Praeformativkonjugation) legt engen Anschluß an das vorhergehende Verbot nahe.

3 Der inf. abs. verstärkt die Betonung der Fortdauer. Vgl. GRETHER $\S 85 a$. Er fehlt in den Versionen und ist wohl durch Dittographie entstanden.

4 So die Versionen. 5 G bietet hier eine lectio conflata.

6 Metri causa zu streichen, vgl. BHS.

7 So bildet der Vers ein sinnvolles Gelenk zwischen V 17 und V 19. Durch Umpunktierung wurden aus den kausativen Verbformen "sehen lassen" und "hören lassen" Ausdrücke für Offenbarungsempfang. Der Vers wurde jetzt als skeptische Zwischenfrage im Sinne der Weisheitslehre von Ijob 15,8 gelesen. G streicht die überflüssige zweite Erwähnung "seine Worte". Das Qere versucht die Störung zu beheben. Ein Abschreiber des hebräischen Textes hat sich an der wenig geläufigen Wendung "das Wort sehen" aufgehalten und e in "Hören" nachgetragen. 
19 Siehe, ein Jahwesturm [ ] ${ }^{1}$ ist Zosgebrochen, ein wirbelnder sturm ${ }^{2}$, er trifft das Haupt der Ubeltäter.

20 Nicht wird sich wenden Jahwes Zorn, bis er erfüllt und ausgeführt den Plan seines Herzens.

Im Nachhinein

wird es euch völlig klar werden!

21 Ich habe die Propheten nicht gesandt, sie aber laufen!

Ich habe zu ihnen nicht gesprochen, sie aber prophezeien!

22 Und hätten sie in meinem Rat gestanden, so würden sie mein Volk meine Worte hören lassen sie von ihren schlechten Taten [ ] 3 bekehren.

Verwirrend wirkt in der heutigen Textgestalt von $M^{4}$ die Abfolge von Jahwerede (JR) und Prophetenrede (PR), erkennbar an der Erwähnung Jahwes in 3. pers. in nichtidiomatischen Wendungen. Es ergibt sich folgende Sequenz: 16a JR; 16b PR; 17 JR; 18a PR; 18b JR; 19.20 PR; 21.22 JR.

Die Obergänge sind allesamt unvermittelt und fallen auch nicht etwa mit dem Einsatz neuer Strukturglieder (Anklage, Ankündigung u.ä.) zusammen.

Nachträgliche Glossierungen, lectiones conflatae und Auflösungen vermeintlicher Abkürzungen mögen diesen Text-

1 "Zorn" ist erklärende Glosse.

2 Mit der Parallele Jer 30,23 ist das waw copulativum zu streichen.

3 Doppelung des M-Textes: "von ihrem bösen Weg und ihren schlechten Taten". Vgl. G.

4 Den ursprünglichen Text der Einheit 23,16-22 hat LIPIÍSKI, b 'ahorit hajjamim, dans les textes préexiliques, 445-450, herauszustellen versucht. So bestechend optisch sein rhythmisches Schema wirkt, so bedenklich ist die Aufteilung des parallel gebauten V 17 auf "Introduction" und "Strophe I du Corps de I" oracle"; ebenso fragwirdig wirkt seine Abtrennung der "Conclusion". 
befund mitverursacht haben. Die Versionen zeugen teilweise für eine Vorlage, die von M abweicht, teilweise für Versuche, einen schwierigen Text zu verbessern. Ein glatter, störungsfreier Text läßt sich aber mit besonnener Anwendung ausschließlich konventioneller textkritischer Argumente nicht erreichen. Man wird form- und redaktionskritische oberlegungen anstellen müssen.

So fällt etwa die jetzige Gestalt von $V 18$ als weisheitliche Frage formmäßig aus dem Rahmen des Kontextes und würde inhaltlich - als Glosse - höchstens unmittelbar vor V 22 passen ${ }^{1}$. Andererseits werden wir auf Spuren eines mehrstufigen Redaktionsprozesses stoßen. Die Verse sind einzeln zu diskutieren:

V 16: Nach der einleitenden Botenformel ergeht ein Verbot an nicht ausdrücklich genannte Adressaten, welches untersagt, den Propheten Gehör zu verleihen. Formmäßig ist $V 16$ als Boteneinleitungsformel + Mahnspruch (genauer: Warnspruch) zu bestimmen. Dem Vetitiv folgen zwei asyndetische Motivierungen, die erste ein Nominalsatz (Partizip), die zweite ein Verbalsatz mit modal zu interpretierender Präfixkonjugationsform ${ }^{2}$.

Für unseren Vers gilt festzuhalten: Die Funktion von אל "wendet sich in der Zeitstufe nur an die Zukunft und drückt die Erwartung und den Wunsch aus, daß eine Handlung oder ein Ereignis nicht eintrete... Es liegt keine Abstraktion zur Zeitneutralität und damit Generalisierung vor, womit deutlich wird, daß Situationsgebundenheit und damit Personengebundenheit für den Gebrauch entscheidend bleibt, ein Punktualis. Es ist die Erwartung und der Wunsch einer Person in Hinsicht auf eine bestimmte situation" 3 .

1 Vgl. Anm. 7 S.123.

2 Vgl. MICHEL, Tempora und Satzstellung in den Psalmen 143-149. Zu Form und Geschichte dieser Gattung siehe RICHTER, Recht und Ethos. 3 ebd. 71 . 
Der Mahnspruch findet sich bei Propheten selten, erst bei Jeremia mit gewisser Häufigkeit ${ }^{1}$. Ein schichtenspezifischer Gebrauch der Form ist im Jeremiabuch nicht festzustellen.

Die Form stammt wohl aus dem alltäglichen Sprachgebrauch" ${ }^{2}$. Die erste Begründung ("sie machen euch zunichte") erinnert an die Wichtigkeit der Bedeutungsfelder "Leben - Tod" in den Motivierungen weisheitlicher Mahnsprüche ${ }^{3}$. Der Spruch bedarf keiner Fortsetzung. Die Verbindung mit der Botensprucheinleitung ist nicht notwendig, findet sich aber schon in authentischen Texten ( $z$. B. 9,$22 ; 10,2)$. Ist die Erwähnung von Jahwe am Satzende nicht falsch aufgelöste Abkürzung, so war der Vers ursprünglich Prophetenrede.

Das Unerhörte einer solchen Aufforderung (vgl. Dtn 13,4) wird deutlich, wenn bedacht wird, daß die Sünde des Volkes im deuteronomistischen Geschichtswerk zusammenfassend gerade mit den Worten ausgedrückt werden kann: "Ihr habt nicht auf die Worte meiner Knechte, der Propheten, gehört!" (2 Kön 17,13f; 1 Kön 20,36). Dieselbe Aufforderung wie in 23,16 findet sich noch Jer 27,9 (hier geht es um ausländische Adressaten und Propheten); $27,14.16 .17 ; 29,8$ - alles redaktionelle Texte.

Die Umkehrung der normalen religiösen Ordnung fordert eine entsprechende Begründung. "Sie machen euch zunich-

1 RICHTER zählt auf und teilt ein, ebd. 54 Anm. 59: "Jer 1,8; 40, 16 (als Begründung ein Nominalsatz), 7,$16 ; 11,14 ; 23,16 ; 30,10$ (konstatierende Begründung), 16,5 (Begründung aus der Vergangenheit), 1,$17 ; 4,4=21,12 ; 6,8 ; 10,24 ; 22,10 ; 38,25$ (Warnung mit פ ) $, 45,5 ; 46,27.28$ (verheißende Begründung)." Es ist mir allerdings weder klar geworden, was hier Anordnungsprinzip sein soll (worin besteht der formale Unterschied zwischen 30,10 und 45,5 Z.B.?), noch weshalb 22,10 und 38,25 unter der Rubrik "Warnung mit פ" geführt werden.

2 ebd. 54.

3 ebd. 190 . 
te" heißt es hier zunächst ${ }^{1}$. "Gesichte des eigenen Herzens" läßt an die "Lügengesichte" 14,14 denken. Weder Jeremia,noch die Erzähler, noch die Redaktoren brauchen sonst verbale und nominale Formen von הrח. Der Gegensatz zu "Gesichte des eigenen Herzens" lautet "aus meinem Munde reden"2. Die Tempuswahl von V 16b (Präfixkonjugation) im Gegensatz zum Partizip in $V 16 a \beta$ wird man modal übersetzen dürfen: "Sie können euch (nur) Gesichte des eigenen Herzens sagen ..."

$\checkmark 17$ ist ein ad hoc komponiertes Mosaik aus Versteilen, die im Jeremiabuch an anderen Stellen wiederkehren (vgl. THIEL). "Verstockter Eigensinn" ist ein Lieblingswort der Hauptredaktion ${ }^{3}$.

$V 17 a \beta$ ist wörtlich in 4,10 enthalten, $V 17 b \beta$ setzt Teile von 5,12 in direkte Rede um. "Verächter des Wortes Jahwes" ist zwar eine singuläre Bildung, hat aber in Jes 5,24 ein Vorbild.

1 Was an das Wortspiel mit 2,5b erinnert.

$2 \mathrm{Daß}$ "Propheten aus Jahwes Mund reden" ist keine gängige Wendung in vorjeremianischer Zeit. Kap 36 redet vom Schreiben Baruchs "aus Jeremias Mund", d.h. nach seinem Diktat. In späterer Zeit tadelt 2 Chr 36,12 Zidkija, daß er sich nicht "vor Jeremia,dem Propheten aus dem Munde Jahwes", gedemuitigt habe; $2 \mathrm{Chr} 35,22$ wirft Joschija vor, nicht auf die Worte Nechos aus dem Munde Gottes gehört zu haben. Hinweise darauf, daß die Vorstellung Jeremias Zeitgenossen wohl doch geläufig gewesen sein wird, finden sich Ez 3,17; 33,7 und - eine Generation später - in Jes 45,23; 48,3 ; 55,11. $\mathrm{Vgl}$. auch Jer 44,17 . Einen weiteren Hinweis ergäbe $\mathrm{Klgl} 3,37 \mathrm{f}$, wenn man in der rhetorischen Frage nicht bloß eine Gottesprädikation, sondern einen Hinweis auf das Propheteninstitut sehen dürfte: "Wer redet und es geschieht - es sei denn Jahwe habe (ihn) aufgeboten; aus dem Mund des Höchsten geht hervor Unheil (sbotschaft) und Heil (sbotschaft).

38 von insgesamt 10 alttestamentlichen Vorkommen; die Grundstelle wird man in Dtn 29,18 sehen müssen. "In verstocktem Eigensinn wandeln" הלך בשררות לב außer Dtn 29,18 in Jer 7,24;11,8; 13,10; 23,17 variiert in Ps 81,13; daneben הלך אחרי שררות לב Jer 3,17; 9,13; 16,12; einmal עשה שררות לב Jer 18,12. 
$V 18$ ist, was das Vokabular anbelangt, von $V 22$ her formuliert. Die Vorstellung von der Teilhabe der Propheten an Jahwes Rat findet sich auch im deuteronomistischen Vers $\operatorname{Am} 3,7^{1}$.

VV $19 f$ schildern ein Gericht, das offenbar schon angefangen hat (איצ'), seinen Höhepunkt aber noch nicht erreicht hat. Die beiden Verse begegnen fast wörtlich gleich in $30,23 f$, einer späten Passage ${ }^{2}$, die wohl von Kap 23 abhängt. בינה ist jeremianisches hapax legomenon, hitpal-Formen von ביז finden sich im authentischen $\mathrm{Ma}$ terial in 2,10;9,16. באחרית הימים taucht noch in den späten Texten 48,47; 49,39 auf. Der Gedanke, daß Gericht Erkenntnis oder gar Einsicht bewirkt, ist dem Jeremiabuch fremd ${ }^{3}$.

V 21 trägt alle Kennzeichen der Echtheit: nicht stereotype Formulierung, inhaltliche und terminologische obereinstimmung mit authentischen Texten (vgl. zu Jer 14) und Eignung als Prototyp für redaktionelle Variationen.

Für $V 22 \mathrm{a}$ gilt Annliches. Von ihm her scheint $V 18$ formuliert zu sein; $V$ 22b läßt zwar in der Gestalt von $M$ an die Redaktion denken, doch ist hier eher mit einer lectio conflata zu rechnen. Die Copula am Anfang läßt allerdings zweifeln, ob der Vers von je her mit $V 21$ verbunden war. Auch inhaltlich ist nicht mehr als eine Addition von Gedanken zu erkennen ${ }^{4}$.

$1 \mathrm{Vgl}$. SCHMIDT, Die deuteronomistische Redaktion des Amosbuches 185-188. Siehe auch 1 Kön 22,19-23 und die "Berufungsberichte" Jes 6 und 40 sowie Ez $1 \mathrm{ff}$.

2 Wahrscheinlich ist der Einschub in Kap 30 relativ spät: Ein Ergänzer, der 23,18 schon als Frage vorfand, wird die Gerichtsschilderung übertragen haben. 30,22 ist noch später und fehlt in G.

$3 \mathrm{Vgl}$. allenfalls 16,21 (Nachtrag); 44,28 (redaktionel1).

4 Zu signifikanten phraseologischen Differenzen gegenüber der Redaktion vgl. THIEL, Diss. $418 f$. 
Die Beobachtungen am Vokabelbestand und der Phraseologie reichten nicht aus, eindeutig einen Grundbestand und eine redaktionelle Schicht zu trennen. Deutliche Indizien für die Hauptredaktion waren nur in $V 17$ zu erkennen. Der Rest stellt aber auch keine ursprüngliche Einheit, sondern eine Komposition nicht ganz homogener Bestandteile dar, deren Authentizität nicht mit letzter Sicherheit behauptet oder bestritten werden kann. Die VV 16.21.22 werden wohl echt sein, aber nicht immer schon nebeneinander gestanden haben. ( $V 16$ ist selbständiger Mahnspruch, $V 21$ nennt die Propheten im vollen Wortlaut, $V 22$ wird mit Copula angefügt, ohne inhaltich mit dem Vorhergehenden verbunden zu sein.)

Lassen sich nun Zusammenordnung von VV 16.21.22 sowie Einfügung von VV 17.18.19.20 einer einzigen Hand zuweisen? Die Versabfolge spricht nicht dafür. Vielleicht darf man annehmen, die Botenspruchformel habe einst vor $\checkmark 21$ gestanden, $V 16$ sei also als Prophetenrede gelesen worden. Die Akzentverschiebung auf die Anklage in $V 17$ 1 äßt vermuten, daß nachträglich von der Hauptredaktion in ihrer literarischen Manier zwei Prophetenvorwürfe mit Zitaten gestaltet wurden und nun das Bedurfnis entstanden war, ein Gerichtswort anzufügen (VV 19f), das dann mit einem Oberleitungsvers ( $V$ 18) mit der Anklage verbunden wurde. Ebenso gut ist aber auch denkbar, da $\beta V 18$ schon in einem früheren Stadium - vor Entstehung von $V$ 17 - zu VV $19 f$ uberleitete, die ja auch einen Kontrast $z u V 16$ abgeben. Die Botenformel düfte erst an die Spitze von $V 16$ gewandert sein, als man anfing, mit der Botensprucheinleitung auch Versen eine höhere Dignität zu geben, die noch als Prophetenrede zu erkennen sind. 
Jer $23,23.24$

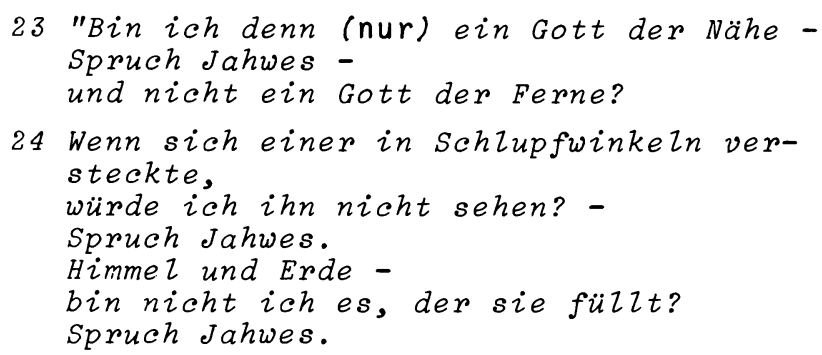

Die lockere Abfolge 23,16-32 erlaubt erst nach einer inhaltlichen Diskussion ein Urteil über Zugehörigkeit von VV 23.24 zum ursprünglichen Kontext oder zu einer Redaktionsstufe.

Die beiden rhetorischen Fragen geben sich durch die באם יהוה - Formel in Mittel-oder Endstellung als Jahwerede $z$ u erkennen ${ }^{1}$, was dem Inhalt entspricht; formale Gegenstücke finden sich im folgenden Abschnitt (vgl. zu VV 26.27.29).

Der Gebrauch kunstvoll gebauter Reihen rhetorischer Fragen gehört zum Auseinandersetzungsstil Jeremias ${ }^{2}$ und zeugt sowohl von beachtlicher Redekunst wie auch von Engagement für die Botschaft und die Hörer.

V 23 drückt nicht ein "Entweder-Oder" aus, sondern ein "Nicht nur, sondern auch". Was meint die nachdrückliche Betonung, daß Jahwe a $u c h$ ferne ist? Liest man $V 23$ mit $V 24$ zusammen, lehnt er das Mißverständnis $a b$, als ob Jahwes Nähe ihm den umfassenden Oberblick verstellen könnte und für sein Auge unerreichbare Schlupfwinkel ermöglichen würde. Die Ferne erlaubt ihm,

1 Die Formel fehlt in $G$ für $V$ 24a.

2 Siehe BRUEGGEMANN, Jeremiah's Use of Rhetorical Questions, vor allem $368 \mathrm{f}$. 
alles zu sehen. Die Aussage bleibt im Bereich des Raumes und der 0 ptik ${ }^{1}$.

VV $23 f$ schlagen also neue Töne an im Vergleich zu VV $16 \mathrm{ff}$, wo inflationäre Heilsverheißung den Hauptvorwurf bildet und die Ansage eines unheimlichen, strafenden Sturmes als das wahre Gotteswort dargestellt wird.

Hier wird nun entweder den Falschpropheten nachgesagt, sie hegten die unsinnige Hoffnung, mit ihrem Treiben unerkannt bleiben zu können, oder die Frevler insgesamt, deren Machenschaften von den Falschpropheten nicht aufgedeckt wurden, werden erinnert, daß Gott in seiner obersicht nichts übersieht.

Immerhin bleibt erwägenswert, den Gegensatz Nähe/ Ferne Gottes vom Vorhergehenden her zu deuten ${ }^{2}$. Ausdrücke für Jahwes Distanz sind auch Chiffren, die

- ein Individuum moralisch oder religiös qualifizieren können (vgl. Jer 12,2; Spr 15,29);

- eine Zeit als Heils-bzw. Unheilszeit charakterisieren $(v g 1 \text {. Jes } 55,6)^{3}$.

1 "Sehen", von Gott ausgesagt, meint natürlich in der vorauszusetzenden religiösen Sprache immer mehr als visuelle Wahrnehmung. Unserem Text kommt vermutlich Jer 12,4 nach $G$ am nächsten. Zur räuml ich ausgedrückten Transzendenzdarstellung vgl. vor allem 1 Kön 8,27; Jes 55,8f.

2 V 24 wäre dann Nachtrag eines Ergänzers, der in Nähe und Ferne von $V 23$ einen Merismus für das All gesehen (vgl. dazu Jes 33,13; 57,19 ; Jer 48,24; Est 9,20; Dan 9,7) und ihn mit dem geläufigeren Parallelausdruck Himmel und Erde ausgestaltet hat zur vollklingenden Aussage von Jahwes Omnipräsenz im Kosmos. Man würde mit dieser Auslegung eine Fragereihe zerstören von der Art, wie sie Jeremia liebt; siehe BRUEGGEMANN, ebd. Man beachte seine Bemerkung: "In this case the argument attached to the question is not obviously or skillfully connected"; ebd. 369 .

3 Wenig hilft der Verweis auf Dtn 32,17, wo es um Jahwe als den fernen = von alters her bekannten Gott im Gegensatz zu den nahen $=$ erst jünst ins Blickfeld getretenen Götzen geht. Gegen KRAUS, Prophetie in der Krisis z.St. 
25 "Ich habe gehört, was die Propheten sagen, die in meinem Namen Lüge prophezeien: Ich habe einen Traum gehabt! Ich habe einen Traum gehabt! 26 Wie lange noch macht Pläne das Herz der Propheten 1 , die die Lüge prophezeien und Gebilde des eigenen Herzens prophezeien ${ }^{2}$. 27 Planen sie etwa [meinem Volk] 3 meinen $\mathrm{Na-}$ men in Vergessenheit geraten zu lassen durch ihre Träume, die einer dem andern erzählt, so wie ihre Väter meinen Namen vergaßen wegen des Baal! 28 Der Prophet, der einen Traum hat, kann nur seinen Traum 4 erzählen! Wer aber mein Wort hat, der wird mein Wort reden! Wahrhaftig! Was hat das Stroh mit dem Korn gemein? - Spruch Jahwes. 29 Ist nicht mein Wort wie Feuer ${ }^{5}$ - Spruch Jahwes - und wie ein Hammer, der Felsen zerschmettert? 30 Deshalb! Siehe, ich stelle mich gegen die Propheten - spruch Jahwes, die da einer vom anderen meine Worte stehlen! 31 Siehe, ich stelle mich gegen die Propheten - Spruch Jahwes, die sich ihre Zunge ausrenken und sprüche sprechen! 32 Siehe, ich stelle mich gegen die propheten, die Lügenträume prophezeien - Spruch Jahwes, und sie erzählen und mein Volk verführen mit ihren Lügen und ihrem Geflunker. Ich aber habe sie nicht gesandt und sie nicht aufgeboten, und Nutzen bringen sie diesem Volk rein gar keinen - Spruch Jahwes."

Die Jahwerede, die schon ab V 21 erkennbar war, wird bis V 32 durchgehalten, in VV 28-32 jeweils durch נאםיהרה ausdrücklich gekennzeichnet ${ }^{6}$.

1 Gegen RUDOLPH z.St. mit KBL 340. $2 \mathrm{Vgl}$. BHS.

3 Doppellesung des Masoratextes durch Buchstabenverwechslung vgl. Septuaginta und ZIEGLER, Beiträge zur Jeremias-Septuaginta 437.

4 Mit $G$ ist ein im Masoratext durch Haplographie ausgefallenes Suffix zu ergänzen.

5 Lectio conflata im Masoratext vgl. JANZEN, ebd. 437.

6 Allerdings fehlt die Formel in G je einmal in VV 28.29.31; zweimal in V 32; die Formel ist hier also nicht als Strukturanzeiger brauchbar, sondern offenbar als rhetorisches Stilmittel gehäuft verwendet, um den Versen ein besonderes Gewicht zu geben. 
Metrische Struktur ist nicht mehr erkennbar; der bewußte Einsatz stilistischer Mittel zur sprachlichen Gestaltung ist unten aufzuzeigen.

Die Einheit VV 25-32 schließt die in V 16 beginnende Argumentation ab. V 25 bringt zur Sprache, wie die bekannten Lügenpropheten sich unter anderem zu legitimieren pflegten. Mit einer Kette von drei Fragen VV 26.27. 29 will Jahwe daraufhin der Autorität der Lügenpropheten den Boden entziehen. In einer Art Kadenz (VV 30-32) erklärt er feierlich seine unwiderrufliche Gegnerschaft. Dreimal betont er mit derselben Formulierung seine Feindschaft und begründet sie jedesmal mit einem neuen Vorwurf. Beim dritten und letzten Mal fällt er dann in herausgestellter Ichrede das Schlußurteil.

Wie die vorhergehenden Einheiten ( $V$ 11: Ich habe gefunden; VV 13f: Ich habe gesehen) 1äßt auch der Schlußabschnitt Jahwe als Beobachter der Propheten auftreten. Diese werden nun von vornherein nicht mehr neutral oder mit bloßer Herkunftsangabe eingeführt, sondern durchgehend mit abwertenden Wendungen tituliert (die in meinem Namen Lüge weissagen $V 25$; die Lüge prophezeien und Gebilde des eigenen Herzens $V 26$; die einer vom anderen meine Worte stehlen $V$ 30; die sich die Zunge ausrenken $\checkmark$ 31; die Lügenträume prophezeien $V 32$ ). Bei den genannten Ausdrücken handelt es sich zum großen Teil nicht um die im bisherigen Verlauf des Kapitels aufgewiesenen Schuldtatbestände, vielmehr liegen hier die aus den anderen Orakeln bekannten Vorwürfe konzentriert vor. Das Zitat in V 25: "Ich habe geträumt! Ich habe geträumt!" will mit seiner Wiederholung wohl die feierliche Ankündigung besonderer Orakel nachahmen ${ }^{1}$.

1 Zur Verwandtschaft von Traum und Vision und zur Verwendung von Traum- bzw. Visionsberichten als prophetisches Legitimationsmittel im Alten Testament und im Alten Orient vgl. LONG, Prophetic Call Traditions and Reports of Visions 494-500. 
Der Traum erfährt im Alten Testament eine vielfältige Bewertung ${ }^{1}$. Außer dem Inkubationstraum 1 Kön 3,5-15 sind symbolische Träume bekannt, die der Deutung eines Weisen bedürfen ( $v g l$. die Josefsgeschichte und Daniels Auftreten). Im weiteren kennt das Alte Testament Fälle, wo Gott durch einen Traum präzise Anweisungen gibt, so in Gen 20; 31,11.13.24. Vom Traum als Mittel des Offenbarungsempfanges von Propheten sprechen 1 Sam 28,6.15; Num 12,6-8. Allerdings wird nicht jedem Traum Offenbarungsqualität zugeschrieben. Man weiß von der Flüchtigkeit von Wunsch- und Angstträumen (Jes 29,7f; Ijob 20,8; Pss 73,$20 ; 126,1)$. Die Weisheitslehrer warnen deshalb davor, dem Traum zuviel Beachtung zu schenken (Koh 5,6; Sir 34,1-8). Ins Kreuzfeuer prophetischer Kritik geraten die Träume als Offenbarungsmittel durch den Mißbrauch bei Falschpropheten (vgl. Dtn 13,2-6; Jer 27,9; 29,8; Sach 10,2). Aus unserer Stelle können wir entnehmen, daß Propheten auftraten, die ihre Botschaft legitimierten, indem sie auf den Empfang eines Traumes verwiesen. Offenbar konnten sie dabei auf besondere Wertschätzung dieser Art von Offenbarungsempfang durch das Volk rechnen.

Der Text zu Beginn von $V 26$ ist offensichtlich gestört ${ }^{2}$. Das war der Anlaß zu verschiedenen Konjekturen ${ }^{3}$.

$1 \mathrm{Vgl}$. EHRLICH, Der Traum im AT sowie RESCH, Der Traum im Heilsplan Gottes.

2 Der Masoratext wäre als Aposiopese zu lesen, was aber keinen Sinn ergibt.

3 WEISER z.St. zieht die Frage: Wie lange? zum Vorhergehenden und macht sie zum Stoßseufzer der Falschpropheten: Wie lange hat es gedauert, bis ich endlich einen Traum hatte! Die entsprechende hebräische Fragepartikel hat aber den Sinn: Wie lange noch? Sie kann sich wohl nicht auf die Vergangenheit beziehen. DUHM und RUDOLPH z.St. lesen ein drittes "Ich habe geträumt" und müssen dafür den Konsonantenbestand erheblich verändern. Die Septuaginta überliest die im Hebräischen nach der Frage: "Wie lange?" unmögliche zusätzliche Fragepartikel. Das zweimalige "Ich habe geträumt" in V 25 gibt sie mit der etymologischen Figur: "Ich habe 
Der plausibelste und graphisch einfachste Vorschlag bleibt der von KOHLER ${ }^{1}$ : "Wie lange noch macht das Herz der Propheten Pläne?"2

Damit beginnt eine Reihe von drei Fragen, die nun nicht in logisch aufeinanderfolgenden. Schritten ein- und denselben Tatbestand als unhaltbar aufdecken, sondern vielmehr dem Unmut des Sprechenden Luft machen und zugleich die Lügenpropheten disqualifizieren wollen. In der ersten Frage $V 26$ äußert Jahwe seine Ungeduld: "Wie lange noch?"Die Frage bleibt vorerst unbeantwortet im Raum stehen. Die zweite Frage $V 27$ nimmt das Stichwort "Pläne machen" auf und insinuiert als erklärtes Ziel dieser Falschpropheten, den Jahwenamen auszulöschen. "Jahwe vergessen (bzw. vergessen machen)" ist seit Hosea Gegenbegriff zum Wissen um Gott ${ }^{3}$. Stereotyp wird im Dtn die Mahnung, Jahwe bzw. Seinen Bund, seine Worte nicht $z u$ vergessen; sie wird zu einer der Variationen der Hauptgebotsformulierungen ${ }^{4}$. Jeremia macht diese Wendung zum Ausdruck des Abfalls von Jahwe $(2,32 ; 3,21 ; 13,24 \mathrm{f}$; $18,15)$. Ausgeprägter als bei Hosea $(2,15)$ wird das Vergessenjahwes mit dem Baalskult in Verbindung gebracht.

einen Traum geträumt" wieder. Als Subjekt von V 26 setzt sie offenbar den genannten Traum voraus, was im Hebräischen unmöglich ist. VOLZ und WEISER z.St. lesen: "Bin ich etwa im Herzen von Propheten?" Aber dagegen spricht, daß die Vorstellung "Jahwe im Herzen eines Menschen" im AT nicht zu belegen ist. Graphisch schwieriger ist RUDOLPHS Vorschlag: "Sollte mein Name im Herzen der Propheten sein?" Die als Parallele dazu angeführte Stelle Ex 23,21 spricht davon, daß Jahwe in seinem Engel ist (sein Name ist in ihm); aber die Parallele redet nicht von der Einwohnung Jahwes im Herzen eines Menschen.

$1 \mathrm{KBL}$ ebd.

2 Vgl. WAMBACQ z.St.

3 Vgl. WOLFF, "Wissen um Gott".

4 Vgl. LOHFINK, ebd, $78 \mathrm{f}$. 
Der Vergleich mit den Vätern stellt die Propheten auf eine Linie mit den Balsdienern, die schon dem Nordreich den Untergang brachten: "Was haben eure Väter an mir Unrechtes gefunden, daß sie von mir weggingen? Daß sie hinter dem Nichts herliefen und selbst zu nichts wurden?" (Jer 2,5) Schon Hosea hatte deutlich gemacht, daß, wer Jahwe vergiBt, von ihm vergessen und verworfen wird (Hos 4,6). Auch die Klagegebete des Volkes (z.B. Ps 44, 18) wissen um die Gefährlichkeit des Vorwurfs und beteuern darum: "Wir haben dich nicht vergessen!"

Das Mittel des Vorhabens der Propheten sind ihre Träume. Die mehrmalige Erwähnung, daß hier einer dem anderen stiehlt (VV 27.30), scheint die Geschäftigkeit dieser Prophetenclique zu verhöhnen.

Die dritte Frage $V 29$ ist rhetorisch und erwartet die Antwort: Ja! Der erste Vergleich von Jahwes Wort mit Feuer findet sich noch an zwei Stellen: Jer 5,14: Jahwe macht seine Worte im Munde des Propheten zum Fever, welches dieses Volk verzehrt und Jer 20,9: Jahwes Wort, das der Prophet vergessen will, wird in seinem Innern zum Feuer, das sich nicht eindämmen läßt.

Die rhetorische Frage V 29 erwartet ein: Ja! Aber nicht, weil hier eine Katechismusantwort über das Wesen des Gotteswortes vorausgesetzt wird, sondern weil daran erinnert wird; daß Jahwes Gerichtswort an alle vernehmlich ergangen ist. Darin wird zugleich auch eine Antwort auf die vorhergehenden Fragen angedeutet: Dem Treiben der Propheten ist durch das Gericht eine Frist gesetzt. Ihr Vorhaben, Jahwes Namen auszulöschen, ist absurd, denn Gottes Wort setzt sich durch wie Feuer!

1 Wörtlich heißt es Jer 20,9: "Ich will nicht mehr seiner gedenken", was die Verneinung des Kontrastbegriffs zum "vergessen" (s.o.) ist; vgl. LOHFINK, ebd. 79. 
V 28 wird Traumkritik in einer Grundsätzlichkeit laut, wie sie sonst weder im Jeremiabuch noch im AT überhaupt zu finden ist (Jer 27,$9 ; 29,8$ sowie im Kontext von 23, 28 wird gegen den Inhalt 1 ü $g$ e $r$ is $c h$ e $r$ Träume und gegen die Träumer polemisiert).

In prinzipieller Weise ist hier der Prophet des Traumes dem echten Verkünder des Wortes gegenübergestellt. Wenn man Jeremia in der Entwicklung einer Worttheologie eine hervorragende Stellung zuschreiben muß ${ }^{1}$, wird man ihm einen solchen Satz nicht ohne weiteres absprechen dürfen.

Der Ausruf zu Anfang von VV 3o-32 setzt die letzten Verse vom Bisherigen ab. Nun wird nicht mehr gefragt;

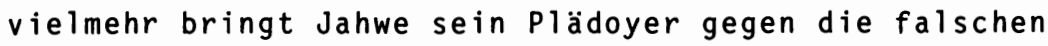
Propheten mit drei leidenschaftlichen und rhetorisch geschickt gestalteten Erklärungen zu Ende.

Dreimal setzt er in derselben Weise an: "Siehe, ich stelle mich gegen die Propheten, Spruch Jahwes!" Dreimal werden die Propheten näher qualifiziert und damit Jahwes Gegnerschaft erneut begründet. Ein einzelner Vorwurf ist es in $V$ 3o. In der zweiten Erklärung stehen zwei Vorwür$f e$ in Stabreimwendungen.

$\checkmark 32$ resümiert, indem er Wendungen des Kontextes wörtlich oder in Modifikation aufnimmt: Die Herausforderungsformel in der Gestalt von VV 31.32; "die Lügenträume, die sie erzählen", VV 25-27; "sie verführen mein Volk", V 13 (hier sind es die Samariapropheten, die Israel verführen); die Distanzierungsformel: "Ich habe

1 So schon PROCKSCH in ThWb IV. S.96f. Stroh und Korn wird man als Kontrastpaar im Sinn von "minderwertig - wertvoll" verstehen müssen. Weitere Ausdeutungen (wie das Korn in der Hülle des Strohs heranreift - so das Wort in der Vision) trägt der Text nicht.

Zur Worttheologie bei Jeremia vgl. ferner von RAD, Theologie II, S. $104,107,278$. 
(sie) nicht gesandt", V 21. Das abschließende Verdikt: "Nutzen bringen sie diesem Volk überhaupt keinen" erinnert an den redaktionellen Text uber die Nutzlosigkeit der Götzen 2,8. Ahnliche Wendungen stehen aber auch in vorredaktionellen Wendungen 2,$11 ; 7,8$.

Der plural בשקרידם ist im Jeremiabuch singulär, פחזר ist hapax legomenon. Einzig die Tatsache, daß anstelle der zweiten Distanzierungsformel von V 21 "Ich habe nicht zu ihnen gesprochen" die deuteronomistische Variante: "Ich habe sie nicht aufgeboten" verwendet wird (vgl. oben zu 14,14), macht wahrscheinlich, daß die Hauptredaktion an diesem Vers mitgestaltet hat. Als $A b-$ schluß der rhetorischen Schlußkadenz ist aber $v 32$ in fast seinem gesamten Wortbestand dem Kompositeur des Prophetenkapitels zuzuschreiben ${ }^{1}$.

Was dieses Kapitel ab V 16 durchzieht, ist ein argumentativer stil. Es wird - obwohl nicht expressis verbis ausgedrückt - das Volk angesprochen und versucht, zwischen Falschpropheten und Auditorium einen Keil zu treiben.

Es häufen sich rhetorische Stilmittel: stereotype Satzanfänge, sich steigernder Ausbau der Satzglieder, Alliterationen, figurae etymologicae, Doppelausdruicke (prophezeien - erzählen, Lügen - Geflunker, schicken aufbieten) und Hervorhebung der wichtigen Satzglieder durch Stellung am Anfang (ich aber.... Nutzen ...). Die besondere Gestaltung verrät auch die Wortwahl sowohl in singulären Worten wie "(Sprüche) sprechen" und "Geflunker" als auch in Wendungen wie "die Zunge ausrenken" und "die Worte stehlen".

Die dreimal wiederholte Herausforderungs- bzw. Be-

1 Gegen THIEL, Diss. 420. 
gegnungsforme $1^{1}$ "(So spricht Jahwe:) Siehe, ich bin gegen ... (Spruch Jahwes)" ist zunächst abzuheben von der sogenannten "Weissagung im Präsentativ" ("Siehe, ich" + part.), weil hier das Partizip, das sonst die Gerichtsaktion beschreibt, fehlt, und an seine Stelle die bloße Präposition ע tritt. Oblicherweise leitet diese Formel ein Gerichtswort ein, wird dann aber immer durch finite Verbformen fortgeführt, die die Gerichtsaktionen beschreiben. An allen diesbezüglichen Stellen, außer hier und Ez 30,22;34,10, handelt es sich um Anrede. Weil in 33,30.31.32 vor allem die Beschreibung des Gerichts fehlt, wird man diese Stelle deshalb nicht ohne weiteres als Gerichtsansage identifizieren können. Andererseits beinhaltet unser Ausdruck aber nicht bloß eine Parteinahme gegen jemand, sondern zugleich Bedrohung ${ }^{2}$.

Nun zu den Vorwürfen von VV 30-32 im einzelnen: Dem ersten Vorwurf geht es nicht um die grundsätzliche Erörterung, ob die Worte der Propheten von Jahwe autorisiert sind, sondern um Verhöhnung: "Nicht einmal Gebilde des eigenen Herzens verkündigen sie, sondern von ihren Kollegen Geklautes" ${ }^{3}$. Der zweite Vorwurf geht darauf aus, die Propheten lächerlich zu machen: "Sie renken sich die Zunge aus ${ }^{4}$ und sprücheln Sprüche". Er entlarvt sie als

$1 \mathrm{Vgl}$. dazu HUMBERT, Die Herausforderungsformel 101-108; von RABENAU, Studien zur Theologie der alttestamentlichen oberl ieferungen 61-80; BAUMGARTEL, Die Formel ne um jahwe 277-29o.

2 Vgl. Ri 16,12: "Die Philister sind über dir!"

3 Eine "Usurpation" im Sinne von "eigenmächtige( $r$ ) Verfügung über die Heilsbotschaft der prophetischen Tradition" - so KRAUS, ebd. 55 - überfordert den Text. Die Propheten klauen $e i n$ a $n d e r$ "meine Worte" und nicht die von Vorgängern. KRAUS denkt hier offenbar an BUBERS "Papageien des Jesaja". Dem rhetorischen Charakter des Stückes entsprechend wird man den Ausdruck "meine Worte" als Breviloquenz für "angeblich von mir stammende Worte" verstehen dürfen.

4 Jeremia liebt offensichtlich originelle Wendungen in Kombination mit dem Wort "Zunge", vgl. 9,2.4.7; 18,18. 
Schwätzer. Der dritte Vorwurf faBt die Anschuldigungen der ganzen Einheit zusammen: zu den Lügenträumen vgl. VV 25.27, zum Hausieren gehen (erzählen) mit ihren Sprüchen vgl. V 27; zum Verführen vgl. VV 13 und 27. Mit der feierlichen Schlußerklärung in $V 32 b$ ist das Haupt thema, das mit der unerhörten Aufforderung: "Hört nicht auf die Propheten!" in V 16 ausgelöst wurde, endguiltig entschieden: Diese Propheten sind nicht von Jahwe legitimiert.

Die redaktionsgeschichtliche Analyse hat nicht immer zu klaren Ergebnissen geführt. Es konnten späte Glossen und Umdeutungen aufgedeckt werden. Der kompositionelle Charakter von 23,9-32 wurde klar erkannt. Spuren der bekannten Arbeitsweise der Hauptredaktion wurden deutlich. Aber schon das der Edition zugrundeliegende Material erwies sich als eine nachträgliche Komposition, welche teilweise sperriges authentisches Material zusammen mit anderen geprägten Elementen zu einer Rede gegen die Propheten verknüpfte. Der ausgeprägt rhetorische Charakter läßt vermuten, daß wir es nicht mit einem "akademischen Schreibtischprodukt" zu tun haben, sondern mit einem Dokument mitten aus einer noch aktuellen Auseinandersetzung ${ }^{1}$.

Da sich diese polemische Rede nie direkt an Falschpropheten wendet, wohl aber das Volk anspricht ("Hört nicht ..."), da ferner die Hauptintention des Textes nicht Gerichtsansage und Schuldaufweis, sondern $E c h$ t$h$ e $i t s$ b $s t r e i t u n g$ ist, kann man sich als Gattung ein Pamphlet vorstellen, das als Flugblatt in der Jerusalemer offentlichkeit zirkulierte. Eine Datierung scheint auch bei diesem Text nicht möglich.

1 Mit den meisten neueren Kommentaren betrachten wir VV 33-40 als Anhang aus sehr später Zeit. Man mag in V 33 ein Wortspiel sehen, das Jeremia zuzutrauen ist, für unser Thema bringt der Abschnitt nichts ein. 


\section{ZUSAMMENFASSUNG}

Vorbemerkung: Wer vom Prophetenkonflikt im Jeremiabuch spricht, denkt zunächst an die Auseinandersetzung zwischen Jeremia und Hananjal. Eine Analyse der Kapitel 27 29 haben wir vorgelegt in HOSSFELD/MEYER, Prophet gegen Prophet ${ }^{2}$. Die dort erzielten Resultate werden für diese Schlußbemerkungen mitberücksichtigt.

Zur theologischen Frage nach der echten Prophetie sollten exegetische Erkenntnisse gewonnen werden. Die Aufmerksamkeit galt der Auseinandersetzung Jeremias mit gegnerischen Propheten. Das historisch-biographische Interesse fand im Jeremiabuch eine literarisch komplizierte Dokumentation vor. Ohne eine Vorstellung von der Entstehung des Buches waren die Texte für unsere Frage nicht auswertbar. Die thematisch begründete Auswahl nötigte zu "Versuchsbohrungen", die eine vorläufige Zeichnung der literarischen stratigraphie des Jeremiabuches ermöglichen.

DUHM hat seinerzeit die Entstehungsgeschichte so charakterisiert: "Das Buch ist ... langsam gewachsen, fast wie ein unbeaufsichtigter Wald wächst und sich langsam ausbreitet" ${ }^{3}$. Das Bild ist hübsch, bedarf aber einiger Präzisierungen.

Tatsächlich begegneten uns immer wieder Glossen, die weder chronologisch noch literarisch oder theologisch in

1 Eine historische Einordnung in die letzten Jahre Jerusalems entwickelt mit anregenden Vermutungen MALAMAT, The Twilight of Judah 135-140.

2 HOSSFELD/MEYER, Prophet gegen Prophet 90-111.

3 ebd. $X X$. 
genauere Zusammenhänge zu bringen waren. Die beträchtliche Differenz im Textbestand zwischen der hebräischen und der griechischen oberlieferung zeugt ebenfalls von nachträglichem Wachstum ${ }^{1}$.

Trotzdem ist das Jeremiabuch kein Resultat unkontrollierten Wildwuchses. Eine konsequente und keineswegs blOB ornamental bearbeitende Redaktion hat ihm im wesentlichen seine heutige Gestalt gegeben. Die Untersuchung von Einzeltexten hat zur Arbeitshypothese von der redaktionellen Tätigkeit geführt und die Verwandtschaft entsprechender Schichten im Text erkennen lassen.

Ob die Herausgeber des Jeremiabuches Deuteronomisten genannt werden sollen, mag offen bleiben. Sprachliche und theologische Verbindungen hin zum Dtn und zum dtr. Geschichtswerk sind ebenso zu erkennen wie spezifische Eigenleistungen ${ }^{2}$.

Wenn es gelingt, jene Bearbeitungswelle, die in exilischer Zeit Israels Traditionen sammelte, redigierte und aktualisierte ${ }^{3}$, differenzierter darzustellen, wird die Jeremiaredaktion ihren gebührenden Platz bekommen ${ }^{4}$.

Was das literarische Profil der Redaktionstätigkeit anbelangt, wird man keine allzu hohen Erwartungen hegen. Die Treue zum vorgegebenen Text führt oft zu mosaikarti-

1 Der griechische Text ist rund ein Achtel kürzer als M. Fragmente aus Qumran ( $4 Q \mathrm{Jer}^{\mathrm{b}}$ ) scheinen die Existenz einer hebräischen Vorlage vom Umfang von $G$ zu belegen. Auch aus inneren Gründen ist meist nachträgliches Wachstum des M-Textes wahrscheinlicher als Kürzung durch die Obersetzer. Ob mit sukzessiven Zuwächsen oder einer zweifachen Edition zu rechnen ist, muß eine breiter angelegte Untersuchung zeigen. Vgl. TOV, critique textuelle 199.

2 Vgl. BRIGHT, Prose Sermons 15-35 und WEIPPERT, Prosareden.

$3 \mathrm{Vgl}$. AUERBACH, Die große Uberarbeitung 1-10.

4 Was die zeitliche und lokale Ansetzung der Jeremiaredaktion anbelangt, vgl. THIEL, Diss 672-675 und JANSSEN, Juda in der Exilszeit 21 . 
gen Kompositionen mit literarischen und theologischen Spannungen ${ }^{1}$.

Die erkennbare theologische Aussageabsicht, der Aktualisierungswille in der neuen hermeneutischen Situation des ergangenen Gerichts verbieten die abschätzige Behandlung der redaktionellen Gestalt des Buches als defizienten Konservierungsmodus authentischer Traditionen.

Wenn nun aber diese Redaktion darauf verzichtet, die Elemente restlos einzuschmelzen und in eine einheitliche, neue Form zu gießen, lädt sie damit dazu ein, die vorgegebenen Literaturfragmente, soweit sie rekonstruierbar sind, als Außerungen mit eigenem Gewicht zu untersuchen. Es begegnete uns dabei unterschiedliches Textmaterial: Erzählungen und Erzählfragmente, poetische Einzelsprüche und komplexe Spruchkompositionen; wo vorredaktionelle komponierte Einheiten vorlagen (Kapp 2; 23; 27f; 29), war zu fragen, ob hier nochmals formale und inhaltliche Differenzen zwischen der Komposition und ihren Elementen festzustellen seien. Sowohl vorgegebene Erzählungen wie Spruchsammlungen erwiesen sich als zusammengesetzt, und zwar in einer Art und Weise, daß angenommen werden mußte, schon die Kompositeure dieser Abschnitte seien in ihrer Gestaltung nur begrenzt frei gewesen. Ihnen müssen bereits Texte mit fixiertem Wortlaut - also doch wohl schriftliches Material, denn Fixierung im Wortlaut ist in hohem Maß ein Zeichen der Schriftlichkeit - vorgelegen haben.

Diese komplizierte Sicht der Entstehungsgeschichte mag manchen enttäuschen, der geglaubt hatte, im Fall des Jeremiabuches komme man möglichst schnell und sehr direkt an die ipsissima vox des Propheten heran ${ }^{2}$. Schließ-

1 Zur Kritik an allzu subtilen Oberlegungen zur Entstehungsgeschichte von Kap $29 \mathrm{vgl}$. HOSSFELD/MEYER, Prophet gegen Prophet Anm 166 S. 178.

$2 \mathrm{Vgl}$. YOUNG, Introduction 229. "There is no satisfac- 
lich weiß man dank Kap 36, daß Jeremia selbst eine Sammlung seiner Aussprüche veranstaltet hat, und Kap 29 bietet einen Brief des Propheten, dessen substantielle Authentizität nicht angezweifelt zu werden braucht. Man hat diese Rolle nach Diktat in ihrer wiederhergestellten Fassung immer gern als Keimzelle des späteren Buches betrachtet. In unserer, allerdings begrenzten Textauswahl sind wir aber nie auf eine authentische Sammlung, sondern nur auf authentische Einzelsprüche gestoßen.

Die Zuweisung der Fremdberichte an Baruch ist schon früher auf Einspruch gestoßen. Die Arbeiten von KREMERS und WANKE haben dieser Hypothese wohl endgültig den Abschied gegeben. Die Erzählungen und Fragmente sind nun aus sich selbst zu erklären, die Jeremiatraditionen gewinnen an Vielstimmigkeit. Abschileßend kann zur formalen Seite unserer Arbeit vermerkt werden:

Die Textauswahl, die von unserem Thema her zu treffen war, hat auf Stellen geführt, die sich für "Versuchsbohrungen durch die literarischen Schichten des Jeremiabuches" sehr gut eigneten. Die vielen Fragen, die offen bleiben mußten, können nicht die Zuversicht zunichte machen, daß es sich weiterhin lohnt, den literarischen Phänomenen literar- und redaktionskritisch nachzugehen und nicht vorschnell resignierend eine traditionsgeschichtlich statuierte Einheitlichkeit zum Ausgangspunkt der Auslegung zu machen ${ }^{1}$.

Was nun die inhaltiche, historische und theologische Seite unserer Ergebnisse anbelangt, darf darauf hingewiesen werden, daß diese andernorts ausführlicher

tory reason for doubting that Jeremiah himself was the author of the entire book." MAYER, Einleitung 2. Teil 232. "Das Buch des Propheten Jeremias ... stellt uns nicht vor so schwierige kritische Probleme, wie das Isaiasbuch ...., es gibt darin verhältnismäßig nur weniges, was man dem Propheten absprechen müßte."

1 Offenbar sind Begriffsuntersuchungen für solche Fragestellungen 
dargestellt und in größere Zusammenhänge gestellt werden ${ }^{1}$.

Hier sei resümierend festgehalten:

Jeremias Konflikte mit den Propheten sind nicht Ausfluß ererbter Rivalitäten $z$ wischen seit alters verfeindeten Parteien. Jeremia steht in prophetischen Traditionen. Vor allem Hosea hat ihn geprägt. Polemik gegen Berufskollegen gehört aber nicht zu diesem Erbe.

Hingegen wei $\beta$ er aus dieser Quelle und erlebt es am eigenen Leib, daß Propheten in Opposition zum halsstarrigen Volk geraten können $(5,12-14)$. Er weiß auch um politische Gefahren des Prophetenlebens (2,3ob).

Doch dann erfährt er, daß unter den Gegnern seiner Botschaft gerade auch Propheten auftreten. Er muß ihre Unfähigkeit entdecken, sich von den Sünden des Volkes zu distanzieren; im Gegenteil, im Verein mit den Priestern machen diese gemeinsame Sache mit dem sündigen Volk, treiben "Baalsdienst" (5,30f; 6,9-15;23,9ff), sind nicht imstande, den Ernst der kritischen Situation zu beurteilen, sagen Heil und Heilung an, statt aus den ersten Symptomen der Krankheit ihre Gefährlichkeit zu diagnostizieren.

Eine historisch plausible Erzählung berichtet, wie es unter Zidkija zu einem Eklat mit Hananja kommt, der ihn auf offener Straße mit seinem Gegenauftritt blamiert. Jeremia muß das Feld räumen.

Bei anderen Gelegenheiten formuliert Jeremia scharfe Polemiken gegen die Berufskollegen, die immer mehr zu seinen Hauptgegnern werden. Er deckt ihre moralische Minderwertigkeit auf und bestreitet schließlich in einem Gotteswort ihre Legitimation.

nicht besonders erfolgversprechend. Siehe OVERHOLT, Continuity of the Jeremiah Tradition 457-462.

1 Vgl. HOSSFELD/MEYER, Prophet gegen Prophet. 
Freunde und Schüler sammeln die Attacken auf die Propheten und komponieren sie zu einer großen polemischen Rede (23,9-32), die Kriterien echter Prophetie zusammenträgt. (Echte Propheten rufen zur Umkehr; moralische Defekte zeugen für Unechtheit; Parteinahme für Obeltäter beweist Falschheit.)

Die Feindschaft zwischen Jeremia und den Propheten ist auch dem Verfasser jener Erzählung geläufig, die eine öffentliche Bestätigung der Legitimität des Propheten berichten soll (Kap 26). Unter seinen Anklägern werden ohne eigene Begründung die Berufskollegen aufgezählt.

Die Falschpropheten werden als Infektionsherd für das ganze Volk denunziert $(23,15)$. Das echte Wort erweist sich vor allem an seiner Durchsetzungskraft: Jahwes Wort ist wie Feuer, wie ein Hammer, der Felsen zerschmettert $(23,29)$.

Die überarbeitete Fassung der Erzählung von der Auseinandersetzung mit Hananja entschärft die für den Propheten blamablen Züge und zeigt einen argumentierenden Jeremia, der sehr genau $z$ wischen Wunsch und Wirklichkeit zu scheiden weiß. Heilsprophetie muß den Echtheitsbeweis erst antreten. Für die Unheilsprophetie spricht hingegen alles, auch die Tradition.

Die große Bestätigung Jeremias bringt der Untergang Jerusalems. Aus der Zeit danach stammen die redaktionellen Texte. Das traditionelle Prophetentum ist untergegangen ( $v g l . K l g l ~ 2,9)$. Was soll jetzt noch Polemik gegen längst erledigte, wenn nicht tote, so doch endgültig widerlegte Gegner des Jeremia?

DUHM meint "nach diesen spätlebenden Autoren hat es im vorexilischen Volk so viele Nabis gegeben, wie zu ihrer Zeit Rabbis"l. Also versteckte Attacken gegen

1 ebd. 164. 
zeitgenössische Gegner? Das ist so wenig wahrscheinlich wie DUHMS Vermutung, die Angriffe auf Priester gälten indirekt dem sadduzäischen Priesteradel. Dazu sind die Vorwürfe viel zu unspezifisch. Die Polemik gegen die Propheten bekommt ihre Vehemenz aus anderen Quellen. Aber auch nicht das Problem einer theologischen Erkenntniskritik, wie wahre und falsche Propheten grundsätzlich erkennbar seien, steht im Vordergrund. Die stereotype, grundsätzliche und rhetorische Argumentationsweise, die Plazierung der Angriffe im Kontext von Gerichtsund Drohreden zeigen vielmehr an: Die Propheten spielen eine entscheidende Rolle im theologischen Hauptproblem der deuteronomistischen Literatur, der geschichtstheologischen Bewältigung des Gerichts über Jerusalem. Sie waren es gewesen, die Jeremia Widerstand geboten hatten. Sie werden nun zum Zentrum dieses Widerstandes in Jerusalem und in der Gola stilisiert. Das generalisierende Urteil: alle Propheten waren Gegner des Jeremia (man denke an Urija!), wird nun sogar umgedreht: wer gegen Jeremia auftrat, war ein Prophet (vgl. Kapp 20 und 29).

Das Versagen Israels war ein Versagen seiner Prophetie. Dieses Urteil aber wird nicht aus der Zuschauerloge der Weltgeschichte gefällt, sondern von Theologen, die selbst das Erbe der Propheten angetreten haben.

Es genügt nicht, mit DUHM zu sagen, daß sich hier "nur die Theologie in den Prophetenmantel gehüllt hat" ${ }^{1}$. Vielmehr geht es um Menschen, die prophetische Worte und Oberlieferungen sammeln und aktualisieren, aber auch neue Mahnungen, Warnungen, Drohungen und $\operatorname{schließ-}$ lich auch Verheißungen zu formulieren wagen.

1 ebd. 9. 
Spätere Generationen, die mit neuen Formen von Prophetie wechselhafte Erfahrungen machten, haben dann aus eben diesen Texten Maßstäbe für die Unterscheidung von echt und falsch zu gewinnen versucht, ein schönes Zeugnis für die Aktualität dieser Texte, die man auch der heutigen Theologie wieder empfehlen darf. 


\section{LITERATURVERZE I CHN IS}

AESCHIMANN A., Le prophète Jérémie. Commentaire Neuchâtel 1959.

AUERBACH E., Die große Oberarbeitung der biblischen Bücher, in: VTS I (1953) 1-10.

AUGÉ D.R., Jeremias (La Biblia, Versio dals textos originals $i$ commentari pels Monjos de Montserrat) Barcelona 1950 .

BAUMGARTEL F., Die Formel ne um jahwe, in: ZAW 73 (1961) 277-29o.

BERRIDGE J.M., Prophet, People, and the Word of Jahwe. An Examination of Form and Content in the Proclamation of the Prophet Jeremiah, Zürich 1970.

BLANK S.H., Jeremiah. Man and Prophet, Cincinnati 1961.

BOECKER H.J., Redeformen des Rechtslebens im AT (WMANT 14) Neukirchen 1964.

BRIGHT J., The Date of the Prose Sermons of Jeremiah, in: JBL LXX (1951) 15-35.

Jeremiah (Anchor Bible 21) New York 1965.

BRUEGGEMANN W.A., Jeremiah's Use of Rhetorical Questions, in: JBL 92 (1973) 358-374.

BUDD P.J., Priestly Instruction in Pre-exil Israel, in: VT XXIII (1973) 1-14.

CHALLENOR J., Jeremiah (Scripture Discussion Commentary 2, Prophets I) London and Sidney 1971.

CODY A., A History of 0ld Testament Priesthood (Analecta Biblica 35) Rom 1969.

CONDAMIN A., Le livre de Jérémie; Paris 1920.

CORNILL C.H., Das Buch Jeremia, Leipzig 1905.

COUTURIER G.P., Jeremiah (The Jerome Biblical Commentary) London 1968, 300-336.

CUNLIFFE-JONES H., The Book of Jeremiah. Introduction and Commentary, London 1960.

DAVIDSON F., The New Bible Commentary, London ${ }^{3} 1968$.

DENNEFELD L., Les grands prophètes (La Sainte Bible VII) Paris $1946,235-406$.

DRIVER G.R., Abbreviations in the Massoretic Text, in: Textus 1 (1960) 112-131.

Once Again Abbreviations, in: Textus 4 (1964) 76-94.

DUHM B., Das Buch Jeremia (Kurzer Hand-Commentar zum AT XI) Tuibingen und Leipzig 1901. 
EHRLICH A.B., Randglossen zur Hebräischen Bibel. Textkritisches, Sprachliches und Sachliches, Bd.IV, Leipzig 1912.

EHRLICH E., Der Traum im AT (BZAW 73) Berlin 1953.

ERBT W., Jeremia und seine Zeit, Göttingen 1902.

GELIN A., Jérëmie (La Sainte Bible de Jerusalem) Paris ${ }^{2} 1959$.

GEMSER B., The Rîb - or Controversy - Pattern in Hebrew Mentality (VTS III) Leiden 1955, 120-137.

GIESEBRECHT $F_{3} \begin{gathered}\text { Das Buch Jeremia (Handkommentar zum AT) Göttingen } \\ 3_{1907} \text {. }\end{gathered}$

GRAF H., Der Prophet Jeremia, Leipzig 1862.

GROSS H., "Gab es in Israel ein prophetisches Amt?" in: EThL XLI (1956) 5-19.

GROSS K., Die literarische Verwandtschaft Jeremias mit Hosea. Diss. Berlin 1930.

GUNKEL H. / BEGRICH J., Einleitung in die Psalmen, Göttingen ${ }^{2} 1966$.

HARVEY J., Le "Rîb-Pattern", réquisitoire prophétique sur la rupture de l'alliance, in: Bibl 43 (1962) 172-196.

HERRMANN S., Die prophetischen Heilserwartungen im AT. Ursprung und Gestal twandel (BWANT 5.F. H 5 ) Stuttgart 1965.

HESSE F., Die Fürbitte im AT, Erlangen 1949.

Wurzelt die prophetische Gerichtsrede im israelitischen Kult? in: ZAW 63 (1953) 45-53.

HILLERS D.R., A Convention in Hebrew Literature: The Reaction to Bad News, in: ZAW 77 (1965) 86-89.

HITZIG F., Der Prophet Jeremia (Kurzgefaßtes exegetisches Handbuch zum AT) Leipzig 21866.

HOLLADAY W.L., The priests scrape out on their hands, in: VT XV (1965) 111-113.

A Fresh Look at "Source B" and "Source C" in Jeremia, in: VT XXV (1975) 394-412.

Prototype and Copies. A New Approach to the PoetryProse Problem in the Book of Jeremiah, in: JBL LXXIX (1960) 351-367.

HORST F., Die Anfänge des Propheten Jeremia, in: ZAW 41 (1923) 94-153.

HOSSFELD F.L. / MEYER I., Prophet gegen Prophet. Eine Analyse der alttestamentlichen Texte zum Thema: Wahre und falsche Propheten (BB 9) Fribourg 1973.

Der Prophet vor dem Tribunal. Neuer Auslegungsversuch von Jer 26, in: ZAW 86 (1974) 30-50.

HUFFMON H., The Covenant Law Suit in the Prophets, in: JBL LXXVIII (1959) 285-295. 
HUMBERT P., Die Herausforderungsforme1 "hinnenî êlékâ, in: ZAW 51 (1933) 101-108.

HYATT J.Ph., The Deuteronomic Edition of Jeremiah, in:Vand.St I (1951) 71-95.

- The Beginning of Jeremiah's Prophecy, in: ZAW 78 (1966) 204-214.

JANSSEN E., Juda in der Exilszeit. Ein Beitrag zur Frage der Entstehung des Judentums (FRLANT NF 51) Göttingen 1956.

JANZEN J.G., Double Readings in the Text of Jeremiah, in: HTR 60 (1967) 433-447.

JEREMIAS J., Theophanie. Die Geschichte einer alttestamentlichen Gattung (WMANT 10) Neukirchen 1965.

Kultprophetie und Gerichtsverkündigung in der späten Königszeit Israels (WMANT 35) Neukirchen 197o.

JOHNSON A.R., The Cultic Prophet in Ancient Israel, Cardiff ${ }^{2} 1962$.

KEIL C.F., Biblischer Commentar über den Propheten Jeremia und die Klagelieder (BC III,2) Leipzig 1872.

KLOPFENSTEIN M.A., Die Lüge nach dem AT. Ihr Begriff, ihre Bedeutung und ihre Beurteilung. Zuirich 1964.

Scham und Schande nach dem AT (ATANT 62 ) Zürich 1972.

KOCH K., Der Spruch "Sein Blut bleibe auf seinem Haupt" und die israelitische Auffassung vom vergossenen Blut, in: VT XII (1962) 396-416.

KOBERLE D.J., Der Prophet Jeremia. Sein Leben und Wirken, dargestellt für die Gemeinde, Stuttgart 21925.

KOHLER L., Deuterojesaja, stilkritisch untersucht, Gießen 1923.

Der hebräische Mensch. Eine Skizze. Mit einem Anhang:

Die hebräische Rechtsgemeinde, Tübingen 1953.

KRAUS H.J., Prophetie in der Krisis. Studien zu Texten aus Jeremia, Neukirchen 1964.

KREMERS H., Der leidende Prophet. Das Prophetenbild der Prosaüber1 ieferung des Jeremiabuches und seine Bedeutung innerhalb der Prophetie Israels, Diss. Göttingen 1952.

- Leidensgemeinschaft mit Gott im AT, in:EvTh 13 (1953) 122-140.

KROEKER J., Jeremia. Der Prophet tiefster Innerlichkeit und schwerster Seelenführung. (Das lebendige Wort) Gießen und Basel 21958.

LATTEY C., Jeremias (A Catholic Commentary on Holy Scripture) London 1953, 574-591.

LAETSCH T., Jeremiah (Bible Commentary) Saint Louis, Missouri 1952. 
LAMPARTER H., Prophet wider Willen. Der Prophet Jeremia. (Die Botschaft des AT) Stuttgart 1964.

LIEDKE G., Gestalt und Bezeichnung alttestamentlicher Rechtssätze. Eine formgeschichtlich-terminologische Studie (WMANT 39) Neukirchen 1971.

LIMBECK M., Bedarf der Christ des Alten Testaments? Der Ausfall des AT im gegenwärtigen kirchlichen Bewußtsein, in: Herder Korrespondenz 29 (1975) 77-84.

LIPINSKI E., besaharit hajjamim dans les textes préèxiliques, in: VT XX (1970) 445-450.

von LOEWENCLAU I., Zu Jeremia II 3o, in: VT XVI (1966) 117-123.

LOHFINK N., Das Hauptgebot. Eine Untersuchung literarischer Einleitungsfragen zu Dtn 5-11. (Analecta Biblica 20) Rom 1963.

LONG B.0., Prophetic Call Traditions and Reports of Visions, in: ZAW 84 (1972) 494-500.

LORETZ 0., Die Sprüche Jeremias in Jer 1,17 - 9,25, in: U.F. 2 (1970) 109-130.

MACHOLZ G.C., Jeremia in der Kontinuität der Prophetie, in: FS von RAD, Muinchen 1971, 306-334.

MALAMAT A., The Twilight of Judah: in the Egyptian-Babylonian Maelstrom (VTS 28 ) Leiden 1975, 123-143.

MAYER R., Einleitung in das AT, 2. Teil, München 1967.

McNAMARA M., Jeremiah (A New Catholic Commentary on Holy Scripture) London 1969, 487-500.

MICHEL D., Tempora und Satzstellung in den Psaimen (AETh 1) Bonn 1960.

MOWINCKEL S., Zur Komposition des Buches Jeremia (SNVAO 1913/5) Kristiana 1914.

NEUMANN K.D., Das Wort, das geschehen ist ... Zum Problem der Wortempfangsterminologie in Jer.I-XXV, in: VT XXIII (1973) 171-217.

NOTSCHER F., Das Buch Jeremias (BB) Bonn 1934. Jeremias (EB III) Wuirzburg 1958.

OVERHOLT Th.W., The Threat of Falsehood. A Study in the Theology of the Book of Jeremiah (SBT 2/16) Allenson 1970. Remarks on the Continuity of the Jeremiah Tradition, in: JBL 91 (1972) 457-462.

PATERSON J., Jeremiah (Peak's Commentary on the Bible) London ${ }^{2} 1967$.

PEARCE R.A., Shilo and Jer VII 12,14 \& 15, in: VT XXIII (1973) 105108.

PERLITT L., Bundestheologie im Alten Testament (WMANT 36) Neukirchen 1969. 
PLOGER 0., Priester und Prophet, in: ZAW 63 (1951) 157-192.

Reden und Gebete im deuteronomistischen und chronistischen Geschichtswerk, in: FS DEHN, Neukirchen 1957 , 35-49.

PORÚBCAN ร̌., Sin in the 01d Testament. A soteriological Study, Cleveland-Rome 1963.

QUELL G., Wahre und falsche Propheten. Versuch einer Interpretation (BFChTh 46. Bd. 1. Heft) Guitersloh 1952.

von RABENAU K., Studien zur Theologie der alttestamentlichen uberlieferungen, in: FS von RAD, Neukirchen 1961, 61-80.

von RAD G., Die falschen Propheten, in: ZAW 51 (1933) 109-120.

Theologie des AT, I München ${ }^{4} 1962$;

II München 31960 .

RENDTORFF R., Zum Gebrauch der Formel $\mathrm{n}^{\mathrm{e}^{\circ}}$ um jahwe im Jeremiabuch, in: ZAW 66 (1954) 27-37.

Botenformel und Botenspruch, in: ZAW 74 (1962) 165177.

von REVENTLOW H., Liturgie und prophetisches Ich bei Jeremia, Gütersloh 1963.

Gattung und Oberlieferung in der Tempelrede Jeremias, Jer 7 und 26, in: ZAW 81 (1969) 315-352.

RICHTER W., Recht und Ethos. Versuch einer Ortung des weisheitlichen Mahnspruches (StANT 15) München 1966.

- Die sogenannten vorprophetischen Berufungsberichte. Eine literaturwissenschaftliche Studie zu $1 \mathrm{Sam}$ 9,1-10,16; Ex 3f. und Ri 6,11b-17 (FRLANT 101) Göttingen 1970.

RIETZSCHEL C., Das Problem der Urrolle. Ein Beitrag zur Redaktionsgeschichte des Jeremiabuches, Gütersloh 1966.

ROSE M., Der Ausschließlichkeitsanspruch Jahwes. Deuteronomische Schultheologie und die Volksfrömmigkeit in der späten Königszeit (BWANT 6. Folge, Heft 6) Stuttgart 1975.

ROTHSTEIN J.W., Das Buch Jeremia (KAUTZSCH-BERTHOLET, Die HI. Schrift des AT) Tübingen 1922, 720-868.

RUDOLPH W. , Jeremia (HAT I,12) Tübingen ${ }^{3} 1968$.

SCHMIDT W.H., Die deuteronomistische Redaktion des Amosbuches. Zu den theologischen Unterschieden zwischen dem Prophetenwort und seinem Sammler, in: ZAW 77 (1965) 168-193.

SCHMUTTERMAYR G., Beobachtungen zu Jer 5,13, in: BZ NF 9 (1965) 215-232.

SCHULZ H., Das Todesrecht im AT (BZAW 114) Berl in 1969. 
SEEBASS H., Art. ברש, in: TWAT I, Stuttgart 1972, Sp.568-580.

SEITZ G., Redaktionsgeschichtliche Studien zum Deuteronomium (BWANT 5. Folge, Heft 13) Stuttgart 1971.

SKINNER J., Prophecy and Religion. Studies in the Life of Jeremiah, Cambridge 21963.

STECK 0.H., Israel und das gewaltsame Geschick der Propheten (WMANT 23) Neukirchen 1967.

STOLZ F., Art. ברש bō' zuschanden werden, in: THAT I, München, Zürich 1971, Sp. 269-272.

THIEL W., Die deuteronomistische Redaktion des Buches Jeremia, Diss. Berl in 1970.

PROCKSCH 0., Art. $\lambda \varepsilon \gamma \omega . .$. C. "Wort Gottes" im AT, in: ThW IV, Stuttgart 1942, 89-100.

TOV E., L'incidence de la critique textuelle sur la critique littéraire dans le livre de Jérémie, in: RB 79 (1972) 189-199.

VOGT E., Jeremias-Literatur, in: Bibl 35 (1954) 357-365.

VOLZ P., Studien zum Text des Jeremia, Leipzig 1920.

Der Prophet Jeremia (KAT X) Leipzig 1922.

WAMBACQ B.N., Jeremias. (De Boeken van het Oude Testament) Roermond 1957.

WANKE G., Untersuchungen zur sogenannten Baruchschrift (BZAW 122) Berlin 1971.

WEIPPERT H., Die Prosareden des Jeremiabuches (BZAW 132) Berlin 1973.

WEISER A., Der Prophet Jeremia (ATD 20/21) Göttingen ${ }^{4} 1960$.

WELCH A.C., Jeremiah, his Time and his Work, Oxford 1955.

WESTERMANN C. 3 Grundformen prophetischer Rede (BEvTh 31) München

WILDBERGER H., Jahwewort und prophetische Rede bei Jeremia, Zürich 1942.

WOLFF H.W., Die Begruindung der prophetischen Heils- und Unheilsspruiche, in: ZAW 52 (1934) 1-22.

- Das Zitat im Prophetenspruch. Eine Studie zur prophetischen Verkündigungsweise. (BEvTh 4) München 1937.

"Wissen um Gott" bei Hosea als Urform von Theologie, in: EvTh 15 (1955) 116-168.

Hosea, Joel, Amos (BK AT XIV, 1ff) Neukirchen $1961 \mathrm{ff}$.

WORTHWEIN E., Der Ursprung der prophetischen Gerichtsrede, in:

ZThK 49 (1952) 1-16.

YOUNG E., An Introduction to the 01d Testament, Grand Rapids 1956. 
ZIEGLER J., Beiträge zur Jeremias-Septuaginta, in: NAG (1958 Nr.2) Göttingen 1958.

ZIMMERLI W., Die Eigenart der prophetischen Rede des Ezechiel, in: ZAW 66 (1954) 1-26.

"Leben" und "Tod" im Buche des Propheten Ezechiel, in: ThZ 13 (1957) 494-508.

Ezechiel (BK AT XIII) Neukirchen 1969. 